\title{
Review \\ Opportunities, Challenges and Pitfalls of Using Cannabidiol as an Adjuvant Drug in COVID-19 †
}

\author{
Barbara Malinowska ${ }^{1, *, \ddagger}$, Marta Baranowska-Kuczko ${ }^{1,2, \ddagger}$, Aleksandra Kicman ${ }^{1}$ and Eberhard Schlicker ${ }^{3, *}$ \\ 1 Department of Experimental Physiology and Pathophysiology, Medical University of Białystok, \\ 15-222 Białystok, Poland; mabar@umb.edu.pl (M.B.-K.); olakicman@gmail.com (A.K.) \\ 2 Department of Clinical Pharmacy, Medical University of Białystok, 15-222 Białystok, Poland \\ 3 Department of Pharmacology and Toxicology, University of Bonn, 53127 Bonn, Germany \\ * Correspondence: bmalin@umb.edu.pl (B.M.); e.schlicker@uni-bonn.de (E.S.); Tel.: +48-85-748-5699 (B.M.) \\ + To the memory of our friend Professor Daniel Moura (Department of Pharmacology, University of Porto, \\ Portugal), who was scientifically active in the field of ACE2 and angiotensin II. \\ $\ddagger$ These authors contributed equally to this work.
}

check for updates

Citation: Malinowska, B.; Baranowska-Kuczko, M.; Kicman, A.; Schlicker, E. Opportunities,

Challenges and Pitfalls of Using Cannabidiol as an Adjuvant Drug in COVID-19 t. Int. J. Mol. Sci. 2021, 22, 1986. https://doi.org/10.3390/ ijms22041986

Academic Editor: William C. (Trey) Putnam

Received: 11 January 2021

Accepted: 12 February 2021

Published: 17 February 2021

Publisher's Note: MDPI stays neutral with regard to jurisdictional claims in published maps and institutional affiliations.

Copyright: (c) 2021 by the authors. Licensee MDPI, Basel, Switzerland. This article is an open access article distributed under the terms and conditions of the Creative Commons Attribution (CC BY) license (https:// creativecommons.org/licenses/by/ $4.0 /)$.

\begin{abstract}
Severe acute respiratory syndrome coronavirus 2 (SARS-CoV-2) infection may lead to coronavirus disease 2019 (COVID-19) which, in turn, may be associated with multiple organ dysfunction. In this review, we present advantages and disadvantages of cannabidiol (CBD), a non-intoxicating phytocannabinoid from the cannabis plant, as a potential agent for the treatment of COVID-19. CBD has been shown to downregulate proteins responsible for viral entry and to inhibit SARS-CoV-2 replication. Preclinical studies have demonstrated its effectiveness against diseases of the respiratory system as well as its cardioprotective, nephroprotective, hepatoprotective, neuroprotective and anti-convulsant properties, that is, effects that may be beneficial for COVID-19. Only the latter two properties have been demonstrated in clinical studies, which also revealed anxiolytic and antinociceptive effects of CBD (given alone or together with $\Delta^{9}$-tetrahydrocannabinol), which may be important for an adjuvant treatment to improve the quality of life in patients with COVID-19 and to limit post-traumatic stress symptoms. However, one should be aware of side effects of CBD (which are rarely serious), drug interactions (also extending to drugs acting against COVID-19) and the proper route of its administration (vaping may be dangerous). Clearly, further clinical studies are necessary to prove the suitability of CBD for the treatment of COVID-19.
\end{abstract}

Keywords: ACE2; cannabidiol; COVID-19; SARS-CoV-2; respiratory disease

\section{Introduction}

Coronavirus disease 2019 (COVID-19) is caused by a new virus entity, the severe acute respiratory syndrome coronavirus 2 (SARS-CoV-2) and has grown to be one of the most dangerous pandemics in the history of mankind [1-3]. Its death toll of more than 2.2 million (1 February 2021) people has a similar magnitude like the Asian flu (1957-1958; 1-4 million) and Hong Kong flu (1968-1970; 1-4 million) and is already higher than that of the swine flu (2009-2010; up to 0.6 million; [4]). It is responsible for significantly more fatalities than the severe acute respiratory syndrome (SARS, 2002-2004; 774 deaths) and Middle East respiratory syndrome (MERS, 2012-present; 935 deaths) pandemics caused by the SARS-CoV and MERS-CoV viruses, respectively [4]; the latter two, like SARS-CoV-2, belong to the Coronaviridae family [5].

Vaccines protecting against SARS-CoV-2 have become available within a year of its emergence and they appear to be effective and safe [6,7]. Although general vaccination began in December 2020 in many countries, it will take months until the number of vaccinated people is high enough to provide herd immunity [6]. Therapeutic approaches are largely symptomatic and supportive. Many drugs have been examined in clinical 
studies, mostly with disappointing results $[2,3,8,9]$. Nonetheless, the antiviral drug remdesivir shortens hospitalization time and the glucocorticoid dexamethasone even reduces mortality $[10,11]$. In addition, it is suggested that alternative compounds, including phytochemicals and natural agents targeting coronavirus development directly or as a result of their immunomodulatory effects, could be applied as potential therapies and for the prevention of COVID-19 [12-15].

The two senior authors of the present article (B.M. and E.S.) serve as editors of a Special Issue of Int. J. Mol. Sci. dedicated to research on cannabidiol (CBD), which has been suggested as a putative drug against COVID-19 but the views of different investigators on this compound have been found to vary greatly. Thus, we decided to conduct a review on the advantages and disadvantages of using CBD as a potential agent for the prevention and treatment of COVID-19 based on scientific reports on its influence on selected disease models and in clinical studies. We also summarize current knowledge about the effects of this compound on SARS-CoV-2 infection. The aim of the present review is to examine the suitability of CBD (Section 3) as an antiviral drug against SARS-CoV-2 (Section 4) and as an agent for the prevention and treatment of disease states in the preclinical (Section 5) and clinical (Section 6) settings. The review ends with a synopsis of the pros and cons of using CBD as a potential drug to treat COVID-19 (Section 7).

\section{Mode of Infection and Symptoms of COVID-19}

Infection with SARS-CoV-2 occurs mainly by aerosol/droplet transmission through direct contact with an infected person. The virus enters the body through the epithelial cells of the tongue, bronchi and lungs after attaching to angiotensin-converting enzyme 2 (ACE2). An important function of membrane-bound and soluble ACE2 is degradation of angiotensin II (Ang II) to angiotensin 1-7 (Ang 1-7), which exerts a beneficial influence, as opposed to numerous detrimental effects of high concentrations of Ang II (for details, see Figure 1 and Supplementary Table S1). The affinity of SARS-CoV-2 to ACE2 is determined by glycoprotein S1 localized on the characteristic viral "spikes." S1 binds to the enzyme via the receptor-binding domain. Transmembrane serine protease 2 (TMPRSS2), which allows the entry of the virus into the cytoplasm of host cells $[1,2,5,16]$, also plays a significant role in COVID-19 infection. Moreover, quite recently, it was shown that the membrane protein neuropilin-1 (NRP1) promotes SARS-CoV-2 entry [17].

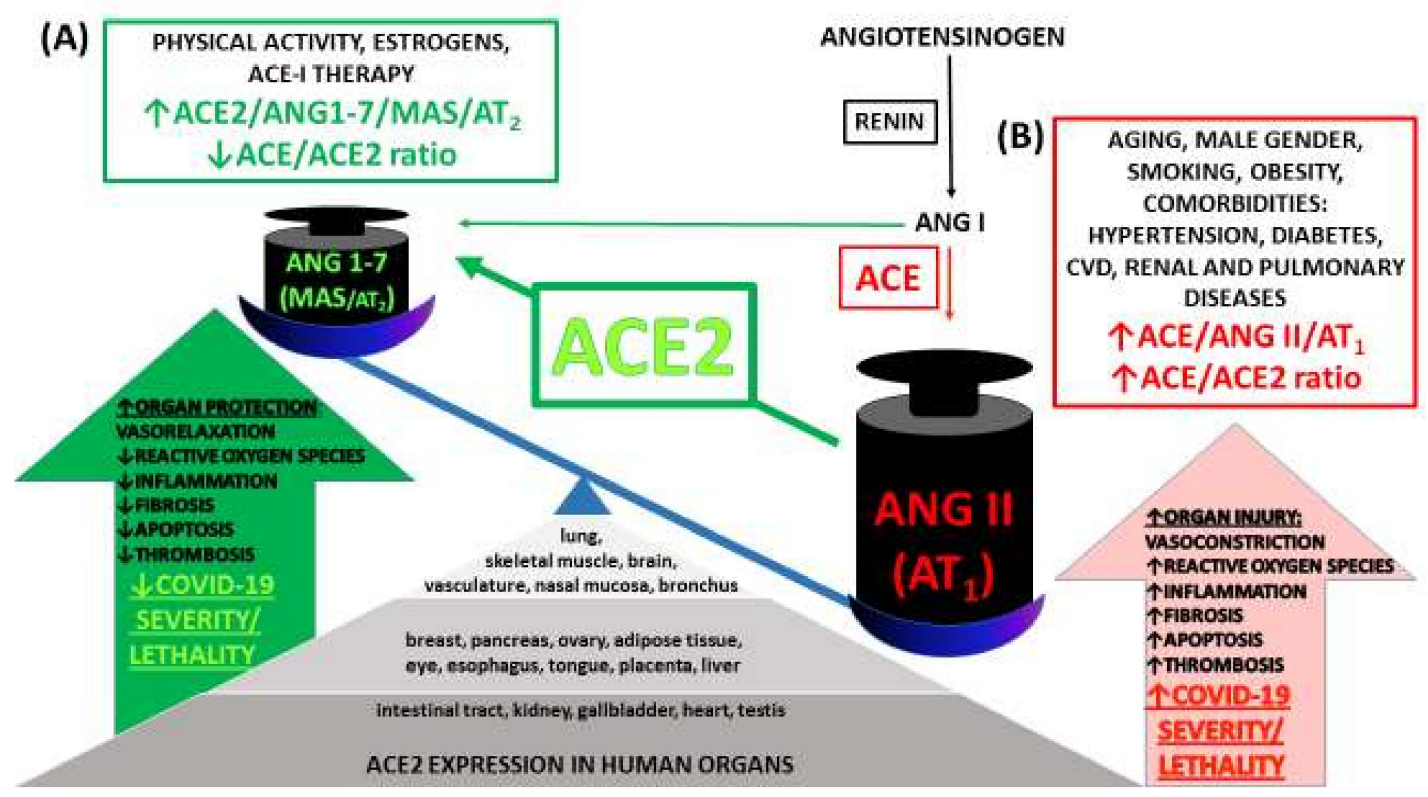

Figure 1. Expression of angiotensin-converting enzyme 2 (ACE2) in human tissues and organs, its counter-regulatory effects on the ACE $\rightarrow$ Ang II $\rightarrow$ AT $_{1}$ axis and interaction with coronavirus disease 2019 (COVID-19). ACE2 is ubiquitous and widely expressed in many organs targeted and damaged by COVID-19 caused by severe acute respiratory syndrome coronavirus 2 
(SARS-CoV-2). It is a membrane-bound enzyme and an endogenous counter-regulator of the renin-angiotensin hormonal cascade. It degrades angiotensin II (Ang II) to angiotensin 1-7 (Ang 1-7) that exerts beneficial effects opposed to those of Ang II. Ang 1-7 acts through the G protein-coupled receptor MAS and, to a lesser extent, Ang II type 2 receptors $\left(\mathrm{AT}_{2}\right)$. ACE and ACE2 and their major products, Ang II and Ang 1-7, respectively, are linked in almost a ying/yang process, that is, when one decreases, the other increases and vice versa [18]. Thus, reduced activity of the deleterious ACE $\rightarrow$ Ang II $\rightarrow$ Ang II receptor type 1 ( $\mathrm{AT}_{1}$ ) axis (red) is coupled with increased activity of the protective ACE2 $\rightarrow$ Ang 1-7 $\rightarrow$ MAS receptor axis (green). A lower ACE/ACE2 ratio (A) (occurring in women, in exercise-trained individuals and patients well-treated with ACE inhibitors (ACE-I)) leads to beneficial effects such as vasorelaxation, anti-inflammatory, anti-oxidative, anti-fibrotic and anti-thrombotic effects that predispose towards a lower risk of cardiovascular disease (CVD) and better COVID-19 outcomes. By contrast, a high ACE/ACE2 ratio (B) that is increased in males, elderly and many pathologies (especially CVD, pulmonary and renal diseases and obesity) may aggravate COVID-19 infection [19-22].

COVID-19 is usually asymptomatic. In most symptomatic patients, SARS-CoV-2 infection is mild with symptoms including fever, shortness of breath, coughing, fatigue, anosmia, ageusia and muscle pain. Less common symptoms are nausea, vomiting and diarrhea $[1,2,16,23]$. The risk of developing a severe form of the disease increases with male gender, age and smoking; a further aggravation occurs in people with comorbidities such as hypertension, diabetes, obesity, cardiovascular or chronic respiratory system diseases, in which the concentration of the soluble form of ACE2 is substantially higher (Figure 1). By contrast, in healthy individuals ACE2 activity is much lower or not detected [24,25].

Because ACE2 is ubiquitous and widely expressed in the heart, blood vessels, gut, lungs (particularly in type 2 pneumocytes and macrophages) and in different types of cells (for details, see Figure 1 and Supplementary Table S1), COVID-19 is a multiple-organ disease, as summarized in Figure 2. One of the most common complications is an acute respiratory distress syndrome (ARDS) resulting from the cytokine storm phenomenon, a violent and uncontrolled inflammatory reaction in response to the presence of the virus in the host organism $[1,2,16,23]$. However, the negative consequences of COVID-19 are also connected with other disorders of the respiratory system $[1,16,26,27]$, with the cardiovascular system (for review, see $[1,16,22,26,28-30]$ ) and with dangerous hematological complications, particularly thromboembolism [1,16,31-36]. In addition, pathological changes in the renal $[1,16,27,33,37,38]$, gastrointestinal, hepatic, pancreatic $[1,16,27,31,39,40]$ and nervous systems $[1,27,41-43]$ have been described. Disturbances of the eyes $[1,44]$, endocrine $[45,46]$ and reproductive functions [31,45-47], skeletal muscles $[1,33,48]$ and skin $[1,49,50]$ occur as well (for details, see Figure 2). 


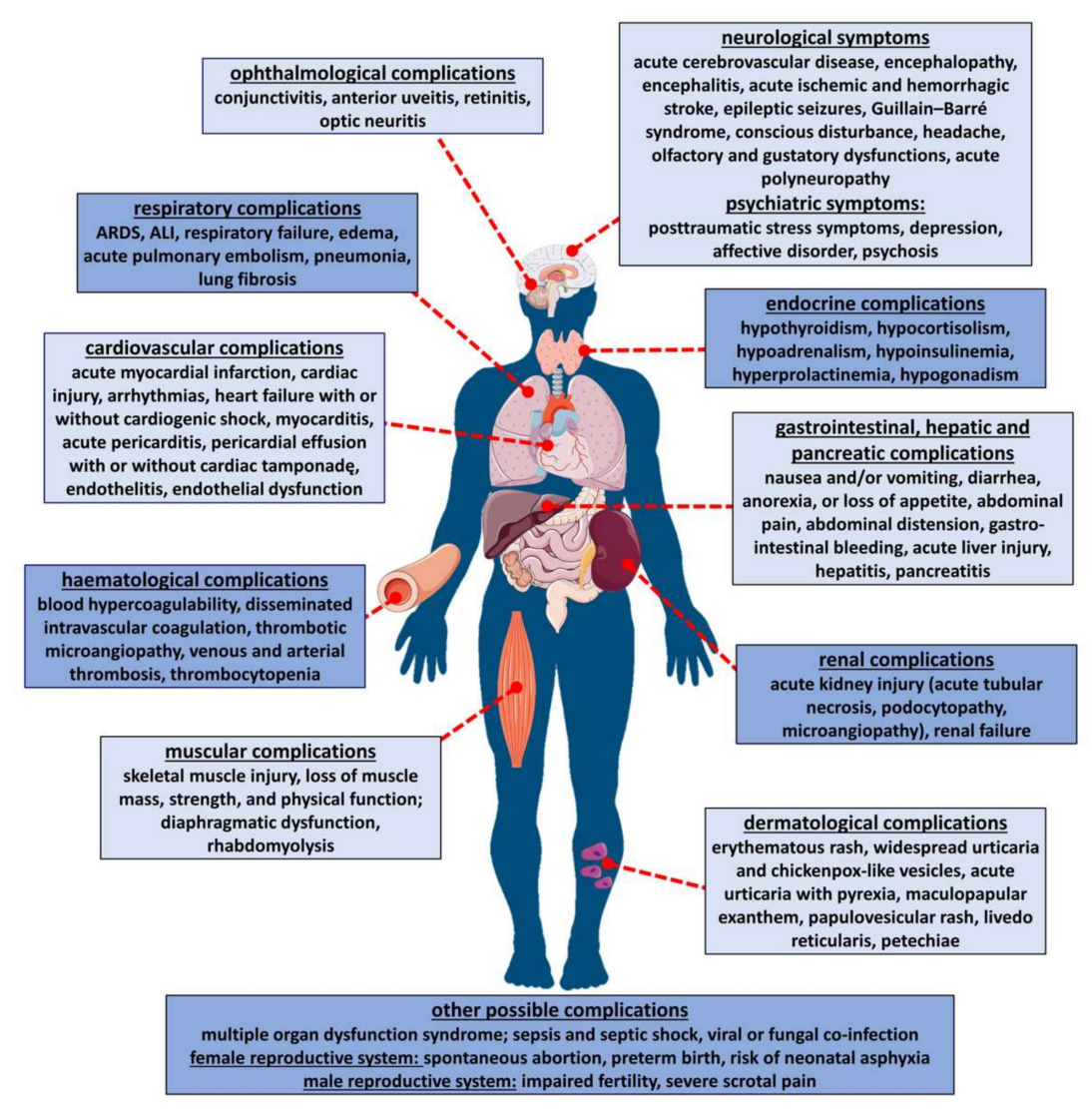

Figure 2. Systemic manifestation of COVID-19 infection. For respective literature, see Section 2. ALI, acute lung injury; ARDS, acute respiratory distress syndrome.

\section{Cannabidiol-Pharmacological Potential and Mechanism of Action}

Non-intoxicating CBD is a phytocannabinoid isolated from the Cannabis sativa plant $[13,14]$ and, apart from the psychoactive $\Delta^{9}$-tetrahydrocannabinol (THC), represents the best-studied compound in this group.

Numerous studies have demonstrated a range of beneficial properties associated with CBD, including anti-inflammatory, antioxidant, antiarthritic, cardio- and neuroprotective, anticonvulsant, procognitive and analgesic effects (for detail, see reviews, for example, [51-53]). At the moment, there are two indications. CBD (Epidiolex ${ }^{\circledR}$ ) has been approved for the treatment of intractable childhood-onset epilepsy (Dravet and Lennox-Gastaut syndrome). Its combination with THC (nabiximols (Sativex ${ }^{\circledR}$ ); $100 \mu \mathrm{L}$ of oromucosal spray contains $2.5 \mathrm{mg}$ CBD and $2.7 \mathrm{mg}$ THC) has been approved for the therapy of spasticity in multiple sclerosis. Moreover, a potential therapeutic effect of CBD is suggested for inflammatory and autoimmune diseases, anxiety disorders, schizophrenia, depression, Alzheimer's disease, Parkinson's disease, chronic pain, cancer and diabetic complications [54,55].

With respect to the potential use of CBD in COVID-19, sixteen publications have so far appeared. Four publications are experimental (see Section 4) whereas another twelve discuss data from the literature.

Within the group of papers dealing with the literature, seven publications consider the potential use of CBD for the treatment of COVID-19 mainly due to its potent antiinflammatory activity $[14,15,56-60]$. However, as suggested by another three authors, there is a lack of high-quality studies dedicated to the anti-inflammatory effects of CBD [61,62] or to its effects on the central nervous system (e.g., anxiety or neurological complications) [63]. Two authors warn that the anti-inflammatory action of CBD might exert a potential detrimental effect on the immune system even leading to enhancement of viral infections $[64,65]$. 
One should also consider that vaping CBD was associated with severe COVID-19 problems [57] and not overlook the unclear impact of "over-the-counter" CBD on the immunity of the SARS-CoV-2 infection [62]. Due to the lack of rigorous legal regulations, CBD is indeed commonly used as over-the-counter product, often of unapproved and unknown composition $[51,54,55]$.

The multi-directional properties of CBD mentioned above arise from its complex mechanism of action. CBD has a low affinity for cannabinoid receptors (CB-Rs); it acts as a negative allosteric modulator of cannabinoid receptor type $1\left(C_{1}-R\right)$ and as an inverse agonist of cannabinoid receptor type $2\left(\mathrm{CB}_{2}-\mathrm{R}\right)$. In addition, $\mathrm{CBD}$ acts via many other molecular targets including G-protein-coupled receptors (GPCRs; for example, activation of the peroxisome proliferator-activated $\gamma(\operatorname{PPAR} \gamma)$ receptor and serotonin 5- $\mathrm{HT}_{1 \mathrm{~A}}$ and 5- $\mathrm{HT}_{2 \mathrm{~A}}$ receptors) and ionotropic receptors (e.g., activation of vanilloid TRPV1 but inhibition of serotonin $5-\mathrm{HT}_{3}$ receptors). Moreover, it inhibits various transporters (e.g., adenosine uptake) and enzyme activities (e.g., fatty acid amide hydrolase (FAAH), an enzyme responsible for the degradation of the endocannabinoid anandamide) (for details and other molecular targets, see reviews $[51,66])$. In order to explain its effect against oxidative/nitrative stress, direct effects on the mitochondria and nuclei have been taken into consideration as additional molecular mechanisms [66].

\section{Potential Antiviral Activity of CBD}

Various effects and molecular mechanisms of CBD have been described in the previous section and some of them may be helpful in the context of the COVID-19 infection. Before discussing them in preclinical studies (Section 5) and in the clinical setting (Section 6), we would like to draw the attention of the reader to four experimental papers on the basis of which the potential usefulness of CBD against the SARS-CoV-2 virus was suggested.

In the first paper, Wang et al. [67] examined whether the gateways for the entry of the virus into cells, ACE2 and TMPRSS2, are affected by CBD. They found that high-CBD Cannabis sativa extracts decreased ACE2 and TMPRSS2 protein levels in artificial human 3D models of oral, airway or intestinal tissues primed by tumor necrosis factor $\alpha$ (TNF- $\alpha$ ) plus interferon $\gamma($ IFN- $\gamma)$. Extracts had different cannabinoid and terpene profiles and not all extracts under study were equally effective. In particular, pure CBD failed to affect ACE2 and TMPRSS2 protein levels in the airways, suggesting an entourage effect of the components of the extracts; the possibility that a component in the extracts other than CBD is the active principal component can so far not be excluded. Some extracts produced undesired molecular effects, that is, upregulated the levels of the ACE2 gene and protein. The idea of using high-CBD products (administered, for example, via mouth wash) to limit the entry of SARS-CoV-2 into susceptible hosts seems to be attractive but requires unambiguous scientific confirmation [56].

In the second paper (Raj et al. [68]), a direct antiviral effect of CBD was identified. The authors first screened several cannabinoids in silico and then examined CBD and THC, which appeared to have particularly promising effects in cultured Vero cells infected with SARS-CoV-2. CBD exhibited an $\mathrm{IC}_{50}$ value of $8 \mu \mathrm{M}$ for its inhibitory effect on SARS-CoV-2 replication and was at least as potent, in this respect, as the antiviral drugs remdesivir, chloroquine and lopinavir, which are already used for the treatment of COVID-19 [2,3,8,9]. Again, these interesting data await unambiguous confirmation. By the way, CBD also inhibits the replication of hepatitis $C$ virus in vitro [69] but was not active against the hepatitis B virus [69] or the Kaposi sarcoma-associated herpesvirus [70].

In the third and fourth experimental study suggesting the potential usefulness of CBD for treatment of COVID-19 [71,72] an acute respiratory distress syndrome was induced in mice by poly(I:C), a synthetic analogue of viral double-stranded RNA. Table 1 shows that CBD indeed had a beneficial effect in this condition. Chronic CBD application was also effective against the negative consequences of the infection in mice suffering from Theiler's murine encephalomyelitis virus, which induces demyelinating disease [73,74]. However, in the aforementioned in vivo experiments, the beneficial effects of chronic 
CBD administration were due to its anti-inflammatory properties and not direct antiviral activities (Table 1).

\section{Preclinical Studies on the Use of CBD for COVID-19 Treatment}

As discussed in the previous section, $\mathrm{CBD}$ has a direct as well as an indirect antiviral effect by reducing the number of ACE2 molecules via which the SARS-CoV-2 virus enters cells. Table 1 shows that, in preclinical models, CBD has a beneficial effect in many disease states also occurring in COVID-19. We mainly concentrated on the in vivo effects of chronic CBD administration. Acute in vivo or in vitro effects were considered if they were of interest with respect to COVID-19. Table 1 differentiates between prophylactic (preventive) and therapeutic CBD administration, that is, whether CBD was given before (or simultaneously with) the stimulus leading to the disease or after the pathological state had fully developed, respectively.

First of all, we would like to underline the effectiveness of CBD found in experimental models of respiratory failure. As already mentioned in the previous section, chronic CBD administration reduced the acute respiratory distress syndrome and the cytokine storm induced by polyriboinosinic:polyribocytidylic acid (poly(I:C)), a synthetic analogue of viral RNA [71,72]. Interestingly, it increased the expression of blood apelin [72], which serves as a catalytic substrate for ACE2 [24]. Moreover, the administration (mainly intraperitoneally (i.p.)) of CBD improved lung function and reduced inflammation in experimental acute lung injury (ALI) [75,76], pulmonary hypertension [77], lung injury induced by brain hypoxic/ischemic damage [78] and asthma [79,80] (Table 1). The beneficial influence of CBD resulted mainly from its significant anti-inflammatory properties $[75,76,78-80]$. Importantly, CBD has been shown to improve lung function [76], gas exchange [77], blood oxygen saturation [77] and to reduce allergen-induced airway obstruction [81]. Undoubtedly, a favorable effect of CBD is also the strong relaxation of the human pulmonary artery determined under in vitro conditions [82]. The unequivocally beneficial action profile of CBD is, however, contrasted by the results obtained by Karmaus et al. [83], who described a proinflammatory effect of prophylactically administered CBD (once daily for 3 days) in lipopolysaccharide-induced lung inflammation in mice. Moreover, CBD does not have antitussive properties and does not affect trachea contraction [84]. In most studies, CBD (i.p. or per os (p.o.) in doses of 5-10 mg/ $\mathrm{kg}$ per day) was administered prophylactically or therapeutically for 2-4 days only (Table 1 ). Only in the rat model of monocrotaline-induced pulmonary hypertension CBD was given prophylactically for 3 weeks [77].

A cardioprotective influence of CBD has been mainly shown in experiments in which prophylactic administration (predominantly in one dose given before occlusion or reperfusion) prevented the negative consequences of experimental myocardial infarction by decreasing the infarct size or arrhythmia ([85-88]; Table 1). Beneficial therapeutic effects (including improvement of cardiac systolic and diastolic dysfunction, reduction in coronary vasoconstriction, enhancement of mesenteric artery vasorelaxation and improvement of metabolic parameters) of chronic CBD administration (1 to 11 weeks) have been demonstrated in autoimmune myocarditis [89], diabetic cardiomyopathy [90], primary and secondary hypertension [91,92] and in Zucker diabetic fatty rats [93]. As in the case of respiratory failure, the favorable influence of $\mathrm{CBD}$ on the cardiovascular system is connected mainly with its anti-inflammatory properties and, in addition, with its antioxidative, antinitrative and antifibrotic effects (for details, see Table 1).

There is a significant association between severe COVID-19 and the occurrence of thromboembolism (for review, see [1,16,32-36]). Unfortunately, only a few publications have addressed the influence of CBD on the components or parameters of hemostasis. Thus, the chronic administration of CBD normalized the plasma tissue plasminogen activator and plasminogen activator inhibitor- 1 enhanced by monocrotaline-induced pulmonary hypertension in rats [77]. A decrease in platelet aggregation occurred after a single CBD dose given before (but not after) myocardial infarction [87]. CBD (injected prophylactically, 
acutely or chronically) failed to reduce vessel thrombogenesis and did not modify human platelet aggregation when given in vitro [94].

Nephroprotective properties of CBD have been described only for its acute administration (one or maximally two doses) in experimental models of ischemic acute kidney injury [95-97]. They were connected with its anti-inflammatory, antioxidative and antinitrative properties (Table 1).

With respect to disorders of the gastrointestinal tract, cases of acute and chronic prophylactic CBD administration have been associated with anti-nausea and antiemetic effects in experimental nausea and vomiting induced by lithium chloride via the activation of serotonin $5-\mathrm{HT}_{1 \mathrm{~A}}$ receptors [98]. Since $\mathrm{CBD}$ antagonizes $5-\mathrm{HT}_{3}$ receptors under in vivo conditions [99], its antiemetic effect might also result from the antagonism of 5- $\mathrm{HT}_{3}$ receptors. Hepatoprotective properties of CBD have been described in models of liver injury induced by hepatic artery and portal vein occlusion [100], chronic ethanol administration [101], thioacetamide [102] or cocaine [103]. Again, the beneficial influence of CBD is connected mainly with its anti-inflammatory and antioxidative properties. Unfortunately, with the exception of chronic ethanol administration [101], CBD was only given once. Prophylactic administration of CBD had a beneficial influence in experimental acute pancreatitis, based on its anti-inflammatory properties [104]. Moreover, its therapeutic administration at one [105] or three [106] doses was shown to reduce intestinal hypermotility (Table 1). Interestingly, cannabis extract with a high CBD content reduced inflammatory changes in the colon more strongly than CBD did alone [106].

The most common symptoms of COVID-19 include anosmia, ageusia and fever. A PubMed-based search did not identify any publications showing that CBD is useful in the case of loss of smell or taste. With respect to the nervous system, one might mention its prohedonic activity, which occurred upon chronic administration in rats that were exposed to chronic unpredictable mild stress [107]. Moreover, CBD is approved for the treatment of Dravet syndrome, a condition that features recurrent seizures triggered by fever [108]. Its effective anticonvulsant activity has been confirmed both in human (for review, see [108]) and different experimental models (for example [109,110], see Table 1). In addition, a neuroprotective influence of CBD (administered once or twice) has been determined in hepatic encephalopathy [102], perinatal hypoxia/ischemia encephalopathy [111,112], sepsis-related encephalitis (including increase in integrity of blood-brain barrier; [113]) or cerebral ischemia $[114,115]$. CBD (given for up to 10 days) had also a beneficial effect on encephalomyelitis and multiple sclerosis induced by Theiler's murine encephalomyelitis virus $[73,74]$.

Tears and the eyes in general, create portals for coronavirus entry. Although we did not find any publications regarding the potential application of $C B D$ for conjunctivitis (the most common ocular manifestation of COVID-19), one should remember that CBD has been suggested as a putative novel therapy for diabetic retinopathy [116] and retinal inflammation ([117]; Table 1). Both protective effects are associated with the anti-inflammatory and antioxidative actions of CBD which are also beneficial in the reduction of the negative consequences of perinatal hypoxia/ischemia [111,112]. In this context, one may consider the risk of neonatal asphyxia in children from mothers suffering from COVID-19 (Figure 2).

Unfortunately, there are limited publications suggesting potential beneficial effects of $\mathrm{CBD}$ in endocrine, muscular and dermatological disorders, that also are listed among those related to COVID-19 (Table 1). Thus, chronic CBD administration has been shown to reduce hyperglycemia and to improve metabolic dysfunction $[118,119]$ in experimental models of obesity/diabetes, which is important if one considers that high glucose plasma levels and diabetes are risk factors for COVID-19 [120]. Moreover, CBD was found to prevent losses in functionality due to skeletal muscle degeneration [121]. Beneficial antiinflammatory properties of chronic and acute administration of CBD on skin function have been shown in nude rats [122] and in vitro in human sebocytes, keratinocytes and skin organ culture $[123,124]$. 
Table 1. Potential use of cannabidiol (CBD) for COVID-19 treatment as suggested by preclinical studies.

\begin{tabular}{|c|c|c|c|c|c|c|}
\hline & Model & Species & $\begin{array}{c}\text { Dose and Route of } \\
\text { Administration of CBD }\end{array}$ & Effects & $\begin{array}{c}\text { CBD Properties } \\
\text { Important for COVID-19; } \\
\text { Mechanisms }\end{array}$ & References \\
\hline \multirow{4}{*}{ 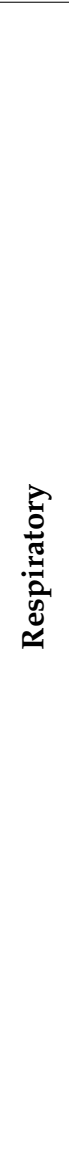 } & \multirow[t]{2}{*}{$\frac{\text { ARDS induced }}{\text { by poly(I:C) }}$} & \multirow[t]{2}{*}{ mouse } & $\begin{array}{l}5 \mathrm{mg} / \mathrm{kg} \text {, i.p. therapeutic, } \\
\text { once a day for } 3 \text { days }\end{array}$ & $\begin{array}{l}\text { cytokine storm and ARDS symptoms } \\
\text { totally or partially improved (blood } \\
\text { oxygen saturation, perivascular and } \\
\text { peribronchiolar interstitial } \\
\text { inflammatory infiltrate, lung } \\
\text { fibrosis, hypertrophy and } \\
\text { pulmonary edema) } \\
\downarrow I \mathrm{IL}-6 \text { expression and } \downarrow \text { neutrophil } \\
\text { frequency in the lung }\end{array}$ & anti-inflammatory & {$[71,72]$} \\
\hline & & & $\begin{array}{l}5 \mathrm{mg} / \mathrm{kg} \text {, i.p. therapeutic, } \\
\text { once a day for } 3 \text { days }\end{array}$ & $\begin{array}{c}\text { improvement of lung structure } \\
\downarrow \bar{T} \text { cells and } \uparrow \text { neutrophils returned } \\
\text { towards the normal } \\
\text { level, } \uparrow \text { expression of apelin in the } \\
\text { blood }\end{array}$ & $\frac{\text { anti-inflammatory }}{\text { regulation of apelin level }}$ & [72] \\
\hline & \multirow{2}{*}{$\underline{\text { ALI induced by LPS }}$} & \multirow{2}{*}{ mouse } & $\begin{array}{c}1-80 \mathrm{mg} / \mathrm{kg} \text {, i.p. } \\
20 \mathrm{mg} / \mathrm{kg} \text {, i.p. prophylactic; one } \\
\text { dose before ALI induction } \\
\text { (effects determined 1, } 2 \text { and } 4 \\
\text { days after LPS) }\end{array}$ & 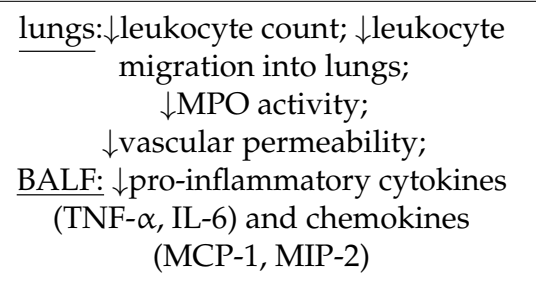 & $\begin{array}{l}\text { anti-inflammatory; } \\
\text { partially dependent on } \\
\text { adenosine } \mathrm{A}_{2 \mathrm{~A}}-\mathrm{Rs}\end{array}$ & [75] \\
\hline & & & $\begin{array}{c}20 \text { or } 80 \mathrm{mg} / \mathrm{kg} \text {, i.p. therapeutic; } \\
\text { one dose } 6 \mathrm{~h} \text { after ALI induction } \\
\text { (effects determined } 24 \mathrm{~h} \text { after } \\
\text { LPS) }\end{array}$ & 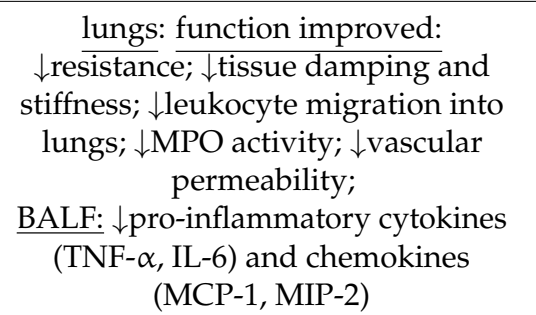 & $\frac{\text { anti-inflammatory; }}{\text { antagonists not used }}$ & {$[76]$} \\
\hline
\end{tabular}


Table 1. Cont.

\begin{tabular}{|c|c|c|c|c|c|c|}
\hline & Model & Species & $\begin{array}{c}\text { Dose and Route of } \\
\text { Administration of CBD }\end{array}$ & Effects & $\begin{array}{l}\text { CBD Properties } \\
\text { Important for COVID-19; } \\
\text { Mechanisms }\end{array}$ & References \\
\hline \multirow{7}{*}{ 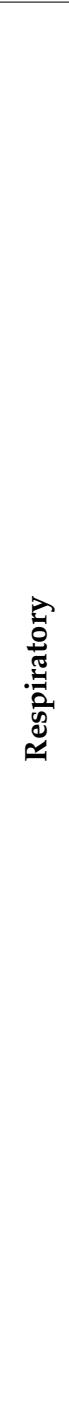 } & $\frac{\text { lung inflammation }}{\text { induced by LPS }}$ & mouse & $\begin{array}{c}75 \mathrm{mg} / \mathrm{kg} \text {, p.o. prophylactic; } \\
\text { once a day for } 3 \frac{\text { days; LPS } 1 \mathrm{~h}}{\text { before }} \\
\text { the last dose of CBD }\end{array}$ & $\begin{array}{c}\text { lungs: } \uparrow \text { inflammatory } \\
\text { changes in tissue; } \\
\text { BALF: } \uparrow \text { pro-inflammatory TNF- } \alpha, \\
\text { IL-6, IL-23, GCSF; slight } \\
\quad \uparrow \text { inflammatory cells }\end{array}$ & $\frac{\text { pro-inflammatory; }}{\text { antagonists not used }}$ & [83] \\
\hline & due $\frac{\text { pulmonary }}{\text { hypertension }}$ to monocrotaline & rat & $\begin{array}{l}10 \mathrm{mg} / \mathrm{kg} \text {, i.p. prophylactic; } \\
\text { once a day for } 21 \text { days }\end{array}$ & $\begin{array}{l}\quad \text { heart: } \downarrow \text { right ventricular } \\
\text { systolic pressure; } \\
\leftrightarrow \text { right hypertrophy and lung } \\
\text { edema; } \uparrow \text { blood oxygen saturation; } \\
\quad \text { plasma: } \downarrow \text { leukocytes }\end{array}$ & $\begin{array}{c}\uparrow \text { blood oxygen } \\
\text { saturation; } \\
\text { antagonists not used }\end{array}$ & [77] \\
\hline & $\begin{array}{l}\text { lung injury } \\
\text { induced by brain } \\
\text { hypoxic-ischemic } \\
\text { damage }\end{array}$ & $\begin{array}{l}\text { newborn } \\
\text { piglets }\end{array}$ & $\begin{array}{l}1 \mathrm{mg} / \mathrm{kg} \text {, i.v. therapeutic; } \\
\text { one dose } \overline{30 \mathrm{~min}} \\
\text { after lung injury }\end{array}$ & $\begin{array}{c}\text { improvement of } \\
\text { gas exchange; } \uparrow \text { TLC, } \\
\text { lungs: } \downarrow \text { histological } \\
\text { damage and edema; } \\
\downarrow \text { leukocyte migration into lungs, } \\
\downarrow \text { inflammatory changes; } \\
\downarrow \text { vascular permeability; } \\
\text { BALF: } \downarrow \text { pro-inflammatory } \\
\text { cytokines (IL-1) }\end{array}$ & $\begin{array}{l}\text { anti-inflammatory } \\
5-\mathrm{HT}_{1 \mathrm{~A}}-\mathrm{Rs} \text { in all } \\
\text { parameters, except for } \\
\text { improvement of gas } \\
\text { exchange; site of CBD } \\
\text { action (brain and/or } \\
\text { lungs) unclear }\end{array}$ & [78] \\
\hline & \multirow[b]{2}{*}{$\begin{array}{l}\text { asthma induced } \\
\text { by ovalbumin }\end{array}$} & rat & $\begin{array}{l}5 \mathrm{mg} / \mathrm{kg} \text {, i.p. therapeutic; } \\
\text { once a day for } 2 \text { days }\end{array}$ & $\begin{array}{l}\text { serum: } \downarrow \text { IL-4, IL-5, IL-6, IL-13 } \\
\text { and TNF- } \alpha ; \leftrightarrow \text { IL-10 }\end{array}$ & $\begin{array}{l}\text { anti-inflammatory; } \\
\text { antagonists not used }\end{array}$ & [79] \\
\hline & & mouse & $\begin{array}{l}5 \text { or } 10 \mathrm{mg} / \mathrm{kg} \text {, i.p. therapeutic; } \\
\text { once a day for } 3 \text { days }\end{array}$ & 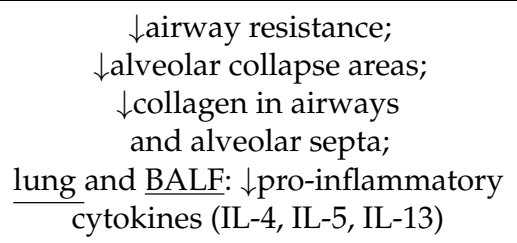 & $\begin{array}{l}\frac{\text { anti-inflammatory; }}{\text { anti-fibrotic; }} \\
\text { airway resistance: } \\
\quad \mathrm{CB}_{1} \text {-Rs } \\
\text { other effects: } \mathrm{CB}_{1} / \mathrm{2}_{2} \text {-Rs }\end{array}$ & [80] \\
\hline & $\frac{\text { airway obstruction }}{\begin{array}{l}\text { induced by } \\
\text { ovalbumin }\end{array}}$ & $\begin{array}{l}\text { guinea- } \\
\text { pig }\end{array}$ & $\begin{array}{l}1 \mathrm{mg} / \mathrm{kg} \text {, i.v. prophylactic; } \\
\text { one dose }\end{array}$ & $\begin{array}{l}\downarrow \text { airway obstruction induced } \\
\text { by ovalbumin }\end{array}$ & $\begin{array}{l}\text { bronchoprotective; } \\
\text { reduction of the } \\
\text { antigen-induced } \\
\text { contractile responses }\end{array}$ & [81] \\
\hline & $\begin{array}{l}\text { cough induced by } \\
\text { aerosolized } \\
\text { citric acid }\end{array}$ & $\begin{array}{l}\text { guinea- } \\
\text { pig }\end{array}$ & $\begin{array}{l}\text { prophylactic; aerosolized } \\
\text { solution of } 10 \mathrm{mg} / \mathrm{mL} \text { for } \\
20 \text { minutes using a nebulizer }\end{array}$ & $\begin{array}{l}\text { cough inhibition only in three out } \\
\text { of eight animals }\end{array}$ & antagonists not used & [84] \\
\hline
\end{tabular}


Table 1. Cont.

\begin{tabular}{|c|c|c|c|c|c|c|}
\hline & Model & Species & $\begin{array}{c}\text { Dose and Route of } \\
\text { Administration of CBD }\end{array}$ & Effects & $\begin{array}{c}\text { CBD Properties } \\
\text { Important for COVID-19; } \\
\text { Mechanisms }\end{array}$ & References \\
\hline \multirow{2}{*}{ 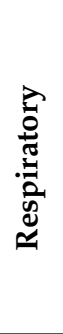 } & isolated trachea & $\begin{array}{l}\text { guinea- } \\
\text { pig }\end{array}$ & $10 \mu \mathrm{M}$ & $\begin{array}{l}\leftrightarrow \text { resting basal tension; } \\
\leftrightarrow \text { contractions induced electrically } \\
\text { or by methacholine }\end{array}$ & antagonists not used & [84] \\
\hline & $\begin{array}{l}\text { isolated human } \\
\text { pulmonary artery }\end{array}$ & human & $0.1-30 \mu \mathrm{M}$ & $\begin{array}{l}\text { almost full } \\
\text { concentration-dependent } \\
\text { vasorelaxation }\end{array}$ & $\begin{array}{c}\text { endothelium-dependent } \\
\text { vasodilatation mediated } \\
\text { via } \mathrm{K}^{+} \text {channels, } \mathrm{IP}, \mathrm{EP}_{4} \\
\text { TRPV1 and PPAR } \gamma \\
\text { receptors }\end{array}$ & [82] \\
\hline \multirow{5}{*}{ 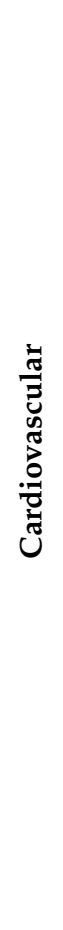 } & \multirow{4}{*}{$\begin{array}{c}\text { myocardial infarction } \\
\text { induced } \\
\text { by left coronary } \\
\text { artery occlusion }\end{array}$} & rabbit & $\begin{array}{l}0.1 \mathrm{mg} / \mathrm{kg} \text {, i.v. prophylactic; } \\
\text { one dose before occlusion and } \\
\text { one before reperfusion }\end{array}$ & $\begin{array}{c}\text { heart: } \downarrow \text { infarct area; } \uparrow \text { left ventricular } \\
\text { function; } \uparrow \text { blood supply to } \\
\text { perfusion-defective region; } \\
\downarrow \text { neutrophil infiltration; } \\
\downarrow \text { MPO activity } \\
\text { plasma: } \downarrow \text { cardiac troponin I }\end{array}$ & $\begin{array}{l}\frac{\text { anti-inflammatory; }}{\frac{\text { cardioprotective; }}{\text { potentially }}} \\
\text { anti-ischemic; } \\
\text { antagonists not used }\end{array}$ & {$[85]$} \\
\hline & & \multirow[t]{3}{*}{ rat } & $\begin{array}{l}50 \mu \mathrm{g} / \mathrm{kg} \text {, i.v. prophylactic; } \\
\text { one dose before occlusion }\end{array}$ & $\begin{array}{l}\text { heart: } \downarrow \text { infarct area; } \\
\downarrow \text { arrhythmias; } \leftrightarrow \mathrm{HR}\end{array}$ & \multirow{2}{*}{$\frac{\text { antiarrhythmic; }}{\text { cardioprotective; }}$} & \multirow[t]{2}{*}{ [87] } \\
\hline & & & $\begin{array}{l}50 \mu \mathrm{g} / \mathrm{kg} \text {, i.v. prophylactic; } \\
\text { one dose before reperfusion }\end{array}$ & $\begin{array}{c}\text { heart: } \\
\leftrightarrow \text { arrhythmarct area; } \\
\end{array}$ & & \\
\hline & & & $\begin{array}{l}50 \mu \mathrm{g} / \mathrm{kg} \text {, i.v. prophylactic; } \\
\text { one dose before occlusion }\end{array}$ & $\begin{aligned} \text { heart: } & \downarrow \text { arrhythmias; } \\
& \leftrightarrow \mathrm{HR}\end{aligned}$ & $\begin{array}{l}\text { potential involvement of } \\
\mathrm{A}_{1}-\mathrm{Rs}\end{array}$ & [88] \\
\hline & $\frac{\text { autoimmune }}{\text { myocarditis }}$ & mouse & $\begin{array}{l}10 \mathrm{mg} / \mathrm{kg} \text {, i.p. therapeutic; } \\
\text { once a day for } 46 \text { days }\end{array}$ & $\begin{array}{l}\text { heart: improved systolic and } \\
\text { diastolic dysfunction and } \\
\text { myocardial stiffness; } \downarrow \text { left } \\
\text { ventricular inflammatory changes; } \\
\downarrow \text { necrosis; oxidative stress; } \downarrow \text { fibrosis }\end{array}$ & $\begin{array}{l}\frac{\text { anti-inflammatory; }}{\frac{\text { anti-oxidative; }}{\text { anti-fibrotic; }}} \\
\text { cardioprotective } \\
\text { antagonists not used }\end{array}$ & [89] \\
\hline
\end{tabular}


Table 1. Cont.

\begin{tabular}{|c|c|c|c|c|c|c|}
\hline & Model & Species & $\begin{array}{c}\text { Dose and Route of } \\
\text { Administration of CBD }\end{array}$ & Effects & $\begin{array}{l}\text { CBD Properties } \\
\text { Important for COVID-19; } \\
\text { Mechanisms }\end{array}$ & References \\
\hline \multirow{3}{*}{ 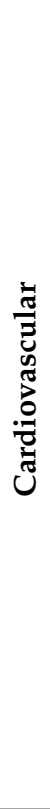 } & $\begin{array}{l}\frac{\text { diabetic }}{\text { cardiomyopathy }} \\
\text { induced by } \\
\text { streptozotocin }\end{array}$ & mouse & $\begin{array}{l}1,10 \text { or } 20 \mathrm{mg} / \mathrm{kg} \text {, i.p. } \\
\text { therapeutic; }\end{array}$ & $\begin{array}{c}\text { heart: } \uparrow \text { diastolic and systolic left } \\
\text { ventricular function; } \downarrow \text { oxidative and } \\
\text { nitrative stress; } \\
\downarrow \text { inflammation and NF-кB } \\
\text { activation; } \downarrow \text { fibrosis; } \\
\downarrow \text { expression of pro-fibrotic genes }\end{array}$ & $\frac{\frac{\text { anti-inflammatory; }}{\text { antioxidative; anti-nitrative; }}}{\text { anti-fibrotic; }}$ & [90] \\
\hline & $\frac{\text { changes in vascular }}{\text { endothelium function in }}$ & rat & $\begin{array}{l}10 \mathrm{mg} / \mathrm{kg} \text {, i.p. } \\
\text { therapeutic for } 7 \text { days }\end{array}$ & $\begin{array}{c}\text { mesenteric arteries: } \\
\uparrow \text { endothelium-dependent } \\
\text { vasorelaxation due to COX- or } \\
\text { NO-mediated mechanisms; } \\
\text { serum: } \downarrow \text { cardiovascular biomarkers } \\
\text { (C-peptide, insulin and intracellular } \\
\text { adhesion molecule- } 1) ; \leftrightarrow \text { glucose, } \\
\text { body weight }\end{array}$ & $\frac{\begin{array}{c}\text { vasoprotective; } \\
\text { improvement in the profile }\end{array}}{\underline{\text { of cardiovascular and }}}$ & [93] \\
\hline & $\begin{array}{l}\text { hypertension: } \\
\text { primary (SHR); } \\
\text { secondary } \\
\text { (DOCA-salt) }\end{array}$ & rat & $\begin{array}{c}10 \mathrm{mg} / \mathrm{kg} \text {, i.p. therapeutic; } \\
\text { once a day for } 2 \text { weeks }\end{array}$ & $\begin{array}{c}\leftrightarrow \text { blood pressure, } \mathrm{HR} ; \\
\text { heart: } \downarrow \text { oxidative stress; } \\
\downarrow \text { carbachol-induced coronary } \\
\text { constriction; } \downarrow \text { left ventricular } \\
\text { cardiomyocyte width; } \\
\leftrightarrow \text { left ventricular hypertrophy }\end{array}$ & $\frac{\text { anti-oxidative; }}{\text { antagonists not used }}$ & {$[91,92]$} \\
\hline \multirow{3}{*}{ 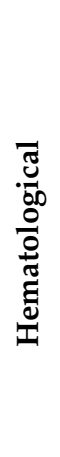 } & $\begin{array}{c}\text { myocardial infarction } \\
\text { induced by left } \\
\text { coronary } \\
\text { artery occlusion }\end{array}$ & rat & $\begin{array}{l}-50 \mu \mathrm{g} / \mathrm{kg} \text {, i.v. } \\
\text { before occlusion } \\
-50 \mu \mathrm{g} / \mathrm{kg} \text {, i.v. } \\
\text { before reperfusion }\end{array}$ & $\begin{array}{l}\downarrow \text { platelet aggregation } \\
\leftrightarrow \text { platelet aggregation }\end{array}$ & antagonists not used & [87] \\
\hline & due $\frac{\text { pulmonary }}{\text { hypertension }}$ to monocrotaline & rat & 10 mg/kg, i.p. prophylactic; & plasma: $\downarrow$ t-PA and PAI-1 & antagonists not used & [77] \\
\hline & $\begin{array}{l}\text { pharmacologically } \\
\text { induced thrombus in } \\
\text { ear venules }\end{array}$ & mouse & $\begin{array}{l}5 \mathrm{mg} / \mathrm{kg} \text {, i.p. prophylactic; } \\
\text { acute: one dose } 30 \text { min before } \\
\text { thrombus induction; } \\
\text { chronic for } 3 \text { days }\end{array}$ & $\begin{array}{c}\text { acute: } \leftrightarrow \text { vessel thrombogenesis } \\
\text { chronic: } \leftrightarrow \text { vessel thrombogenesis }\end{array}$ & antagonists not used & [94] \\
\hline
\end{tabular}


Table 1. Cont.

\begin{tabular}{|c|c|c|c|c|c|c|}
\hline & Model & Species & $\begin{array}{c}\text { Dose and Route of } \\
\text { Administration of CBD }\end{array}$ & Effects & $\begin{array}{l}\text { CBD Properties } \\
\text { Important for COVID-19; } \\
\text { Mechanisms }\end{array}$ & References \\
\hline 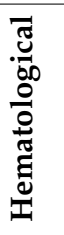 & platelet aggregation & human & in vitro, $0.1-10 \mu \mathrm{M}$ & $\begin{array}{l}\leftrightarrow \text { resting platelets; } \\
\leftrightarrow \text { activation induced by thrombin } \\
\text { receptor activating peptide }\end{array}$ & & [94] \\
\hline \multirow{3}{*}{ ๕్ల } & \multirow{3}{*}{$\begin{array}{l}\text { acute kidney injury } \\
\text { induced by renal is- } \\
\text { chemia/reperfusion }\end{array}$} & \multirow{2}{*}{ rat } & $\begin{array}{c}5 \mathrm{mg} / \mathrm{kg} \text {, i.v. } \\
\text { two doses before occlusion and } \\
\text { after reperfusion }\end{array}$ & $\begin{array}{c}\text { kidney: } \downarrow \text { tubular necrosis and } \\
\text { dilatation; } \downarrow \text { inflammatory changes; } \\
\downarrow \text { NF- } \mathrm{B}, \mathrm{COX}-2, \mathrm{TNF}-\alpha \text { and iNOS; } \\
\text { serum: } \downarrow \text { oxidative } \\
\text { and nitrative stress }\end{array}$ & $\begin{array}{l}\frac{\text { anti-inflammatory; }}{\frac{\text { anti-oxidative; }}{\text { anti-nitrative; }}} \\
\text { nephroprotective; } \\
\text { antagonists not used }\end{array}$ & [95] \\
\hline & & & $\begin{array}{c}5 \mathrm{mg} / \mathrm{kg} \text {, i.a. } \\
\text { one dose after occlusion }\end{array}$ & $\begin{array}{l}\text { kidney: } \downarrow \text { MPO activity; } \\
\downarrow \text { IL- } 1, \overline{T N F-\alpha} \text { and NO levels; } \downarrow \text { lipid } \\
\text { and protein oxidative damage; } \\
\leftrightarrow \text { nitrite } / \text { nitrate levels }\end{array}$ & $\begin{array}{l}\frac{\text { anti-inflammatory; }}{\text { anti-oxidative; }} \\
\text { nephroprotective; } \\
\mathrm{CB}_{1} \text {-Rs and } \mathrm{CB}_{2}-\mathrm{Rs} \\
\text { expression unaltered }\end{array}$ & [96] \\
\hline & & mouse & $\begin{array}{l}10 \mathrm{mg} / \mathrm{kg} \text { i.p. one dose } \\
\text { before reperfusion }\end{array}$ & $\begin{array}{l}\text { kidney: pattern of } \\
\text { innate lymphoid cells } \\
\text { restored to control values }\end{array}$ & $\frac{\text { nephroprotective; }}{\text { antagonists not used }}$ & [97] \\
\hline \multirow{3}{*}{ 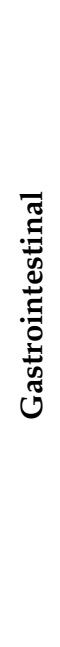 } & $\begin{array}{l}\text { nausea or } \\
\frac{\text { vomiting induced by }}{\text { lithium chloride }}\end{array}$ & $\begin{array}{c}\text { rat } \\
\text { shrew }\end{array}$ & $\begin{array}{c}\text { prophylactic; } \\
\text { acute: } 5 \text { and } 20 \mathrm{mg} / \mathrm{kg} \text {, s.c. } \\
\text { chronic: } 5 \mathrm{mg} / \mathrm{kg} \text { s.c. for } 7 \text { days }\end{array}$ & $\begin{array}{c}\text { acute and chronic: } \\
\downarrow \text { nausea and/or vomiting }\end{array}$ & $\frac{\text { anti-nausea, }}{\frac{\text { antiemetic; }}{5-\mathrm{HT}_{1 \mathrm{~A}}-\mathrm{Rs}}}$ & [98] \\
\hline & $\begin{array}{l}\text { hepatic ischemia/ } \\
\text { reperfusion injury } \\
\text { induced by hepatic } \\
\text { artery and } \\
\text { portal vein } \\
\text { occlusion }\end{array}$ & mouse & $\begin{array}{c}3 \text { or } 10 \mathrm{mg} / \mathrm{kg} \text {, i.p. prophylactic; } \\
\text { one dose before reocclusion or } \\
90 \mathrm{~min} \text { after }\end{array}$ & $\begin{array}{c}\text { serum: } \downarrow \text { AST and ALT; } \\
\text { liver: } \downarrow \text { inflammatory changes; } \\
\downarrow \text { cell apoptosis (10 mg/kg only); } \\
\downarrow \text { pro-inflammatory cytokines; } \\
\downarrow \text { oxidative and nitrative stress (10 } \\
\text { mg/kg only); } \downarrow \text { neutrophil migration } \\
\text { to liver tissue }\end{array}$ & $\begin{array}{l}\frac{\text { anti-inflammatory; }}{\frac{\text { antioxidant; }}{\text { anti-nitrative; }}} \\
\text { hepatoprotective; } \\
\text { independent of } \mathrm{CB}_{2} \text {-Rs }\end{array}$ & [100] \\
\hline & $\begin{array}{l}\text { liver injury and } \\
\text { steatosis induced by } \\
\text { chronic ethanol } \\
\text { administration }\end{array}$ & mouse & $\begin{array}{c}5 \text { or } 10 \mathrm{mg} / \mathrm{kg} \text {, i.p. prophylactic } \\
\text { for } 11 \text { days during the ethanol } \\
\text { exposure }\end{array}$ & $\begin{array}{l}\quad \text { serum: } \downarrow \text { AST and ALT; } \\
\text { liver: } \downarrow \text { inflammatory changes; } \\
\downarrow \text { pro-inflammatory chemokines; } \\
\quad \downarrow \text { neutrophil accumulation; } \\
\downarrow \text { oxidative burst of neutrophils; } \\
\downarrow \text { oxidative and nitrative stress }\end{array}$ & $\begin{array}{l}\frac{\text { anti-inflammatory; }}{\text { anti-oxidative; }} \\
\text { hepatoprotective; } \\
\text { antagonists not used }\end{array}$ & {$[101]$} \\
\hline
\end{tabular}


Table 1. Cont.

\begin{tabular}{|c|c|c|c|c|c|c|}
\hline & Model & Species & $\begin{array}{c}\text { Dose and Route of } \\
\text { Administration of CBD }\end{array}$ & Effects & $\begin{array}{l}\text { CBD Properties } \\
\text { Important for COVID-19; } \\
\text { Mechanisms }\end{array}$ & References \\
\hline \multirow{5}{*}{ 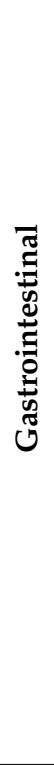 } & $\frac{\text { hepatic encephalopathy }}{\text { due to thioacetamide }}$ & mouse & $\begin{array}{l}5 \mathrm{mg} / \mathrm{kg} \text {, i.p. therapeutic; } \\
\text { one dose after } \\
\text { thioacetamide injection }\end{array}$ & $\begin{array}{c}\text { liver: } \leftrightarrow \text { necrosis; } \\
\text { plasma: } \downarrow \text { ALT and AST, } \\
\text { ammonia and bilirubin }\end{array}$ & $\frac{\text { partly hepatoprotective; }}{\text { antagonists not used }}$ & [102] \\
\hline & $\frac{\text { acute hepatic toxicity }}{\text { induced by cocaine }}$ & mouse & $\begin{array}{l}\text { 30, } 60 \text { and } 90 \mathrm{mg} / \mathrm{kg} \text {, } \\
\text { i.p. prophylactic; } \\
\text { acute } 30 \text { min before } \\
\text { cocaine injection }\end{array}$ & $\begin{array}{c}\text { liver: } \downarrow \text { dacute inflammation and } \\
\text { damage ( } \downarrow \text { histological changes) } \\
\text { serum: } \downarrow \text { ALT; } \\
\downarrow \text { acute behavioral seizure }\end{array}$ & $\begin{array}{l}\text { anti-inflammatory; } \\
\text { FAAH inhibitor did not } \\
\text { modify cocaine-induced } \\
\text { changes in liver }\end{array}$ & [103] \\
\hline & induced by cerulein & mouse & $\begin{array}{l}0.5 \mathrm{mg} / \mathrm{kg} \text {, i.p. prophylactic; } \\
8 \text { doses ( } 2 \text { before and } 6 \\
\text { simultaneously with cerulein) }\end{array}$ & $\begin{array}{l}\text { pancreas: } \downarrow \text { pathological changes, } \\
\downarrow \downarrow \text { MPO activity in pancreas tissue; } \\
\text { plasma: } \downarrow \text { amylase and lipase; } \\
\downarrow \text { Il- } 6 \text { and TNF- } \alpha\end{array}$ & $\begin{array}{l}\text { anti-inflammatory; } \\
\text { pancreas-protective; } \\
\text { possibly via GPR55 } \\
\text { (presence in pancreas) }\end{array}$ & [104] \\
\hline & $\begin{array}{l}\text { inflammation and } \\
\text { intestinal hypermotility } \\
\text { induced by croton oil }\end{array}$ & mouse & $\begin{array}{l}5 \text { and } 10 \mathrm{mg} / \mathrm{kg} \text {, } \\
\text { i.p. therapeutic; } \\
\text { one dose to mice with } \\
\text { inflammation }\end{array}$ & intestine: $\downarrow$ hypermotility & $\begin{array}{l}\text { involvement of } \mathrm{CB}_{1}-\mathrm{Rs} \\
\text { (but not } \mathrm{CB}_{2}-\mathrm{Rs} \text { ) } \\
\text { and FAAH }\end{array}$ & [105] \\
\hline & $\begin{array}{l}\text { colitis in- } \\
\text { duced by intracolonic } \\
\text { dinitrobenzensulfonic acid }\end{array}$ & mouse & $\begin{array}{l}5-30 \mathrm{mg} / \mathrm{kg} \text {, i.p. and } \\
10-60 \mathrm{mg} / \mathrm{kg} \text {, p.o. therapeutic } \\
\text { for } 3 \text { days after colitis induction }\end{array}$ & $\begin{array}{c}\quad \begin{array}{c}\text { intestine: } \\
\downarrow \\
\leftrightarrow \text { hypermotility; }\end{array} \\
\downarrow \text { colitis; } \\
\downarrow \text { colon weight and MPO activity }\end{array}$ & $\frac{\text { anti-inflammatory; }}{\text { antagonists not used }}$ & [106] \\
\hline \multirow{2}{*}{ 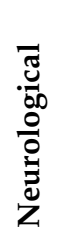 } & $\begin{array}{c}\text { chronic } \\
\text { unpredictable } \\
\text { mild stress model of } \\
\text { depression }\end{array}$ & rat & $\begin{array}{l}10 \mathrm{mg} / \mathrm{kg} \text {, i.p. prophylactic } \\
\quad \text { for } 28 \text { days }\end{array}$ & $\begin{array}{l}\text { higher rate of body weight gain and } \\
\text { sucrose preference } \\
\text { compared to controls }\end{array}$ & $\frac{\text { prohedonic; }}{\text { antagonists not used }}$ & [107] \\
\hline & $\frac{\text { various acute seizure }}{\underline{\text { models }}}$ & $\begin{array}{l}\text { rat } \\
\text { mouse }\end{array}$ & $\begin{array}{l}\text { one different i.v. dose } \\
\text { dependent on the model }\end{array}$ & acute antiseizure activity & antiseizure activity & [109] \\
\hline
\end{tabular}


Table 1. Cont.

\begin{tabular}{|c|c|c|c|c|c|c|}
\hline & Model & Species & $\begin{array}{c}\text { Dose and Route of } \\
\text { Administration of CBD }\end{array}$ & Effects & $\begin{array}{c}\text { CBD Properties } \\
\text { Important for COVID-19; } \\
\text { Mechanisms }\end{array}$ & References \\
\hline \multirow{6}{*}{ 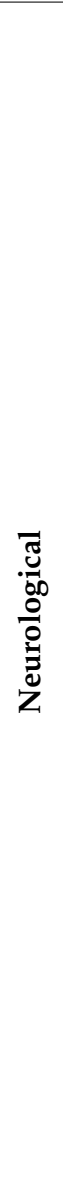 } & $\begin{array}{l}\text { status epilepticus- } \\
\text { spontaneous } \\
\frac{\text { recurrent seizures }}{\text { (RISESRS) model }}\end{array}$ & rat & $200 \mathrm{mg} / \mathrm{kg}$ for 7 weeks & $\begin{array}{l}\downarrow \text { seizure burden and } \\
\text { motor comorbidities; } \\
\text { reversal of the epilepsy-induced } \\
\text { cognitive deficits }\end{array}$ & & [109] \\
\hline & $\begin{array}{l}\text { seizure induced by } \\
\text { pentylene-tetrazole }\end{array}$ & mouse & $\begin{array}{c}60 \mathrm{mg} / \mathrm{kg} \text {, i.p. prophylactic; } \\
\text { once before induction of } \\
\text { epileptic attack }\end{array}$ & $\begin{array}{l}\downarrow \text { seizure duration; } \\
\quad \downarrow \text { EEG changes }\end{array}$ & $\begin{array}{l}\mathrm{CB}_{1}, \mathrm{CB}_{2} \text { and } \mathrm{TRPV} 1 \\
\text { receptors }\end{array}$ & [110] \\
\hline & $\begin{array}{l}\frac{\text { hepatic }}{\text { encephalopathy }} \\
\frac{\text { induced by }}{\text { thioacetamide }}\end{array}$ & mouse & $\begin{array}{c}5 \mathrm{mg} / \mathrm{kg} \text {, i.p. therapeutic; } \\
\text { one dose after } \\
\text { thioacetamide injection }\end{array}$ & $\begin{array}{c}\text { } \text { neurological and } \\
\text { cognitive functions; } \\
\uparrow \text { activity; } \\
\downarrow \text { activated astrocytes }\end{array}$ & $\begin{array}{c}\text { procognitive; } \\
\text { neuroprotective; } \\
\text { antagonists not used }\end{array}$ & [102] \\
\hline & $\frac{\text { sepsis-related }}{\text { encephalitis }}$ & mouse & $\begin{array}{c}3 \mathrm{mg} / \mathrm{kg} \text {, i.v. } \\
\text { one dose } \\
\text { simultaneously with LPS }\end{array}$ & $\begin{array}{c}\text { Tintegrity of blood-brain barrier; } \\
\downarrow \text { leukocyte margination } \\
\text { in brain vessels; } \\
\leftrightarrow \text { level of oxidative stress; } \\
\downarrow \text { TNF- } \alpha \text { and COX- } 2\end{array}$ & $\frac{\text { anti-inflammatory; }}{\underline{\text { neuroprotective }}}$ & [113] \\
\hline & \multirow[t]{2}{*}{$\begin{array}{l}\text { perinatal hypoxic- } \\
\text { ischemic encephalopathy } \\
\text { induced by occlusion } \\
\text { of carotid arteries }\end{array}$} & \multirow{2}{*}{$\begin{array}{l}\text { newborn } \\
\text { piglet }\end{array}$} & $\begin{array}{c}1 \mathrm{mg} / \mathrm{kg} \text {, i.v. therapeutic; } \\
\text { one dose } \overline{30 \mathrm{~min}} \\
\text { after induction of } \\
\text { brain injury }\end{array}$ & $\begin{array}{l}\text { brain: } \downarrow \text { EEG changes; } \\
\downarrow \text { neuronal mortality; } \\
\downarrow \text { excitotoxicity; } \downarrow \text { IL-1; } \\
\quad \downarrow \text { oxidative stress }\end{array}$ & $\begin{array}{c}\text { anti-inflammatory; } \\
\text { anti-oxidative; } \\
\text { neuroprotective } \\
\text { partially dependent on } \\
5-\mathrm{HT}_{1 \mathrm{~A}} \text {-Rs and } \mathrm{CB}_{2}-\mathrm{Rs} \\
\leftrightarrow \text { brain } \\
\text { endocannabinoid levels }\end{array}$ & [111] \\
\hline & & & $\begin{array}{l}1 \mathrm{mg} / \mathrm{kg} \text {, i.v. therapeutic; } \\
\text { one dose after induction } \\
\text { of brain injury }\end{array}$ & $\begin{array}{c}\text { brain: } \uparrow \text { activity (EEG); } \\
\downarrow \text { neuronal mortality; } \\
\downarrow \text { excitotoxicity; } \downarrow \text { oxidative stress; } \\
\downarrow \text { TNF- } \alpha \text {; effects on excitotoxicity, } \\
\text { oxidative stress and TNF- } \alpha \text { additive } \\
\text { to those of hypothermia }\end{array}$ & $\begin{array}{l}\frac{\text { anti-inflammatory; }}{\text { anti-oxidative; }} \\
\text { neuroprotective; } \\
\text { antagonists not used }\end{array}$ & [112] \\
\hline
\end{tabular}


Table 1. Cont.

\begin{tabular}{|c|c|c|c|c|c|c|}
\hline & Model & Species & $\begin{array}{c}\text { Dose and Route of } \\
\text { Administration of CBD }\end{array}$ & Effects & $\begin{array}{l}\text { CBD Properties } \\
\text { Important for COVID-19; } \\
\text { Mechanisms }\end{array}$ & References \\
\hline \multirow{4}{*}{ 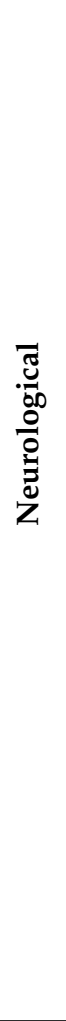 } & $\begin{array}{l}\frac{\text { cerebral ischemia }}{\text { (stroke model) }} \\
\text { induced by MCA } \\
\text { occlusion }\end{array}$ & mouse & $\begin{array}{c}0.1 ; 1 ; 3 \mathrm{mg} / \mathrm{kg}, \text { i.p. } \\
\text { two doses } \\
\text { (before and after occlusion) }\end{array}$ & $\begin{array}{c}\text { brain: } \uparrow \text { neurological } \\
\text { function and motor } \\
\text { coordination; } \\
\text { dose-dependent } \downarrow \text { infarct area } \\
\downarrow \mathrm{MPO} \text { activity and } \uparrow \mathrm{CBF} \text { (tested } \\
\text { only at } 3 \mathrm{mg} / \mathrm{kg} \text { ); } \\
\text { blood: } \leftrightarrow \mathrm{pCO}_{2}, \mathrm{pO}_{2}\end{array}$ & $\begin{array}{l}\frac{\text { anti-inflammatory; }}{\text { neuroprotective; }} \\
\text { partially dependent on } \\
\quad 5-\mathrm{HT}_{1 \mathrm{~A}}-\mathrm{Rs} \\
\text { independent of } \mathrm{CB}_{1}, \mathrm{CB}_{2} \\
\text { and TRPV1 receptors }\end{array}$ & {$[114,115]$} \\
\hline & $\begin{array}{l}\text { encephalomyelitis } \\
\text { induced by TMEV }\end{array}$ & mouse & $\begin{array}{l}180 \mathrm{mg} / \mathrm{kg} \text {, i.p. twice daily } \\
\text { starting } 2 \text { days before } \\
\text { (prophylactic) or } 3 \text { days after } \\
\text { infection (therapeutic) }\end{array}$ & $\begin{array}{c}\downarrow \text { acute behavioral seizures } \\
\text { from } 5 \text { days (prophylactic) } \\
\text { and } 6 \text { days after infection onward } \\
\text { (therapeutic) }\end{array}$ & 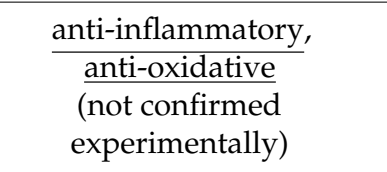 & [73] \\
\hline & \multirow[t]{2}{*}{$\frac{\text { multiple sclerosis }}{\text { induced by TMEV }}$} & \multirow[t]{2}{*}{ mouse } & $\begin{array}{l}5 \mathrm{mg} / \mathrm{kg} \text {, i.p. therapeutic, } \\
\text { once a day for } 7 \text { days }\end{array}$ & $\begin{array}{l}\text { sub chronic effects (after } 8 \text { days): } \\
\downarrow \text { transmigration of leukocytes to the } \\
\text { nervous parenchyma } \\
\text { by downregulating the expression } \\
\text { of VCAM- } 1, \text { CCL2 and CCL5 and } \\
\text { the proinflammatory cytokine } \\
\text { IL-1 } \beta \text { and } \\
\text { by attenuating } \\
\text { the activation of microglia }\end{array}$ & $\begin{array}{l}\text { anti-inflammatory } \\
\text { partial involvement of } \\
\text { adenosine } \mathrm{A}_{2 \mathrm{~A}}-\mathrm{Rs} \\
\text { (experiments with } \\
\text { an appropriate } \\
\text { antagonist) }\end{array}$ & \multirow[t]{2}{*}{ [74] } \\
\hline & & & $\begin{array}{l}\text { same treatment } \\
\text { for } 10 \text { days }\end{array}$ & $\begin{array}{l}\text { chronic effects (after } 80 \text { days): } \\
\text { improvement of motor deficits } \\
\downarrow \text { microglial activation and } \\
\text { pro-inflammatory } \\
\text { cytokine production }\end{array}$ & & \\
\hline 盆 & $\frac{\text { retinal inflammation }}{\text { due to LPS }}$ & rat & $\begin{array}{c}1 \mathrm{mg} / \mathrm{kg} \text {, i.p. prophylactic } \\
\text { before LPS treatment }\end{array}$ & $\downarrow$ retinal TNF- $\alpha$ levels & $\begin{array}{l}\text { anti-inflammatory; due } \\
\text { to } \mathrm{A}_{2} \text {-Rs but not } \mathrm{A}_{1} \text {-Rs }\end{array}$ & [117] \\
\hline
\end{tabular}


Table 1. Cont.

\begin{tabular}{|c|c|c|c|c|c|c|}
\hline & Model & Species & $\begin{array}{c}\text { Dose and Route of } \\
\text { Administration of CBD }\end{array}$ & Effects & $\begin{array}{l}\text { CBD Properties } \\
\text { Important for COVID-19; } \\
\text { Mechanisms }\end{array}$ & References \\
\hline \multirow{2}{*}{ 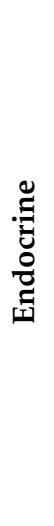 } & $\begin{array}{l}\text { high-fat diet- } \\
\text { induced obesity }\end{array}$ & rat & $\begin{array}{l}10 \mathrm{mg} / \mathrm{kg} \text {, i.p. prophylactic } \\
\text { for } 2 \text { weeks }\end{array}$ & $\begin{array}{l}\text { plasma: } \downarrow \text { insulin; } \\
\text { skeletal muscle: improved insulin } \\
\text { signal transduction } \\
\text { and glycogen recovery }\end{array}$ & $\begin{array}{l}\downarrow \text { lipotoxicity, leading to } \\
\text { insulin-sensitization } \\
\text { in myocytes; } \\
\downarrow \text { expression of } \\
\mathrm{CB}_{1}, \mathrm{CB}_{2}, \mathrm{TRPV} 1 \\
\text { and } 5-\mathrm{HT}_{1 \mathrm{~A}} \text { receptors } \\
\end{array}$ & [118] \\
\hline & $\begin{array}{l}\text { type } 1 \text { diabetes by } \\
\text { streptozotocin } \\
\text { submitted to } \\
\text { chronic cerebral } \\
\text { hypoperfusion }\end{array}$ & rat & $\begin{array}{l}10 \mathrm{mg} / \mathrm{kg} \text {, i.p. } 30 \mathrm{~min} \text { before } \\
\text { and for } 30 \text { days after } \\
\text { cerebral hypoperfusion surgery }\end{array}$ & $\begin{array}{c}\downarrow \text { body weight; } \\
\text { plasma: } \downarrow \text { hyperglycemia; } \\
\uparrow \text { insulinemia; } \\
\downarrow \text { AGEs and fructosamine; } \\
\downarrow \text { dyslipidemia (LDL, HDL, TGs and } \\
\text { total cholesterol levels); } \downarrow \text { AST and } \\
\text { ALT; } \uparrow \text { memory performance }\end{array}$ & $\frac{\frac{\text { improvement of }}{\text { metabolic dysfunction; }}}{\frac{\text { hepatoprotective; }}{\text { neuroprotective; }}}$ & [119] \\
\hline 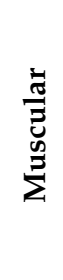 & 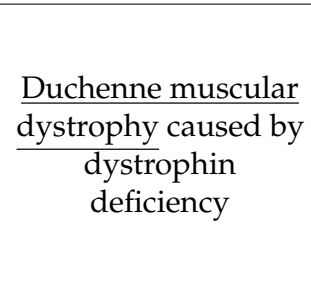 & mouse & $\begin{array}{l}60 \mathrm{mg} / \mathrm{kg} \text {, i.p., therapeutic; } \\
\text { three times a week for } 2 \text { weeks }\end{array}$ & $\begin{array}{l}\text { muscle: prevention of the } \\
\text { functionality loss and tissue } \\
\text { degeneration; restoration of } \\
\text { locomotor activity; } \\
\downarrow \text { inflammation (IL-6, TNF- } \alpha \text { ); } \\
\text { muscle strength and } \\
\text { autophagy restored }\end{array}$ & $\begin{array}{c}\text { anti-inflammatory; } \\
\text { (involvement of TRP } \\
\text { channels—based on } \\
\text { in vitro } \\
\text { experiments) }\end{array}$ & [121] \\
\hline \multirow{3}{*}{$\frac{5}{\infty}$} & $\begin{array}{l}\text { skin irradiated with } \\
\text { UVA/UVB }\end{array}$ & nude rat & $\begin{array}{c}2.5 \mathrm{~g} \text { in } 100 \mathrm{~g} \text { petrolatum } \\
\text { applied to the back of rats every } \\
12 \mathrm{~h} \text { for } 4 \text { weeks }\end{array}$ & $\begin{array}{c}\downarrow U V \text {-induced changes in } \\
\text { inflammation; apoptosis and } \\
\text { oxidative stress }\end{array}$ & $\begin{array}{l}\text { prevention of } \\
\text { UV-induced metabolic } \\
\text { changes in epidermal } \\
\text { keratinocytes }\end{array}$ & [122] \\
\hline & $\begin{array}{l}\text { cultured human } \\
\text { sebocytes and } \\
\text { human skin } \\
\text { organ culture }\end{array}$ & human & $10 \mu \mathrm{M}$ & $\begin{array}{c}\downarrow \text { lipogenic actions of } \\
\text { arachidonic acid } \\
\text { and a combination of linoleic acid } \\
\text { and testosterone; suppression of } \\
\text { sebocyte proliferation }\end{array}$ & $\begin{array}{l}\text { anti-inflammatory } \\
\left.\text { (adenosine } \mathrm{A}_{2 \mathrm{a}} \mathrm{Rs}\right) ; \\
\text { sebostatic; lipostatic; } \\
\text { antiproliferative (TRP4) }\end{array}$ & [123] \\
\hline & $\begin{array}{c}\text { experimental model } \\
\text { of allergic contact } \\
\text { dermatitis in } \\
\text { keratinocytes }\end{array}$ & human & $5,10,20 \mu \mathrm{M}$ & $\begin{array}{c}\text { inhibition of } \\
\text { polyinosinic-polycytidylic } \\
\text { acid-induced release of MCP-2, IL-6, } \\
\text { IL- } 8 \text { and TNF- } \alpha \text {; } \\
\text { no cytotoxic effect }\end{array}$ & $\begin{array}{l}\frac{\text { anti-inflammatory }}{\text { via } \mathrm{CB}_{2} \text { and } \mathrm{TRPV} 1} \\
\text { receptors }\end{array}$ & [124] \\
\hline
\end{tabular}


Table 1. Cont.

\begin{tabular}{|c|c|c|c|c|c|c|}
\hline & Model & Species & $\begin{array}{c}\text { Dose and Route of } \\
\text { Administration of CBD }\end{array}$ & Effects & $\begin{array}{c}\text { CBD Properties } \\
\text { Important for COVID-19; } \\
\text { Mechanisms }\end{array}$ & References \\
\hline \multirow{2}{*}{$\stackrel{\grave{\Xi}}{ \pm}$} & \multirow[t]{2}{*}{$\begin{array}{l}\text { sepsis induced by } \\
\text { cecal ligation } \\
\text { and puncture }\end{array}$} & \multirow[t]{2}{*}{ rat } & $\begin{array}{c}10 \mathrm{mg} / \mathrm{kg} \text {, i.p. } \\
\text { Acute- }- \text { therapeutic; } \\
\text { one dose (after sepsis induction) }\end{array}$ & $\begin{array}{l}\downarrow \text { lipid peroxidation in lung, heart } \\
\text { and kidney; } \downarrow \text { oxidative protein } \\
\text { damage in spleen, liver and heart; } \\
\downarrow \text { oxidative damage of proteins in } \\
\text { striatum, cortex and hippocampus; } \\
\text { } \text { oxidative damage of proteins } \\
\text { in lung }\end{array}$ & $\begin{array}{c}\frac{\text { anti-oxidative; }}{\text { organo-protective; }} \\
\text { pro-oxidative in lungs } \\
\end{array}$ & \multirow[t]{2}{*}{ [125] } \\
\hline & & & $\begin{array}{l}10 \mathrm{mg} / \mathrm{kg} \text {, i.p. } \\
\text { Chronic- therapeutic; } \\
\text { once daily for } \overline{9 \text { days; first dose }} \\
\text { after sepsis induction }\end{array}$ & $\begin{array}{c}\downarrow \text { mortality; improvement of } \\
\text { memory-related processes; } \downarrow \text { lipid } \\
\text { peroxidation in kidney; } \\
\downarrow \text { oxidative protein damage in } \\
\text { spleen, liver, heart }\end{array}$ & $\frac{\frac{\text { anti-oxidative; }}{\text { organo-protective; }}}{\underline{\text { procognitive }}}$ & \\
\hline
\end{tabular}

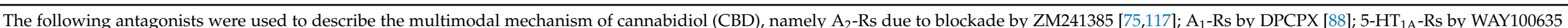

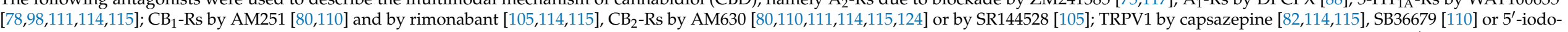

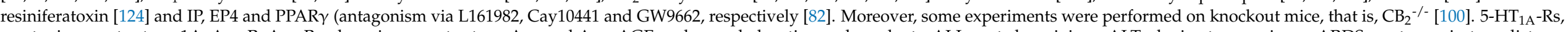

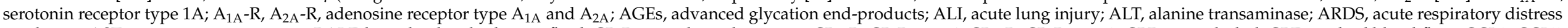

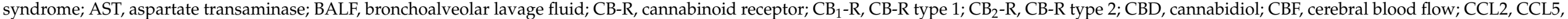

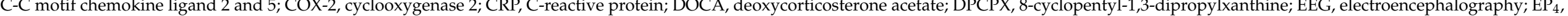

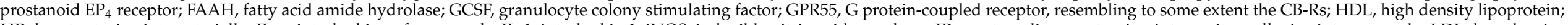

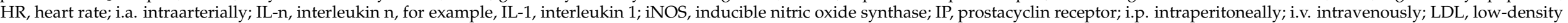

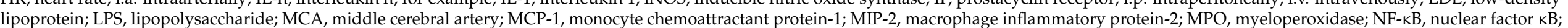

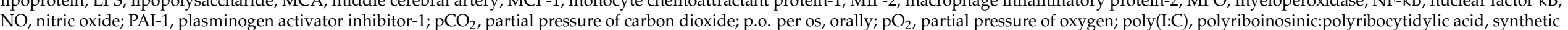

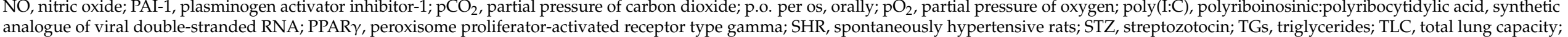

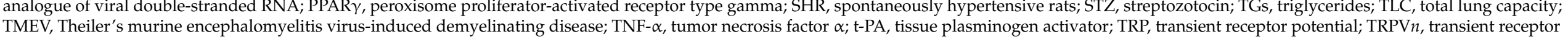
potential vanilloid subfamily member $n$; UVA and UVB, ultraviolet A and B; VCAM-1, vascular cell adhesion molecule- 1 . $\uparrow$, increase; $\downarrow$, decrease; $\leftrightarrow$, no change. 
Importantly, the effectiveness of CBD has been shown in multiple organ dysfunction. Acute and chronic administration in an experimental model of sepsis reduced mortality, lipid peroxidation and oxidative damage of proteins in many vital organs [125]. However, one should keep in mind that $\mathrm{CBD}$, given acutely, had a pro-oxidative effect and increased oxidative damage of proteins in the lungs ([125]; Table 1).

In summary, preclinical studies show that acute and chronic administration of CBD through prophylactic and/or therapeutical interventions has numerous beneficial effects in organs that are also targeted by the coronavirus; they mainly result from CBD's antiinflammatory and antioxidative actions. The precise mechanism(s) is/are still unknown although in a few studies, the involvement of cannabinoid $\mathrm{CB}_{1}, \mathrm{CB}_{2}$, GPR55, vanilloid TRPV1, adenosine $\mathrm{A}_{2 \mathrm{~A}}$ and serotonin $5-\mathrm{HT}_{1 \mathrm{~A}}$ receptors has been described (Table 1).

\section{Use of CBD for COVID-19 Treatment? Clinical Studies}

In the ClinicalTrials.gov database (accessed on 1 February 2021), we found six clinical trials (two active, not recruiting; two not yet recruiting; and two recruiting) in which the use of CBD is being addressed in the context of COVID-19. Two studies are dedicated to the use of CBD in patients with mild to moderate symptoms, including the study entitled "Cannabidiol for COVID-19 patients with mild to moderate symptoms" (daily doses of $300 \mathrm{mg}$ for 14 days) and the study entitled "Synthetic CBD as a therapy for COVID-19" (dose and duration of administration not specified). Another two studies are dedicated to patients with higher risk, including the study entitled "Cannabidiol treatment for severe and critical coronavirus (COVID-19) pulmonary infection" (daily doses of $300 \mathrm{mg}$ for 14-28 days or until discharge) and the study entitled "Cannabidiol in patients with COVID-19 and cardiovascular disease or risk factors" (daily doses of $525 \mathrm{mg} / 70 \mathrm{~kg}$ for 28 days). The fifth study, entitled "Outcomes mandate national integration with Cannabis as medicine for prevention and treatment of COVID-19 (OMNI-Can)" will examine the efficacy and safety of using medical cannabis for chronic medical conditions, including COVID-19 (dose and duration of administration not specified). As suggested by the title "Burnout and distress prevention with cannabidiol in front-line health care workers dealing with COVID-19," the final study is dedicated to the hospital staff rather than to patients (daily doses of $175 \mathrm{mg} / 70 \mathrm{~kg}$ for 28 days).

Since it will take some time until the latter studies have been completed, the question arises as to whether there are other clinical studies based on CBD that may point to its suitability for the prevention/treatment of COVID-19 (Table 2). In the ClinicalTrials.gov database (accessed on 1 February 2021), there are 186 items regarding formulations containing CBD (59 studies were signed as completed; the results of 13 of the latter trials are presented in the database and 9 of them have been published). In contrast to the results of preclinical studies (Table 1), so far, no clinical studies have demonstrated promising effects of CBD on patients with respiratory failure (Table 2). There are two publications based on a few patients with chronic obstructive pulmonary disease (COPD). CBD given acutely together with THC in vaporized form [126] or as a sublingual spray [127] had no or only minimal beneficial effects on airway function, exertional breathlessness at rest and during exercise and simulated breathlessness (Table 2). Clinical trials indicating a potential usefulness of CBD in cardiovascular, hematological and renal symptoms associated with COVID-19 could not be found. 
Table 2. Efficacy and safety of cannabidiol in clinical studies.

\begin{tabular}{|c|c|c|c|c|c|c|c|}
\hline & Disease & $n$ & $\begin{array}{l}\text { * Study Design; } \\
\text { Dose of CBD } \\
\text { and THC }\end{array}$ & Application & $\begin{array}{l}\text { Final Results and/or Conclusions, } \\
\text { Properties Important for COVID-19 } \\
\end{array}$ & Profile Safety/Side Effects & References \\
\hline \multirow{2}{*}{ 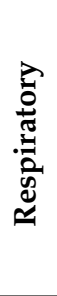 } & \multirow[b]{2}{*}{ COPD } & 16 & $\begin{array}{l}\text { * Cannabis } 35 \mathrm{mg} \\
\text { (THC, } 18.2 \%, \\
\text { CBD, } 0.1 \%) ; \text { acute }\end{array}$ & vaporized & $\begin{array}{l}\text { no effect on airway function, } \\
\text { exertional breathlessness at rest } \\
\text { and exercise }\end{array}$ & & [126] \\
\hline & & 9 & $\begin{array}{c}\text { * THC: CBD } \\
2.7: 2.5 \mathrm{mg} / \text { spray; } \\
\text { maximum single dose } \\
\text { of } 4 \text { sprays }\end{array}$ & $\begin{array}{l}\text { oromucosal } \\
\text { spray }\end{array}$ & $\begin{array}{l}\text { no effect on simulated breathlessness } \\
\text { in COPD subjects; } \\
\frac{\downarrow \text { unpleasantness of breathlessness as }}{\text { judged by descriptors }}\end{array}$ & & [127] \\
\hline \multirow{5}{*}{ 胥 } & $\begin{array}{l}\text { chemotherapy- } \\
\text { induced nausea } \\
\text { and vomiting } \\
\text { (CINV) }\end{array}$ & 7 & $\begin{array}{c}* \text { THC: CBD } \\
\text { 2.7:2.5 mg/spray, } \\
\leq 3 \text { sprays within } 2 \mathrm{~h} \text { after } \\
\text { chemotherapy plus } \\
\leq 8 \text { sprays each at } \\
\text { days } 2,3 \text { and } 4\end{array}$ & $\begin{array}{l}\text { oromucosal } \\
\text { spray }\end{array}$ & $\begin{array}{c}\text { better protection against delayed CINV } \\
\text { compared to standard antiemetic } \\
\text { therapy alone }\end{array}$ & well tolerated & [128] \\
\hline & $\begin{array}{l}\text { cancer-related anorexia- } \\
\text { cachexia syndrome }\end{array}$ & 99 & $\begin{array}{l}\text { * THC } 2.5 \mathrm{mg} \text { and CBD } \\
1 \mathrm{mg} \text {; twice daily } 1 \mathrm{~h} \\
\text { before meals for } 6 \text { weeks }\end{array}$ & p.o. & $\begin{array}{l}\text { no effect on patients' appetite } \\
\text { or quality of life }\end{array}$ & well tolerated & [129] \\
\hline & $\begin{array}{l}\text { aspirin-induced increased } \\
\text { gut permeability }\end{array}$ & 10 & * CBD:600 mg & p.o. & $\downarrow$ increased gut permeability & & [130] \\
\hline & $\begin{array}{l}\text { moderately } \\
\text { active Crohn's disease }\end{array}$ & 20 & $\begin{array}{c}\text { * CBD } 10 \mathrm{mg} / \mathrm{kg} \text { twice } \\
\text { daily for } 8 \text { weeks }\end{array}$ & p.o. & no clinical improvement & $\begin{array}{l}\text { excellent tolerability } \\
\text { and safety profile }\end{array}$ & [131] \\
\hline & $\begin{array}{l}\text { ulcerative } \\
\text { colitis }\end{array}$ & 60 & $\begin{array}{l}\text { *250 mg CBD-rich extract } \\
\text { (up to } 4.7 \% \text { THC) twice } \\
\text { daily before meals } \\
\text { for } 10 \text { weeks }\end{array}$ & p.o. & $\begin{array}{l}\text { no effect on ulcerative colitis } \\
\text { but } \uparrow \text { quality of life outcomes }\end{array}$ & $\begin{array}{c}\text { mild/moderate, } \\
\text { mainly } \\
\text { dizziness and somnolence }\end{array}$ & [132] \\
\hline \multirow{2}{*}{ 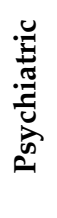 } & \multirow{2}{*}{$\begin{array}{l}\text { anxiety in healthy } \\
\text { volunteers }\end{array}$} & 40 & ${ }^{*}$ CBD:300 mg acute & p.o. & $\downarrow$ anxiety to simulated public speaking & & [133] \\
\hline & & 10 & * CBD:400 mg acute & p.o. & $\begin{array}{c}\frac{\downarrow \text { subjective anxiety to a simulated }}{\text { public speaking test, }} \\
\qquad \text { mental sedation }\end{array}$ & & [134] \\
\hline
\end{tabular}


Table 2. Cont.

\begin{tabular}{|c|c|c|c|c|c|c|c|}
\hline & Disease & $n$ & $\begin{array}{l}\text { * Study Design; } \\
\text { Dose of CBD } \\
\text { and THC }\end{array}$ & Application & $\begin{array}{l}\text { Final Results and/or Conclusions, } \\
\text { Properties Important for COVID-19 } \\
\end{array}$ & Profile Safety/Side Effects & References \\
\hline \multirow{8}{*}{ 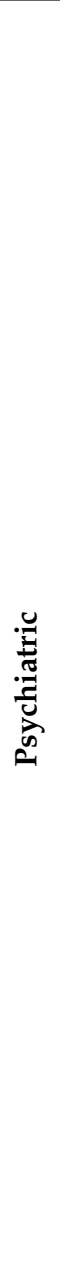 } & $\begin{array}{l}\text { anxiety in healthy } \\
\text { volunteers }\end{array}$ & 60 & $\begin{array}{l}\text { *CBD: } 100,300 \text { and } \\
900 \mathrm{mg} \text { acute }\end{array}$ & p.o. & $\begin{array}{l}\downarrow \text { ssubjective anxiety with a } \\
\text { dose-dependent bell-shaped curve } \\
\text { (effective dose:300 mg only) }\end{array}$ & $\begin{array}{l}\text { CBD } 300 \text { mg has a lower } \\
\text { sedation level than } \\
\text { clonazepam }\end{array}$ & [135] \\
\hline & \multirow[t]{2}{*}{$\begin{array}{l}\text { naïve social } \\
\text { anxiety disorder }\end{array}$} & 24 & * CBD:600 mg acute & p.o. & 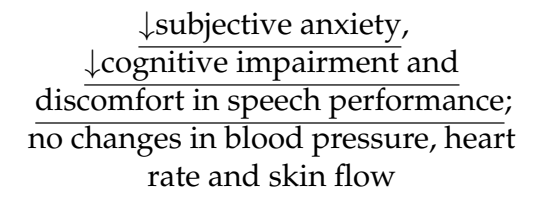 & $\begin{array}{l}\text { absence of psychoactive or } \\
\text { cognitive effects }\end{array}$ & [136] \\
\hline & & 10 & ${ }^{*}$ CBD:400 mg acute & p.o. & $\frac{\downarrow \text { subjective anxiety, changes in }}{\text { regional cerebral flow }}$ & & [137] \\
\hline & stress-related disorders & 11 & $\begin{array}{l}\text { ** CBD: flexible doses, } \\
\text { starting from } 25 \text { to } 49 \\
\text { mg/d for } 8 \text { weeks }\end{array}$ & p.o. & $\frac{\downarrow \text { stress-related disorders }}{\underline{\downarrow \text { nightmares) }} \text { (including }}$ & $\begin{array}{l}\text { well tolerated, no patients } \\
\text { discontinued treatment } \\
\text { due to side effects; mild } \\
\text { side effects: fatigue, } \\
\text { reduced concentration; } \\
\text { gastrointestinal } \\
\text { bloating or pain }\end{array}$ & [138] \\
\hline & $\begin{array}{l}\text { psychiatric patients with } \\
\text { anxiety or poor sleep }\end{array}$ & 103 & $\begin{array}{l}\text { CBD: } 25 \mathrm{mg} / \mathrm{d} \text { to } \\
50-75 \mathrm{mg} / \mathrm{d} ; \\
\text { for } 1-3 \text { months }\end{array}$ & p.o. & $\frac{\downarrow \text { anxiety in a sustained manner, }}{\downarrow \text { sleep disturbances }}$ & $\begin{array}{c}\text { well tolerated, fatigue } \\
\text { (may be related to dosing), } \\
\text { mild sedation, } \\
\text { dry eyes }\end{array}$ & [139] \\
\hline & \multirow{2}{*}{$\begin{array}{l}\text { patients at high risk for } \\
\text { psychosis }\end{array}$} & 32 & $\begin{array}{l}{ }^{*} \text { CBD: } 600 \mathrm{mg} / \text { day } \\
\text { for } 1 \text { week }\end{array}$ & p.o. & $\frac{\text { cortisol reaction: tended to be better; }}{\frac{\text { anxiety: tended to be better; }}{\downarrow \text { negative self-statement }}}$ & & [140] \\
\hline & & 33 & $\begin{array}{l}\text { * CBD } 600 \mathrm{mg} \\
\text { acute }\end{array}$ & p.o. & 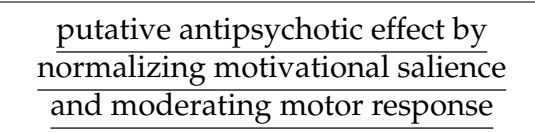 & & [141] \\
\hline & cannabis use disorder & 128 & $\begin{array}{c}\text { * THC:CBD 2.7:2.5 } \\
\mathrm{mg} / \text { spray for } 6 \text { days, up to } \\
32 \text { sprays } / \mathrm{d}\end{array}$ & $\begin{array}{l}\text { oromucosal } \\
\text { spray }\end{array}$ & $\frac{\downarrow \frac{\downarrow \text { anxiety, }}{\text { depression, }}}{\downarrow \text { craving }}$ & $\begin{array}{l}\text { no differences in adverse } \\
\text { effects between THC:CBD } \\
\text { and placebo group }\end{array}$ & [142] \\
\hline
\end{tabular}


Table 2. Cont.

\begin{tabular}{|c|c|c|c|c|c|c|c|}
\hline & Disease & $n$ & $\begin{array}{l}\text { * Study Design; } \\
\text { Dose of CBD } \\
\text { and THC }\end{array}$ & Application & $\begin{array}{l}\text { Final Results and/or Conclusions, } \\
\text { Properties Important for COVID-19 } \\
\end{array}$ & Profile Safety/Side Effects & References \\
\hline \multirow{6}{*}{ 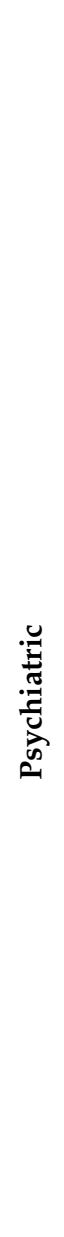 } & regular cannabis users & 20 & $\begin{array}{l}\text { ** CBD:200 mg } \\
\text { for } 10 \text { weeks }\end{array}$ & p.o. & $\begin{array}{c}\frac{\downarrow \text { depressive symptoms, }}{\downarrow \text { psychotic symptoms, }} \\
\frac{\uparrow \text { attentional switching, }}{\uparrow \text { verbal learning, } \uparrow \text { memory }} \\
\end{array}$ & & [143] \\
\hline & $\begin{array}{l}\text { drug-abstinent patients } \\
\text { with history } \\
\text { of heroin abuse }\end{array}$ & 42 & $\begin{array}{l}\text { *CBD } 400 \text { or } 800 \mathrm{mg} / \mathrm{d} \\
\text { for } 3 \text { days }\end{array}$ & p.o. & $\frac{\frac{\downarrow \text { anxiety, }}{\downarrow \text { craving, }}}{\frac{\downarrow \text { HR, }}{\downarrow \text { salivary cortisol levels }}}$ & $\begin{array}{l}\text { no serious adverse events; } \\
\text { mild side effects: } \\
\text { diarrhea, headache, } \\
\text { tiredness, fatigue }\end{array}$ & [144] \\
\hline & $\begin{array}{l}\text { volunteers pre-selected for } \\
\text { high paranoid traits }\end{array}$ & 32 & $\begin{array}{l}\text { * CBD:600 mg } \\
\text { acute }\end{array}$ & p.o. & $\frac{\text { no benefits on anxiety }}{\text { or persecutory ideation }}$ & & [145] \\
\hline & schizophrenia & 42 & $\begin{array}{l}\text { *** CBD; week 1: gradual } \\
\text { increase to } 800 \mathrm{mg} / \text { day; } \\
\text { weeks } 2-4: 800 \mathrm{mg} / \text { day }\end{array}$ & p.o. & $\begin{array}{l}\downarrow \text { positive psychotic symptoms (no } \\
\text { difference compared to amisulpride), } \\
\text { mitigation of psychotic symptoms }\end{array}$ & $\begin{array}{c}\text { marked tolerability / } \\
\text { safety (with respect to } \\
\text { weight, prolactin, hepatic } \\
\text { or cardiac functions) } \\
\text { compared with current } \\
\text { medications }\end{array}$ & [146] \\
\hline & \multirow[t]{2}{*}{ schizophrenia } & 88 & $\begin{array}{l}{ }^{*} \mathrm{CBD}: 1000 \mathrm{mg} / \mathrm{d} \text { for } \\
6 \text { weeks on top of } \\
\text { antipsychotic medication }\end{array}$ & p.o. & $\frac{\downarrow \text { impressions and severity of illness, }}{\frac{\downarrow \text { positive psychotic symptoms, }}{\text { cognitive performance and overall }}}$ & $\begin{array}{c}\text { good tolerance; } \\
\text { diarrhea, nausea, } \\
\text { headache, infections, } \\
\text { insomnia; mild } \downarrow \text { blood } \\
\text { pressure and moderate } \\
\text { chest pain; no significant } \\
\text { changes in prolactin, } \\
\text { weight, liver function, } \\
\text { inflammatory markers or } \\
\text { HDL cholesterol levels }\end{array}$ & [147] \\
\hline & & 36 & $\begin{array}{l}{ }^{*} \text { CBD: } 600 \mathrm{mg} / \text { day } \\
\text { for } 6 \text { weeks }\end{array}$ & p.o. & $\begin{array}{l}\text { no improvement of cognitive } \\
\text { impairments and } \\
\text { psychotic symptoms in stable } \\
\text { antipsychotic-treated outpatients }\end{array}$ & $\begin{array}{l}\text { well tolerated with no } \\
\text { worsening of mood, } \\
\text { suicidality or movement } \\
\text { side effects; sedation }\end{array}$ & [148] \\
\hline
\end{tabular}


Table 2. Cont.

\begin{tabular}{|c|c|c|c|c|c|c|c|}
\hline & Disease & $n$ & $\begin{array}{l}* \text { Study Design; } \\
\text { Dose of CBD } \\
\text { and THC }\end{array}$ & Application & $\begin{array}{l}\text { Final Results and/or Conclusions, } \\
\text { Properties Important for COVID-19 } \\
\end{array}$ & Profile Safety/Side Effects & References \\
\hline \multirow{6}{*}{ ฮี } & chronic pain & 94 & $\begin{array}{l}\text { CBD-rich hemp extract }{ }^{1} \\
\text { for } 8 \text { weeks }\end{array}$ & soft gels & $\begin{array}{c}\downarrow \text { chronic pain and } \uparrow \text { life quality } \\
\overline{(\downarrow \text { opioid use, } \uparrow \text { sleep quality) }}\end{array}$ & & [149] \\
\hline & $\begin{array}{l}\text { chronic pain in kidney } \\
\text { transplant patients }\end{array}$ & 7 & $\begin{array}{l}\text { CBD increasing from } 50 \text { to } \\
150 \mathrm{mg} \text { twice a day } \\
\text { for } 3 \text { weeks }\end{array}$ & p.o. & $\begin{array}{l}2 \text { patients, total improvement of pain } \\
4 \text { patients, }\end{array}$ & $\begin{array}{c}\text { no serious adverse effects; } \\
\text { dizziness, nausea, dry } \\
\text { mouth, drowsiness, } \\
\text { intermittent } \\
\text { episodes of heat }\end{array}$ & [150] \\
\hline & $\begin{array}{l}\text { chronic pain in patients } \\
\text { with fibromyalgia }\end{array}$ & 20 & $\begin{array}{c}* \mathrm{THC}: \mathrm{CBD}(\mathrm{mg}) \\
\text { 1. } 22.4:<1 \\
\text { 2. } 13.4: 17.8 \\
\text { 3. }<1: 18.4\end{array}$ & $\begin{array}{l}\text { single vapor } \\
\text { inhalation }\end{array}$ & small analgesic responses & $\begin{array}{l}\text { limited, such as dizziness } \\
\text { and nausea }\end{array}$ & [151] \\
\hline & $\begin{array}{l}\text { neuropathic pain in } \\
\text { patients with MS }\end{array}$ & 20 & $\begin{array}{c}\text { THC:CBD } \\
2.7: 2.5 \mathrm{mg} / \text { spray for } \\
4 \text { weeks, } 8 \text { sprays } / \mathrm{d}\end{array}$ & sublin. spray & $\frac{\downarrow \text { pain rating, }}{\uparrow \text { life quality }}$ & $\begin{array}{l}\text { few side effects: dizziness, } \\
\text { nausea, dry mouth and } \\
\text { weakness }\end{array}$ & [152] \\
\hline & $\begin{array}{l}\text { painful diabetic } \\
\text { neuropathy }\end{array}$ & 30 & $\begin{array}{l}\text { * THC:CBD 2.7:2.5 } \\
\text { mg/spray; dose was } \\
\text { titrated over } 2 \text { weeks, } \\
\text { followed by a 10-week } \\
\text { maintenance phase } \\
\text { (4 sprays/d) }\end{array}$ & sublin. spray & $\begin{array}{l}\text { no significant improvements in pain } \\
\text { rating and life quality }\end{array}$ & & [154] \\
\hline & $\begin{array}{l}\text { advanced cancer patients } \\
\text { with chronic pain }\end{array}$ & 199 & $\begin{array}{c}\text { * THC:CBD 2.7:2.5 } \\
\text { mg/spray: initially } 4 \text { up to } \\
7 \text { sprays } / \mathrm{d}\end{array}$ & oromucosal spray & $\begin{array}{l}\text { average pain score not superior to } \\
\text { placebo }\end{array}$ & & [155] \\
\hline
\end{tabular}


Table 2. Cont.

\begin{tabular}{|c|c|c|c|c|c|c|c|}
\hline & Disease & $n$ & $\begin{array}{l}\text { * Study Design; } \\
\text { Dose of CBD } \\
\text { and THC }\end{array}$ & Application & $\begin{array}{l}\text { Final Results and/or Conclusions, } \\
\text { Properties Important for COVID-19 } \\
\end{array}$ & Profile Safety/Side Effects & References \\
\hline \multirow{5}{*}{ 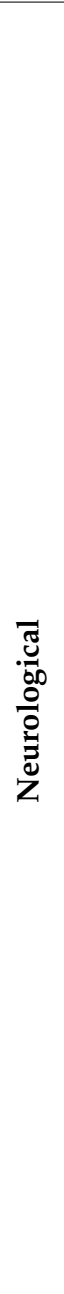 } & \multirow[t]{2}{*}{$\begin{array}{l}\text { Dravet } \\
\text { syndrome } \\
\text { in children }\end{array}$} & 198 & $\begin{array}{l}{ }^{*} \mathrm{CBD}: 10 \text { and } 20 \mathrm{mg} / \mathrm{kg} / \mathrm{d} \\
\quad \text { for } 14 \text { weeks }\end{array}$ & p.o. & $\frac{\text { improvement of patients' condition; }}{\text { similar effectiveness of both doses }}$ & $\begin{array}{l}\text { \appetite, diarrhea, } \\
\text { somnolence, pyrexia, } \\
\text { and fatigue, } \\
\uparrow \text { aminotransferases in } \\
\text { patients also taking } \\
\text { valproate sodium; at } \\
10 \mathrm{mg} / \mathrm{kg} / \mathrm{d} \text { better } \\
\text { tolerance and safety profile }\end{array}$ & [156] \\
\hline & & 108 & $\begin{array}{l}{ }^{*} \text { CBD: } 20 \mathrm{mg} / \mathrm{kg} / \mathrm{d} \\
\text { for } 14 \text { weeks }\end{array}$ & p.o. & $\downarrow$ frequency of drug-resistant seizures & $\begin{array}{c}\text { somnolence, } \downarrow \text { appetite, } \\
\text { diarrhea, } \\
\text { †aminotransferases in } \\
\text { patients also } \\
\text { taking valproate }\end{array}$ & [157] \\
\hline & \multirow{2}{*}{$\begin{array}{l}\text { Lennox-Gastaut syndrome } \\
\text { in children and adults }\end{array}$} & 225 & $\begin{array}{l}{ }^{*} \mathrm{CBD}: 10 \text { or } 20 \mathrm{mg} / \mathrm{kg} / \mathrm{d} \\
\quad \text { for } 28 \text { days }\end{array}$ & p.o. & $\begin{array}{l}\downarrow \text { epileptic seizures in some patients, } \\
\quad \downarrow \text { total seizure frequency, } \\
\text { improvement of patients' condition }\end{array}$ & $\begin{array}{c}\text { somnolence, } \downarrow \text { appetite, } \\
\text { diarrhea (at } 20 \mathrm{mg} / \mathrm{kg} / \mathrm{d}), \\
\text { threefold } \\
\uparrow \text { aminotransferases }\end{array}$ & [158] \\
\hline & & 171 & $\begin{array}{l}{ }^{*} \mathrm{CBD}: 20 \mathrm{mg} / \mathrm{kg} / \mathrm{d} \\
\text { for } 14 \text { weeks }\end{array}$ & p.o. & $\downarrow$ frequency of drug-resistant seizures & $\begin{array}{l}\text { in general good tolerance } \\
\text { of CBD as add-on therapy; } \\
\text { mild or moderate side } \\
\text { effects: } \downarrow \text { appetite, } \\
\text { vomiting, diarrhea, } \\
\text { somnolence, fever }\end{array}$ & [159] \\
\hline & $\begin{array}{l}\text { multiple } \\
\text { sclerosis }\end{array}$ & 160 & $\begin{array}{c}* \text { THC:CBD } \\
\text { 2.7:2.5 mg/spray up to a } \\
\text { maximum of } 120 \mathrm{mg} \text { THC } \\
\text { and } 120 \mathrm{mg} \text { CBD/day with } \\
\text { no more than } 20 \mathrm{mg} \text { of } \\
\text { each in any } 3-\mathrm{h} \text { period for } \\
6 \text { weeks }\end{array}$ & $\begin{array}{l}\text { oromucosal } \\
\text { spray }\end{array}$ & $\downarrow$ spasticity associated with MS & $\begin{array}{l}\text { good tolerance, no effects } \\
\text { on cognition or mood; } \\
\text { dizziness, disturbance in } \\
\text { attention, headache, } \\
\text { fatigue, somnolence, } \\
\text { disorientation, feeling } \\
\text { drunk, vertigo, application } \\
\text { site discomfort, nausea, } \\
\text { diarrhea, mouth ulceration }\end{array}$ & [160] \\
\hline
\end{tabular}


Table 2. Cont.

\begin{tabular}{|c|c|c|c|c|c|c|c|}
\hline & Disease & $n$ & $\begin{array}{l}\text { * Study Design; } \\
\text { Dose of CBD } \\
\text { and THC }\end{array}$ & Application & $\begin{array}{l}\text { Final Results and/or Conclusions, } \\
\text { Properties Important for COVID-19 }\end{array}$ & Profile Safety/Side Effects & References \\
\hline \multirow{3}{*}{$\begin{array}{l}\frac{3}{00} \\
\frac{0}{0} \\
\frac{\pi}{0} \\
z\end{array}$} & \multirow{3}{*}{$\begin{array}{l}\text { multiple } \\
\text { sclerosis }\end{array}$} & 137 & $\begin{array}{c}\text { THC:CBD 2.7:2.5 } \\
\text { mg/spray up to } 48 \\
\text { sprays/day for } 21-814 \\
\text { days (extension study of } \\
\text { Wade et al. [160]) }\end{array}$ & $\begin{array}{l}\text { oromucosal } \\
\text { spray }\end{array}$ & $\begin{array}{c}\frac{\downarrow \text { spasticity associated with MS, }}{\text { clinical effect maintained after a long }} \\
\text { treatment period }\end{array}$ & $\begin{array}{l}\text { serious adverse effects: } \\
\text { seizures, fall, aspiration } \\
\text { pneumonia, gastroenteritis; } \\
\text { mild adverse effects: sore } \\
\text { mouth, oromucosal } \\
\text { disorder, oral pain, altered } \\
\text { attention, dizziness, } \\
\text { diarrhea, nausea }\end{array}$ & [161] \\
\hline & & 12 & $\begin{array}{c}\text { THC:CBD 5.4:5.0 mg (two } \\
\text { sublin. sprays at a } \\
\text { 15-min interval) }\end{array}$ & $\begin{array}{l}\text { oromucosal } \\
\text { spray }\end{array}$ & postural and $\frac{\downarrow \text { spasticity }}{\text { motor tests unchanged }}$ & $\begin{array}{c}\text { no differences in adverse } \\
\text { events between THC:CBD } \\
\text { and placebo groups }\end{array}$ & [162] \\
\hline & & 460 & $\begin{array}{c}* \mathrm{THC}: \mathrm{CBD} \\
\text { 2.7:2.5 } \mathrm{mg} / \text { spray; } \\
\text { maximally } 12 \text { sprays/day } \\
\text { for } 12 \text { weeks }\end{array}$ & $\begin{array}{l}\text { oromucosal } \\
\text { spray }\end{array}$ & $\begin{array}{l}\frac{\downarrow \text { spasticity (resistant to previous }}{\text { antispasticity treatment) and }} \\
\text { associated symptoms in patients with } \\
\text { moderate to severe MS }\end{array}$ & & [163] \\
\hline
\end{tabular}

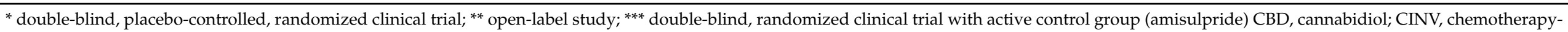

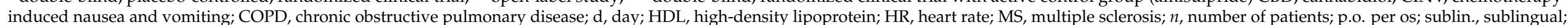

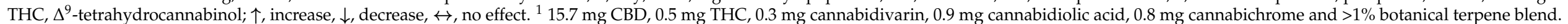


With respect to the gastrointestinal complications related to COVID-19 (see Figure 2), the effect found for Sativex ${ }^{\circledR}$ (combination of $2.7 \mathrm{mg}$ THC and $2.5 \mathrm{mg}$ CBD), given on top of the standard antiemetic therapy against delayed chemotherapy-induced nausea and vomiting, is remarkable but is based on 7 patients only [128]. CBD given orally with THC did not increase appetite or raise the quality of life in patients with cancer-related anorexia-cachexia syndrome [129]. Regarding inflammatory-related disorders, a single dose of CBD reduced aspirin-induced increased gut permeability [130], suggesting its effectiveness in disorders such as inflammatory bowel disease. On the other hand, CBD given chronically, alone or with THC, did not lead to any clinical improvement in patients with moderately active Crohn's disease [131] or ulcerative colitis [132] (Table 2).

Although the effect of CBD on organ function has been considered only in a few clinical trials (as opposed to preclinical studies), its suitability for the treatment of some psychiatric disorders including post-traumatic stress, generalized anxiety, panic disorder and social anxiety, which may also occur in the context of COVID-19, is suggested by numerous clinical studies (for review, see [108]) (Figure 2, Table 2). CBD (given acutely or chronically) has been shown to reduce subjective anxiety and/or other reactions induced by stress (e.g., a simulated public speaking test) in healthy volunteers [133-135], people with naïve social anxiety disorder [136,137], patients with post-traumatic stress disorders [138], some psychiatric patients [139], persons at high risk for psychosis $[140,141]$ and present cannabis [142,143] and past heroin users [144]. Only in a study on volunteers preselected for high paranoid traits [145] did CBD fail to attenuate anxiety. The possibility that CBD may be an effective treatment for schizophrenia has also been considered. CBD was shown to reduce positive psychotic symptoms of schizophrenia in studies by Leweke et al. [146] and McGuire et al. [147] but not in the trial by Boggs et al. [148] (Table 2).

COVID-19 is associated with painful symptoms, including myalgia, headache and abdominal or chest pain (Figure 2). Antinociceptive activity of CBD has been found in patients suffering from chronic pain [149], including pain in kidney transplant recipients [150] and in individuals with fibromyalgia [151], multiple sclerosis [152], diabetes and allodynia $[153,154]$ but not in patients with advanced cancer [155]. In the latter studies, CBD was mainly administered in combination with THC as an oromucosal or sublingual spray (Table 2).

SARS-CoV-2 patients may develop encephalopathic symptoms ranging from alteration in consciousness to delirium, seizures and muscular damage (Figure 2). On the other hand, individuals with epilepsy and multiple sclerosis develop changes that not only increase their risk of morbidity from COVID-19 but may also mask the presentation of acute respiratory symptoms which can potentially delay the diagnosis of COVID-19. Published trials (Table 2) refer to the treatment of Dravet syndrome in children [156,157] and LennoxGastaut syndrome in children and adults [158,159]. Cannabidiol was administered at a dose of 10 or $20 \mathrm{mg} / \mathrm{kg} /$ day for 14 weeks and was found to reduce seizure frequency. Sativex ${ }^{\circledR}$ was used as an oromucosal spray in patients with multiple sclerosis and was found to reduce spasticity [160-163]. As described above, Epidiolex ${ }^{\circledR}$ (which contains a $100 \mathrm{mg} / \mathrm{mL}$ solution of CBD for oral administration) and Sativex ${ }^{\circledR}$ have been approved for the treatment of intractable childhood-onset epilepsy (Dravet and Lennox-Gastaut syndromes) and as a therapy for spasticity in multiple sclerosis, respectively.

In one study [164], chronic use of CBD-enriched ointment improved skin parameters in inflammatory skin diseases (Table 2). However, Epidiolex ${ }^{\circledR}$ induced a delayed skin rash in one patient with medically refractory epilepsy [165].

Importantly, as shown in Table 2, CBD, given alone or together with THC, is generally well tolerated, usually with no severe adverse events or clinical worsening. The most common side effects are nausea and vomiting, loss of appetite, diarrhea, fever and an increased concentration of aminotransferases. Even orally administered spray can produce mild to moderate unwanted effects including dizziness, nausea, diarrhea, oral pain and oromucosal disorder. Unfortunately, these side effects, to some extent, resemble the symptoms of COVID-19. 
In summary, considering the effects of COVID-19 on multiple organs (Figure 2), a CBD-based pharmacotherapy that has been approved by the health authorities is limited to the treatment of some rare types of seizures and the spasticity associated with multiple sclerosis. In addition to these neuroprotective properties, anxiolytic and antinociceptive effects of CBD have been shown in clinical trials. Thus, CBD, given alone or together with THC, may be important as an adjuvant treatment to improve the well-being and quality of life of patients with COVID-19 and may even be used after recovery to limit post-traumatic stress symptoms. Further clinical studies are necessary to clarify beneficial observations obtained in small groups of patients or in cases where conflicting results have been found. Unfortunately, clinical studies (Table 2) have often failed to confirm the promising observations found in preclinical experiments (Table 1).

\section{Opportunities, Challenges and Pitfalls of Cannabidiol Use as a COVID-19 Therapy}

Cannabidiol is an interesting medicine with various pharmacological properties. Our main question is whether it is justified to recommend CBD as a therapy for COVID-19. Unfortunately, despite the identification in preclinical studies of some beneficial properties that are important for COVID-19 treatment, there are still numerous questions that need to be addressed. Preclinical and clinical effects (including their sites of action), the quality of CBD preparations, the route of administration, dosing, side effects and drug interactions are discussed in detail below.

First, the potential effects of CBD against COVID-19 may comprise the following four mechanisms.

a. Numerous preclinical findings (Table 1) and reviews regarding the potential use of CBD in COVID-19 treatment $[14,15,56-60]$ suggest that CBD has beneficial antiinflammatory and antioxidative effects, which can be expected to improve the systemic symptoms that are characteristic of SARS-CoV-2 infection. Unfortunately, a comparison of the results of preclinical (Table 1) and clinical (Table 2) studies demonstrates that the favorable preclinical properties may not translate into the clinical setting (or that the appropriate clinical studies have not been conducted; see also reviews $[58,61,62])$. Above all, there is no confirmation of such beneficial effects of CBD with regard to its effects on respiratory failure. In addition, careful examination of whether the influence of CBD on the immune system could exacerbate viral infection is required (reviews [64,65]). Indeed, viral, fungal infections and pneumonia infections are listed among the side effects of CBD [166-169]. Moreover, it has to be considered that CBD, which was found to have a pro-oxidative effect in one preclinical study ([83]; Table 1), might even aggravate the feared cytokine storm.

b. Anxiolytic and antinociceptive properties of CBD, given alone or together with THC, which have been identified in clinical studies (Table 2), suggest that it may be used as an adjuvant treatment to improve the quality of life of patients with COVID19 and, even after recovery, may limit post-traumatic stress symptoms. However, well-designed double-blind, placebo-controlled clinical trials regarding the efficacy of CBD against COVID-19-associated panic, anxiety, depression and neurological complications are so far missing [63].

c. The decreases in ACE2 and TMPRSS2 protein expression in a human tissue model are extremely interesting but so far this effect has only been shown in an in vitro study by Wang et al. [67]. Even if this mechanism was also found to occur in vivo, certain issues would have to be considered, for example, the mechanism was found for some CBD-rich extracts but did not occur when pure CBD was used. The consequence would be that an extract would need to be administered instead of a pure substance and oral administration would not be possible (for problems associated with topical administration, see below). Next, the question arises about the extent to which ACE2 and TMPRSS2 have to be decreased in order to obtain a robust antiviral effect. Moreover, it is unclear whether a reduction in ACE2 (the importance of which 
is highlighted in Figure 1) will lead to problems other than the struggle against the virus.

d. Inhibition of the replication of SARS-CoV-2 by CBD in a cell line also represents an interesting mechanism, although this effect has only been shown in a study by Raj et al. [68] and transfer to the in vivo situation of the human body is unclear.

Second, a wide range of over-the-counter CBD-based products is now available, for example, capsules, sprays, oil droppers, gummies and plant materials to be used by smoking, dry vaporizers and e-liquid vaporizers [54]. Unfortunately, these products may be of questionable quality, are not subject to appropriate safety controls and are characterized by unknown CBD content. There is little evidence of the pharmacological activity or health benefits of non-commercial CBD preparations [54,167]. Importantly, people taking non-commercial preparations on their own should be very careful due to the possibility of dangerous consequences, such as respiratory depression following, for example, CBD gummy ingestion [170] or CBD oil overdose [171]. One should also consider that the impact of "over-the-counter" CBD on the immunity of the SARS-CoV-2 infection is unclear [62]. The use of CBD as a medication in products like Epidiolex ${ }^{\circledR}$ and Sativex ${ }^{\circledR}$ (see Section 3) is approved, that is, these products fulfil the essential criteria related to efficacy, safety and pharmaceutical quality.

Third, one of the most severe COVID-19 symptoms is connected with disorders of the respiratory system (i.e. ARDS). Therefore, inhalation might be a particularly appropriate route of CBD administration. The relatively high bioavailability level of $\sim 30 \%$ (whereas oral administration leads to a value of $6 \%$ only [172]) is another argument in favor of this route of administration. However, the vaping of cannabis products (including CBD) may lead to acute pulmonary toxicity $[57,173]$, casting some doubt on the suitability of this method of administration; it is unclear as to whether similar problems would occur if pure CBD was used instead. Since Epidiolex ${ }^{\circledR}$ has been administered effectively as an oromucosal spray (Table 2), the use of a mouthwash with CBD-rich extracts might represent an interesting strategy to lower ACE2 topically [67]. It is of interest that the bioavailability of oromucosal administration of CBD is not higher than that of its oral application [172].

Fourth, with respect to dosing, most data refer to neurological disorders and this is in line with the approved indications (reviewed by Britch et al. [54]; Millar et al. [174]). Unfortunately, clinical trials dedicated to the use of CBD to treat inflammation are virtually nonexistent and clinically meaningful conclusions can therefore not be drawn [54]. A special note is necessary for Sativex ${ }^{\circledR}$ ( $2.7 \mathrm{mg}$ THC plus $2.5 \mathrm{mg}$ CBD per spray). If one uses 48 sprays per day (the maximum dose used in the study of Wade et al. [160] for the treatment of multiple sclerosis), the dose of CBD will be $120 \mathrm{mg}$, corresponding to $\sim 1.7 \mathrm{mg} / \mathrm{kg}$. This value is much lower than that planned for use in the three CBD trials listed on ClinicalTrials.gov (2.5-7.5 mg/ $\mathrm{kg}$; see Section 6) or that recommended for use to treat seizures in children $(10-20 \mathrm{mg} / \mathrm{kg})$. CBD may increase the positive effects of THC and simultaneously attenuate the negative ones. A closer look, however, shows that both assumptions frequently do not hold true [175-179].

Fifth, CBD is generally and also according to the Critical Review Report 2018 of the World Health Organization [180], regarded as a safe compound (for review, see [54,181]). However, the authors of the latter two reviews postulated the need to conduct additional clinical trials. Indeed, various side effects of CBD have recently been described [166-169]. In addition to the increased risk of infection mentioned above, the increased tendency for respiratory depression and aspiration to occur, that is, symptoms also occurring in COVID-19, should be considered.

Sixth, CBD interacts with drug-metabolizing enzymes both of phase I (CYP3A4, CYP2C9 and CYP2C19) and phase II (uridine-5'-diphosphoglucurosonyltransferase) [181-183]. If $\mathrm{CBD}$ is used as an anticonvulsant, its combination with other anticonvulsants like clobazam or valproate might increase the risk of side effects $[182,184]$, for example, thrombocytopenia was identified in one-third of 87 pediatric patients treated concurrently with cannabidiol and valproate [184]. Before CBD is used for the treatment of COVID-19, its pos- 
sible interaction with the frontline therapy against COVID-19 should be carefully checked. The combination of CBD and glucocorticoids might lead to an increased plasma concentration of dexamethasone, since some glucocorticoids are substrates for CYP3A4 [185]. Due to the high therapeutic index of acutely administered glucocorticoids, this drug interaction may be tolerated. The situation is, however, entirely different for the antithrombin warfarin, the plasma level of which is also increased by CBD $[183,186]$. In this case, the interaction may lead to life-threatening bleeding.

\section{Conclusions}

COVID-19 is associated with multiple organ dysfunction/failure and a high mortality rate. The COVID-19 pandemic has made everyday life difficult and vaccination against SARS-CoV-2 has only just begun (and its final success is still unknown). New mutations of SARS-CoV-2 are appearing [187], so new promising therapies against COVID-19 are constantly being suggested. These include natural products, for example, CBD, a nonintoxicating phytocannabinoid from the cannabis plant with valuable pharmacological properties including strong anti-inflammatory, antioxidant, antiemetic, anticonvulsant, antipsychotic and anxiolytic properties. The broad pharmacological effectiveness and potential sites of action of CBD are shown in Figure 3. Besides its well-known antioxidant properties, downregulation of ACE2 and TMPRSS2 proteins (which are responsible for the entry of the SARS-CoV-2 virus into host cells) [67] and inhibition of SARS-CoV-2 replication [68] have only been shown very recently. Results require confirmation by independent groups and have to be demonstrated in humans in vivo. Numerous preclinical studies have shown the effectiveness of CBD in treating diseases of the respiratory system (including ARDS, one of the most dangerous symptoms of COVID-19) and its cardioprotective, nephroprotective, hepatoprotective, neuroprotective and anticonvulsant properties, that is, properties that could be beneficial for the treatment of COVID-19 (Section 5, Table 1). The beneficial influence of CBD results mainly from its significant anti-inflammatory and antioxidant properties. The anti-inflammatory properties of CBD are also responsible for a reduction in the short- and long-term consequences of viral infection, as suggested by a few in vitro and in vivo experiments (Section 4).

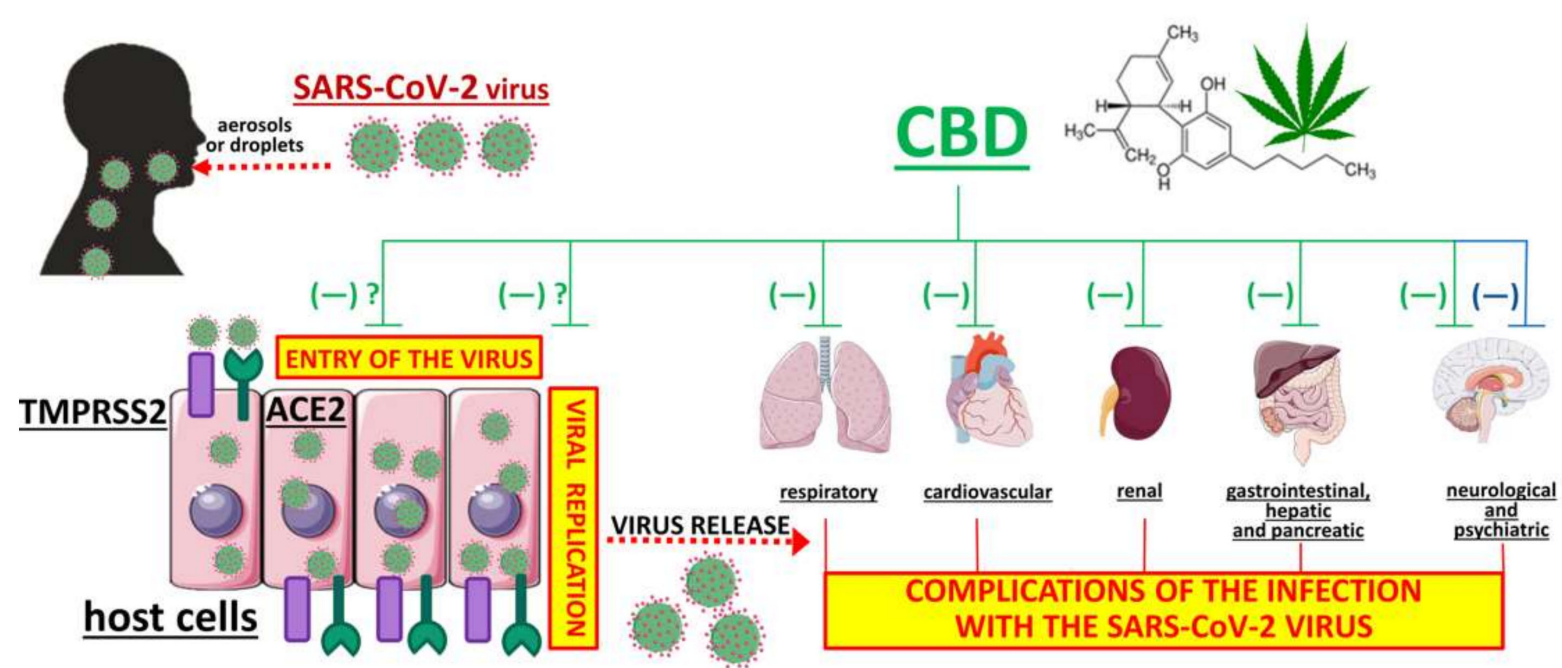

Figure 3. Potential therapeutic effect of cannabidiol against the SARS-CoV-2 virus infection. Three mechanisms have to be considered. The first and second mechanisms are the inhibitory effects on virus entry [67] and replication [68], respectively. These mechanisms have been described only recently and it is unclear whether they also occur in the human body. The third mechanism is a beneficial effect against complications which may also occur under a SARS-CoV-2 virus infection. In animal studies such a beneficial effect has been shown in five organ systems (green lines; Table 1) whereas in humans an effect on neurological and psychiatric disorders has been shown only (blue line; Table 2). ACE2, angiotensin-converting enzyme 2; CBD, cannabidiol; TMPRSS2, transmembrane serine protease 2. 
Unfortunately, so far, clinical studies have not confirmed the beneficial anti-inflammatory properties of CBD but it is suggested that the anxiolytic and antinociceptive properties of CBD (given alone or together with THC) may be important regarding its use as an adjuvant treatment to improve the quality of life of patients with COVID-19 and, after recovery, to limit post-traumatic stress symptoms (Section 6, Table 2). When using CBD, one should be aware of its side effects (which are rarely serious), its frequent drug interactions (which also extend to drugs used for COVID-19 treatment) and the most appropriate administration route (vaping may be effective but sometimes also dangerous). Clearly, further clinical studies are necessary to confirm the beneficial observations made for small numbers of patients, to clarify conflicting results and to broaden our understanding of the true therapeutic potential of CBD against COVID-19.

Supplementary Materials: The following are available online at https://www.mdpi.com/1422-006 7/22/4/1986/s1 [188-279].

Author Contributions: Conceptualization: B.M., E.S.; data acquisition: B.M., M.B.-K., A.K., E.S.; writing—original draft preparation: B.M., M.B.-K., A.K., E.S.; writing—review and editing: B.M., M.B.-K., E.S. All authors have read and agreed to the published version of the manuscript.

Funding: This research was funded by the Medical University of Białystok (Poland) grants number N/ST/ZB/16/003/2213, N/ST/ZB/17/001/2213 and N/ST/ZB/17/002/2213.

Institutional Review Board Statement: Not applicable.

Informed Consent Statement: Not applicable.

Data Availability Statement: No new data were created or analyzed in this study. Data sharing is not applicable to this article.

Conflicts of Interest: The authors declare no conflict of interest.

\begin{tabular}{|c|c|}
\hline $5-\mathrm{HT}_{1 \mathrm{~A}}-\mathrm{R}$ & serotonin receptor type $1 \mathrm{~A}$ \\
\hline$A_{1 A}-R$ & adenosine receptor type $A_{1 A}$ \\
\hline$A_{2 A}-R$ & adenosine receptor type $A_{2 A}$ \\
\hline ACE2 & angiotensin-converting enzyme 2 \\
\hline ACE-I & angiotensin-converting-enzyme inhibitors \\
\hline AGEs & advanced glycation endproducts \\
\hline ALI & acute lung injury \\
\hline ALT & alanine transaminase \\
\hline Ang II & angiotensin II \\
\hline Ang 1-7 & angiotensin $1-7$ \\
\hline AST & aspartate transaminase \\
\hline ARDS & acute respiratory distress syndrome \\
\hline BALF & bronchoalveolar lavage fluid \\
\hline CB-R & cannabinoid receptor \\
\hline $\mathrm{CB}_{1}-\mathrm{R}$ & cannabinoid $\mathrm{CB}_{1}$ receptor \\
\hline $\mathrm{CB}_{2}-\mathrm{R}$ & cannabinoid $\mathrm{CB}_{2}$ receptor \\
\hline CBD & cannabidiol \\
\hline $\mathrm{CBF}$ & cerebral blood flow \\
\hline CCL2, CCL5 & C-C motif chemokine ligand 2 and 5 \\
\hline CINV & chemotherapy-induced nausea and vomiting \\
\hline COPD & chronic obstructive pulmonary disease \\
\hline COVID-19 & coronavirus disease 2019 \\
\hline COX-2 & cyclooxygenase 2 \\
\hline CRP & C-reactive protein \\
\hline CVD & cardiovascular disease \\
\hline
\end{tabular}




\begin{tabular}{|c|c|}
\hline d & $\operatorname{day}(\mathrm{s})$ \\
\hline DOCA & deoxycorticosterone acetate \\
\hline DPCPX & 8-cyclopentyl-1,3-dipropylxanthine \\
\hline EEG & electroencephalography \\
\hline $\mathrm{EP}_{4}$ & prostanoid $\mathrm{EP}_{4}$ receptor \\
\hline FAAH & fatty acid amide hydrolase \\
\hline GCSF & granulocyte colony stimulating factor \\
\hline HDL & high density lipoprotein \\
\hline HR & heart rate \\
\hline i.a. & intra-arterially \\
\hline IFN- $\gamma$ & interferon $\gamma$ \\
\hline IL- $n$ & interleukin $n$,e.g., IL-1, interleukin-1 \\
\hline IL-1 $\beta$ & interleukin-1ß \\
\hline iNOS & inducible nitric oxide synthase \\
\hline IP & prostacyclin receptor \\
\hline i.p. & intraperitoneally \\
\hline i.v. & intravenously \\
\hline LAD & left anterior descending artery \\
\hline $\mathrm{LCx}$ & left circumflex coronary artery \\
\hline LDL & low-density lipoprotein \\
\hline LPS & lipopolysaccharide \\
\hline MCA & middle cerebral artery \\
\hline MCP-1 & monocyte chemoattractant protein- 1 \\
\hline MERS & middle east respiratory syndrome \\
\hline MIP-2 & macrophage inflammatory protein- 2 \\
\hline $\mathrm{MPO}$ & myeloperoxidase \\
\hline MS & multiple sclerosis \\
\hline NF- $k B$ & nuclear factor $\mathrm{kB}$ \\
\hline $\mathrm{NO}$ & nitric oxide \\
\hline NRP1 & protein neuropilin-1 \\
\hline PAI-1 & plasminogen activator inhibitor-1 \\
\hline $\mathrm{pCO}_{2}$ & partial pressure of carbon dioxide \\
\hline p.o. & per os, orally \\
\hline $\mathrm{pO}_{2}$ & partial pressure of oxygen \\
\hline poly(I:C) & polyriboinosinic:polyribocytidylic acid \\
\hline PPAR $\gamma$ & peroxisome proliferator-activated receptor type $\gamma$ \\
\hline SARS & severe acute respiratory syndrome \\
\hline SARS-CoV-2 & severe acute respiratory syndrome coronavirus 2 \\
\hline SHR & spontaneously hypertensive rats \\
\hline STZ & streptozotocin \\
\hline TGs & triglycerides \\
\hline THC & $\Delta^{9}$-tetrahydrocannabinol \\
\hline TLC & total lung capacity \\
\hline TMEV & $\begin{array}{l}\text { Theiler's murine encephalomyelitis virus-induced } \\
\text { demyelinating disease }\end{array}$ \\
\hline TMPRSS2 & transmembrane serine protease 2 \\
\hline TNF- $\alpha$ & tumor necrosis factor $\alpha$ \\
\hline $\mathrm{t}-\mathrm{PA}$ & tissue plasminogen activator \\
\hline TRP & transient receptor potential \\
\hline TRPV1 & transient receptor potential vanilloid subfamily member 1 \\
\hline UVA & ultraviolet A \\
\hline VCAM-1 & vascular cell adhesion molecule-1 \\
\hline
\end{tabular}

\section{References}

1. Baj, J.; Karakuła-Juchnowicz, H.; Teresiński, G.; Buszewicz, G.; Ciesielka, M.; Sitarz, E.; Forma, A.; Karakuła, K.; Flieger, W.; Portincasa, P.; et al. Specific and non-specific clinical manifestations and symptoms: The current state of knowledge. J. Clin. Med. 2020, 9, 1753. [CrossRef] [PubMed] 
2. Tu, Y.F.; Chien, C.S.; Yarmishyn, A.A.; Lin, Y.Y.; Luo, Y.H.; Lin, Y.T.; Lai, W.Y.; Yang, D.M.; Chou, S.J.; Yang, Y.P.; et al. A review of SARS-CoV-2 and the ongoing clinical trials. Int. J. Mol. Sci. 2020, 21, 2657. [CrossRef]

3. Peng, M. Outbreak of COVID-19: An emerging global pandemic threat. Biomed. Pharmacother. 2020, 129, 110499. [CrossRef] [PubMed]

4. List of Epidemics. Available online: https://en.wikipedia.org/wiki/List_of_epidemics (accessed on 1 February 2021).

5. Cannalire, R.; Stefanelli, I.; Cerchia, C.; Beccari, A.R.; Pelliccia, S.; Summa, V. Entry inhibitors: Small molecules and peptides targeting virus or host cells. Int. J. Mol. Sci. 2020, 21, 5707. [CrossRef]

6. World Health Organisation. Draft Landscape of COVID-19 Candidate Vaccines. Available online: https://www.who.int/ publications/m/item/draft-landscape-of-covid-19-candidate-vaccines (accessed on 1 February 2021).

7. Krammer, F. SARS-CoV-2 vaccines in development. Nature 2020, 586, 516-527. [CrossRef]

8. Weisberg, E.; Sattler, M.; Yang, P.L.; Parent, A.; Gray, N.; Griffin, J.D. Current therapies under investigation for COVID-19: Potential COVID-19 treatments. Can. J. Physiol. Pharmacol. 2020, 98, 483-489. [CrossRef]

9. Asai, A.; Konno, M.; Ozaki, M.; Otsuka, C.; Vecchione, A.; Arai, T.; Kitagawa, T.; Ofusa, K.; Yabumoto, M.; Hirotsu, T.; et al. COVID-19 drug discovery using intensive approaches. Int. J. Mol. Sci. 2020, 21, 2839. [CrossRef]

10. Beigel, J.H.; Tomashek, K.M.; Dodd, L.E.; Mehta, A.K.; Zingman, B.S.; Kalil, A.C.; Hohmann, E.; Chu, H.Y.; Luetkemeyer, A.; Kline, S.; et al. ACTT-1 study group members. Remdesivir for the treatment of Covid-19-final report. N. Engl. J. Med. 2020, 383, 1813-1826. [CrossRef]

11. Recovery Collaborative Group; Horby, P.; Lim, W.S.; Emberson, J.R.; Mafham, M.; Bell, J.L.; Linsell, L.; Staplin, N.; Brightling, C.; Ustianowski, A.; Elmahi, E.; et al. Dexamethasone in hospitalized patients with Covid-19_Preliminary report. N. Engl. J. Med. 2020. [CrossRef]

12. McKee, D.L.; Sternberg, A.; Stange, U.; Laufer, S.; Naujokat, C. Candidate drugs against SARS-CoV-2 and COVID-19. Pharmacol. Res. 2020, 157, 104859. [CrossRef]

13. He, Y.Q.; Zhou, C.C.; Yu, L.Y.; Wang, L.; Deng, J.L.; Tao, Y.L.; Zhang, F.; Chen, W.S. Natural product derived phytochemicals in managing acute lung injury by multiple mechanisms. Pharmacol. Res. 2020, 163, 105224. [CrossRef]

14. Mamber, S.W.; Krakowka, S.; Osborn, J.; Saberski, L.; Rhodes, R.G.; Dahlberg, A.E.; Pond-Tor, S.; Fitzgerald, K.; Wright, N.; Beseme, S.; et al. Can unconventional immunomodulatory agents help alleviate COVID-19 symptoms and severity? MSphere 2020, 5, e00288. [CrossRef]

15. Onaivi, E.S.; Sharma, V. Cannabis for COVID-19: Can cannabinoids quell the cytokine storm? Future Sci. 2020, 6, FSO625. [CrossRef] [PubMed]

16. Ni, W.; Yang, X.; Yang, D.; Bao, J.; Li, R.; Xiao, Y.; Hou, C.; Wang, H.; Liu, J.; Yang, D.; et al. Role of angiotensin-converting enzyme 2 (ACE2) in COVID-19. Crit. Care 2020, 24, 422. [CrossRef]

17. Kielian, M. Enhancing host cell infection by SARS-CoV-2. Science 2020, 370, 765-766. [CrossRef]

18. Penna, C.; Mercurio, V.; Tocchetti, C.G.; Pagliaro, P. Sex-related differences in COVID-19 lethality. Br. J. Pharmacol. 2020, 177, 4375-4385. [CrossRef] [PubMed]

19. Gemmati, D.; Bramanti, B.; Serino, M.L.; Secchiero, P.; Zauli, G.; Tisato, V. COVID-19 and individual genetic susceptibility/receptivity: Role of ACE1/ACE2 genes, immunity, inflammation and coagulation. Might the double X-chromosome in females be protective against SARS-CoV-2 compared to the single X-Chromosome in males? Int. J. Mol. Sci. 2020, $21,3474$. [CrossRef] [PubMed]

20. Pagliaro, P.; Penna, C. ACE/ ACE2 ratio: A key also in 2019 Coronavirus disease (Covid-19)? Front. Med. 2020, 7, 335. [CrossRef]

21. Gheblawi, M.; Wang, K.; Viveiros, A.; Nguyen, Q.; Zhong, J.C.; Turner, A.J.; Raizada, M.K.; Grant, M.B.; Oudit, G.Y. AngiotensinConverting Enzyme 2: SARS-CoV-2 receptor and regulator of the renin-angiotensin system: Celebrating the 20th anniversary of the discovery of ACE2. Circ. Res. 2020, 126, 1456-1474. [CrossRef]

22. Guzik, T.J.; Mohiddin, S.A.; Dimarco, A.; Patel, V.; Savvatis, K.; Marelli-Berg, F.M.; Madhur, M.S.; Tomaszewski, M.; Maffia, P.; D'Acquisto, F.; et al. COVID-19 and the cardiovascular system: Implications for risk assessment, diagnosis, and treatment options. Cardiovasc. Res. 2020, 16, 1666-1687. [CrossRef]

23. Coperchini, F.; Chiovato, L.; Croce, L.; Magri, F.; Rotondi, M. The cytokine storm in COVID-19: An overview of the involvement of the chemokine/chemokine-receptor system. Cytokine Growth Factor Rev. 2020, 53, 25-32. [CrossRef]

24. Arendse, L.B.; Danser, A.; Poglitsch, M.; Touyz, R.M.; Burnett, J.C.; Llorens-Cortes, C.; Ehlers, M.R.; Sturrock, E.D. Novel therapeutic approaches targeting the renin-angiotensin system and associated peptides in hypertension and heart failure. Pharmacol. Rev. 2019, 71, 539-570. [CrossRef]

25. Verdecchia, P.; Cavallini, C.; Spanevello, A.; Angeli, F. COVID-19: ACE2centric infective disease? Hypertension 2020, 76, 294-299. [CrossRef]

26. Samidurai, A.; Das, A. Cardiovascular Complications associated with COVID-19 and potential therapeutic strategies. Int. J. Mol. Sci. 2020, 21, 6790. [CrossRef]

27. Iwasaki, M.; Saito, J.; Zhao, H.; Sakamoto, A.; Hirota, K.; Ma, D. Inflammation triggered by SARS-CoV-2 and ACE2 augment drives multiple organ failure of severe COVID-19: Molecular mechanisms and implications. Inflammation 2020, $44,13-34$. [CrossRef]

28. Cremer, P.C. SARS-CoV-2 and myocardial injury: Few answers, many questions. Cleve. Clin. J. Med. 2020, 87, 521-525. [CrossRef] [PubMed] 
29. Evans, P.C.; Rainger, G.E.; Mason, J.C.; Guzik, T.J.; Osto, E.; Stamataki, Z.; Neil, D.; Hoefer, I.E.; Fragiadaki, M.; Waltenberger, J.; et al. Endothelial dysfunction in COVID-19: A position paper of the ESC Working Group for Atherosclerosis and Vascular Biology, and the ESC Council of Basic Cardiovascular Science. Cardiovasc. Res. 2020, 116, 2177-2184. [CrossRef] [PubMed]

30. Kochi, A.N.; Tagliari, A.P.; Forleo, G.B.; Fassini, G.M.; Tondo, C. Cardiac and arrhythmic complications in patients with COVID-19. J. Cardiovasc. Electrophysiol. 2020, 31, 1003-1008. [CrossRef] [PubMed]

31. Zheng, K.I.; Feng, G.; Liu, W.Y.; Targher, G.; Byrne, C.D.; Zheng, M.H. Extrapulmonary complications of COVID-19: A multisystem disease? J. Med. Virol 2020, 10. [CrossRef]

32. De Vries, A. SARS-CoV-2/COVID-19: A primer for cardiologists. Neth. Heart J. 2020, 28, 366-383. [CrossRef]

33. Zaim, S.; Chong, J.H.; Sankaranarayanan, V.; Harky, A. COVID-19 and multiorgan response. Curr. Prob. Cardiol. 2020, 45, 100618. [CrossRef]

34. Gasecka, A.; Borovac, J.A.; Guerreiro, R.A.; Giustozzi, M.; Parker, W.; Caldeira, D.; Chiva-Blanch, G. Thrombotic complications in patients with COVID-19: Pathophysiological mechanisms, diagnosis, and treatment. Cardiovasc. Drugs Ther. 2020, 1-15. [CrossRef] [PubMed]

35. Jayarangaiah, A.; Kariyanna, P.T.; Chen, X.; Jayarangaiah, A.; Kumar, A. COVID-19-associated coagulopathy: An exacerbated immunothrombosis response. Clin. Appl. Thromb. Hemost. 2020, 26, 1076029620943293. [CrossRef]

36. Vinayagam, S.; Sattu, K. SARS-CoV-2 and coagulation disorders in different organs. Life Sci. 2020, 260, 118431. [CrossRef]

37. Chueh, T.I.; Zheng, C.M.; Hou, Y.C.; Lu, K.C. Novel evidence of acute kidney injury in COVID-19. J. Clin. Med. 2020, 9, 3547. [CrossRef] [PubMed]

38. Gan, R.; Rosoman, N.P.; Henshaw, D.; Noble, E.P.; Georgius, P.; Sommerfeld, N. COVID-19 as a viral functional ACE2 deficiency disorder with ACE2 related multi-organ disease. Med. Hypotheses 2020, 144, 110024. [CrossRef]

39. Galanopoulos, M.; Gkeros, F.; Doukatas, A.; Karianakis, G.; Pontas, C.; Tsoukalas, N.; Viazis, N.; Liatsos, C.; Mantzaris, G.J. COVID19 pandemic: Pathophysiology and manifestations from the gastrointestinal tract. World J. Gastroenterol. 2020, 26, 4579-4588. [CrossRef]

40. Hunt, R.H.; East, J.E.; Lanas, A.; Malfertheiner, P.; Satsangi, J.; Scarpignato, C.; Webb, G.J. COVID-19 and gastrointestinal disease. Implications for the gastroenterologist. Dig. Dis. 2020, 1-21. [CrossRef]

41. Asadi-Pooya, A.A. Seizures associated with coronavirus infections. Seizure 2020, 79, 49-52. [CrossRef] [PubMed]

42. Pennisi, M.; Lanza, G.; Falzone, L.; Fisicaro, F.; Ferri, R.; Bella, R. SARS-CoV-2 and the nervous system: From clinical features to molecular mechanisms. Int. J. Mol. Sci. 2020, 21, 5475. [CrossRef]

43. Varatharaj, A.; Thomas, N.; Ellul, M.A.; Davies, N.W.S.; Pollak, T.A.; Tenorio, E.L.; Sultan, M.; Easton, A.; Breen, G.; Zandi, M.; et al. CoroNerve Study Group. Neurological and neuropsychiatric complications of COVID-19 in 153 patients: A UK-wide surveillance study. Lancet Psychiatry 2020, 7, 875-882. [CrossRef]

44. Luís, M.E.; Hipólito-Fernandes, D.; Mota, C.; Maleita, D.; Xavier, C.; Maio, T.; Cunha, J.P.; Tavares Ferreira, J. A review of neuro-ophthalmological manifestations of human coronavirus infection. Eye Brain 2020, 12, 129-137. [CrossRef] [PubMed]

45. Somasundaram, N.P.; Ranathunga, I.; Ratnasamy, V.; Wijewickrama, P.; Dissanayake, H.A.; Yogendranathan, N.; Gamage, K.; de Silva, N.L.; Sumanatilleke, M.; Katulanda, P.; et al. The impact of SARS-Cov-2 virus infection on the endocrine system. J. Endocr. Soc. 2020, 4, bvaa082. [CrossRef]

46. Lundholm, M.D.; Poku, C.; Emanuele, N.; Emanuele, M.A.; Lopez, N. SARS-CoV-2 (COVID-19) and the endocrine system. J. Endocr. Soc. 2020, 4, bvaa144. [CrossRef] [PubMed]

47. Juan, J.; Gil, M.M.; Rong, Z.; Zhang, Y.; Yang, H.; Poon, L.C. Effect of coronavirus disease 2019 (COVID-19) on maternal, perinatal and neonatal outcome: Systematic review. Ultrasound Obstet. Gynecol. 2020, 56, 15-27. [CrossRef]

48. Gonzalez, A.; Orozco-Aguilar, J.; Achiardi, O.; Simon, F.; Cabello-Verrugio, C. SARS-CoV-2/renin-angiotensin system: Deciphering the clues for a couple with potentially harmful effects on skeletal muscle. Int. J. Mol. Sci. 2020, 21, 7904. [CrossRef]

49. Rahimi, H.; Tehranchinia, Z. A comprehensive review of cutaneous manifestations associated with COVID-19. Biomed. Res. Int. 2020, 2020, 1236520. [CrossRef]

50. Mawhirt, S.L.; Frankel, D.; Diaz, A.M. Cutaneous manifestations in adult patients with COVID-19 and dermatologic conditions related to the COVID-19 pandemic in health care workers. Curr. Allergy Asthma Rep. 2020, 20, 75. [CrossRef]

51. Kicman, A.; Toczek, M. The effects of cannabidiol, a non-intoxicating compound of cannabis, on the cardiovascular system in health and disease. Int. J. Mol. Sci. 2020, 21, 6740. [CrossRef] [PubMed]

52. Atalay, S.; Jarocka-Karpowicz, I.; Skrzydlewska, E. Antioxidative and anti-inflammatory properties of cannabidiol. Antioxidants 2019, 9, 21. [CrossRef]

53. Ligresti, A.; De Petrocellis, L.; Di Marzo, V. Phytocannabinoids to cannabinoid receptors and endocannabinoids: Pleiotropic physiological and pathological roles through complex pharmacology. Physiol. Rev. 2016, 96, 1593-1659. [CrossRef]

54. Britch, S.C.; Babalonis, S.; Walsh, S.L. Cannabidiol: Pharmacology and therapeutic targets. Psychopharmacology 2020, 238, 9-28. [CrossRef]

55. Pisanti, S.; Malfitano, A.M.; Ciaglia, E.; Lamberti, A.; Ranieri, R.; Cuomo, G.; Abate, M.; Faggiana, G.; Proto, M.C.; Fiore, D.; et al. Cannabidiol: State of the art and new challenges for therapeutic applications. Pharmacol. Ther. 2017, 175, 133-150. [CrossRef] [PubMed] 
56. Esposito, G.; Pesce, M.; Seguella, L.; Sanseverino, W.; Lu, J.; Corpetti, C.; Sarnelli, G. The potential of cannabidiol in the COVID-19 pandemic. Br. J. Pharmacol. 2020, 177, 4967-4970. [CrossRef]

57. Janmohamed, K.; Soale, A.N.; Forastiere, L.; Tang, W.; Sha, Y.; Demant, J.; Airoldi, E.; Kumar, N. Intersection of the web-based vaping narrative with COVID-19: Topic modeling study. J. Med. Internet Res. 2020, 22, e21743. [CrossRef] [PubMed]

58. Sexton, M. Cannabis in the time of coronavirus disease 2019: The Yin and Yang of the endocannabinoid system in immunocompetence. J. Altern. Complement. Med. 2020, 26, 444-448. [CrossRef] [PubMed]

59. Costiniuk, C.T.; Jenabian, M.A. Acute inflammation and pathogenesis of SARS-CoV-2 infection: Cannabidiol as a potential anti-inflammatory treatment? Cytokine Growth Factor Rev. 2020, 53, 63-65. [CrossRef] [PubMed]

60. Rossi, F.; Tortora, C.; Argenziano, M.; Di Paola, A.; Punzo, F. Cannabinoid receptor type 2: A possible target in SARS-CoV-2 (CoV-19) infection? Int. J. Mol. Sci. 2020, 21, 3809. [CrossRef]

61. Shover, C.L.; Humphreys, K. Debunking cannabidiol as a treatment for COVID-19: Time for the FDA to adopt a focused deterrence model? Cureus 2020, 12, e8671. [CrossRef]

62. Biali, M.; Broers, B.; Besson, M.; Demeules, J. Cannabinoids and COVID-19. Med. Cannabis Cannabinoids 2020, 3, 111-115. [CrossRef]

63. Khalsa, J.H.; Bunt, G.; Maggirwar, S.B.; Kottilil, S. COVID-19 and cannabidiol (CBD). J. Addict. Med. 2020. [CrossRef] [PubMed]

64. Brown, J.D. Cannabidiol as prophylaxis for SARS-CoV-2 and COVID-19? Unfounded claims versus potential risks of medications during the pandemic. Res. Soc. Adm. Pharm. 2021, 17, 2053. [CrossRef]

65. Hill, K.P. Cannabinoids and the coronavirus. Cannabis Cannabinoid Res. 2020, 5, 118-120. [CrossRef]

66. Booz, G.W. Cannabidiol as an emergent therapeutic strategy for lessening the impact of inflammation on oxidative stress. Free Radic. Biol. Med. 2011, 51, 1054-1061. [CrossRef]

67. Wang, B.; Kovalchuk, A.; Li, D.; Rodriguez-Juarez, R.; Ilnytskyy, Y.; Kovalchuk, I.; Kovalchuk, O. In search of preventive strategies: Novel high-CBD Cannabis sativa extracts modulate ACE2 expression in COVID-19 gateway tissues. Aging 2020, 2, 22425-22444. [CrossRef]

68. Raj, V.; Park, J.G.; Cho, K.H.; Choi, P.; Kim, T.; Ham, J.; Lee, J. Assessment of antiviral potencies of cannabinoids against SARS-CoV-2 using computational and in vitro approaches. Int. J. Biol. Macromol. 2020, 168, 474-485. [CrossRef] [PubMed]

69. Lowe, H.I.; Toyang, N.J.; McLaughlin, W. Potential of cannabidiol for the treatment of viral hepatitis. Pharmacognosy. Res. 2017, 9, 116-118. [CrossRef] [PubMed]

70. Maor, Y.; Yu, J.; Kuzontkoski, P.M.; Dezube, B.J.; Zhang, X.; Groopman, J.E. Cannabidiol inhibits growth and induces programmed cell death in kaposi sarcoma-associated herpesvirus-infected endothelium. Genes. Cancer 2012, 3, 512-520. [CrossRef]

71. Khodadadi, H.; Salles, É.L.; Jarrahi, A.; Chibane, F.; Costigliola, V.; Yu, J.C.; Vaibhav, K.; Hess, D.C.; Dhandapani, K.M.; Baban, B. Cannabidiol modulates cytokine storm in acute respiratory distress syndrome induced by simulated viral infection using synthetic RNA. Cannabis Cannabinoid Res. 2020, 5, 197-201. [CrossRef] [PubMed]

72. Salles, É.L.; Khodadadi, H.; Jarrahi, A.; Ahluwalia, M.; Paffaro, V.A.; Costigliola, V.; Yu, J.C.; Hess, D.C.; Dhandapani, K.M.; Baban, B. Cannabidiol (CBD) modulation of apelin in acute respiratory distress syndrome. J. Cell. Mol. Med. 2020, 24, 12869-12872. [CrossRef]

73. Patel, D.C.; Wallis, G.; Fujinami, R.S.; Wilcox, K.S.; Smith, M.D. Cannabidiol reduces seizures following CNS infection with Theiler's murine encephalomyelitis virus. Epilepsia Open 2019, 4, 431-442. [CrossRef]

74. Mecha, M.; Feliú, A.; Iñigo, P.M.; Mestre, L.; Carrillo-Salinas, F.J.; Guaza, C. Cannabidiol provides long-lasting protection against the deleterious effects of inflammation in a viral model of multiple sclerosis: A role for A2A receptors. Neurobiol. Dis. 2013, 59, 141-150. [CrossRef] [PubMed]

75. Ribeiro, A.; Ferraz-de-Paula, V.; Pinheiro, M.L.; Vitoretti, L.B.; Mariano-Souza, D.P.; Quinteiro-Filho, W.M.; Akamine, A.T.; Almeida, V.I.; Quevedo, J.; Dal-Pizzol, F.; et al. Cannabidiol, a non-psychotropic plant-derived cannabinoid, decreases inflammation in a murine model of acute lung injury: Role for the adenosine A2A receptor. Eur. J. Pharmacol. 2012, 678, 78-85. [CrossRef] [PubMed]

76. Ribeiro, A.; Almeida, V.I.; Costola De Souza, C.; Ferraz De Paula, V.; Pinheiro, M.L.; Vitoretti, L.B.; Gimenes-Junior, J.A.; Akamine, A.T.; Crippa, J.A.; Tavares De Lima, W.; et al. Cannabidiol improves lung function and inflammation in mice submitted to LPS-induced acute lung injury. Immunopharmacol. Immunotoxicol. 2015, 37, 35-41. [CrossRef]

77. Sadowska, O.; Baranowska-Kuczko, M.; Gromotowicz-Popławska, A.; Biernacki, M.; Kicman, A.; Malinowska, B.; Kasacka, I.; Krzyżewska, A.; Kozłowska, H. Cannabidiol ameliorates monocrotaline-induced pulmonary hypertension in rats. Int. J. Mol. Sci. 2020, 21, 7077. [CrossRef] [PubMed]

78. Arruza, L.; Pazos, M.R.; Mohammed, N.; Escribano, N.; Lafuente, H.; Santos, M.; Alvarez-Díaz, F.J. Cannabidiol reduces lung injury induced by hypoxic-ischemic brain damage in newborn piglets. Pediatr. Res. 2017, 82, 79-86. [CrossRef] [PubMed]

79. Vuolo, F.; Petronilho, F.; Sonai, B.; Ritter, C.; Hallak, J.E.; Zuardi, A.W.; Crippa, J.A.; Dal-Pizzol, F. Evaluation of serum cytokines levels and the role of cannabidiol treatment in animal model of asthma. Mediators Inflamm. 2015, 2015, 538670. [CrossRef] [PubMed]

80. Vuolo, F.; Abreu, S.C.; Michels, M.; Xisto, D.G.; Blanco, N.G.; Hallak, J.E.; Zuardi, A.W.; Crippa, J.A.; Reis, C.; Bahl, M.; et al. Cannabidiol reduces airway inflammation and fibrosis in experimental allergic asthma. Eur. J. Pharmacol. 2019, 843, 251-259. [CrossRef] 
81. Dudášová, A.; Keir, S.D.; Parsons, M.E.; Molleman, A.; Page, C.P. The effects of cannabidiol on the antigen-induced contraction of airways smooth muscle in the guinea-pig. Pulm. Pharmacol. Ther. 2013, 26, 373-379. [CrossRef] [PubMed]

82. Baranowska-Kuczko, M.; Kozłowska, H.; Kloza, M.; Sadowska, O.; Kozłowski, M.; Kusaczuk, M.; Kasacka, I.; Malinowska, B. Vasodilatory effects of cannabidiol in human pulmonary and rat small mesenteric arteries: Modification by hypertension and the potential pharmacological opportunities. J. Hypertens. 2020, 38, 896-911. [CrossRef]

83. Karmaus, P.W.; Wagner, J.G.; Harkema, J.R.; Kaminski, N.E.; Kaplan, B.L. Cannabidiol (CBD) enhances lipopolysaccharide (LPS)-induced pulmonary inflammation in C57BL/6 mice. J. Immunotoxicol. 2013, 10, 321-328. [CrossRef] [PubMed]

84. Makwana, R.; Venkatasamy, R.; Spina, D.; Page, C. The effect of phytocannabinoids on airway hyper-responsiveness, airway inflammation, and cough. J. Pharmacol. Expl. Ther. 2015, 353, 169-180. [CrossRef]

85. Feng, Y.; Chen, F.; Yin, T.; Xia, Q.; Liu, Y.; Huang, G.; Zhang, J.; Oyen, R.; Ni, Y.J. Effects of cannabidiol on acute reperfused myocardial infarction in rabbits: Evaluated with 3.0T Cardiac Magnetic Resonance Imaging and Histopathology. J. Cardiovasc. Pharmacol. 2015, 66, 354-363. [CrossRef] [PubMed]

86. Durst, R.; Danenberg, H.; Gallily, R.; Mechoulam, R.; Meir, K.; Grad, E.; Beeri, R.; Pugatsch, T.; Tarsish, E.; Lotan, C. Cannabidiol, a nonpsychoactive Cannabis constituent, protects against myocardial ischemic reperfusion injury. Am. J. Physiol. Heart Circ. Physiol. 2007, 293, 3602-3607. [CrossRef]

87. Walsh, S.K.; Hepburn, C.Y.; Kane, K.A.; Wainwright, C.L. Acute administration of cannabidiol in vivo suppresses ischaemiainduced cardiac arrhythmias and reduces infarct size when given at reperfusion. Br. J. Pharmacol. 2010, 160, 1234-1242. [CrossRef]

88. Gonca, E.; Darici, F. The effect of cannabidiol on ischemia/reperfusion-induced ventricular arrhythmias: The role of adenosine A1 receptors. J. Cardiovasc. Pharmacol. Ther. 2015, 20, 76-83. [CrossRef]

89. Lee, W.S.; Erdelyi, K.; Matyas, C.; Mukhopadhyay, P.; Varga, Z.V.; Liaudet, L.; Haskú, G.; Čiháková, D.; Mechoulam, R.; Pacher, P. Cannabidiol limits T cell-mediated chronic autoimmune myocarditis: Implications to autoimmune disorders and organ transplantation. Mol. Med. 2016, 22, 136-146. [CrossRef] [PubMed]

90. Rajesh, M.; Mukhopadhyay, P.; Bátkai, S.; Patel, V.; Saito, K.; Matsumoto, S.; Kashiwaya, Y.; Horváth, B.; Mukhopadhyay, B.; Becker, L.; et al. Cannabidiol attenuates cardiac dysfunction, oxidative stress, fibrosis, and inflammatory and cell death signaling pathways in diabetic cardiomyopathy. J. Am. Coll. Cardiol. 2010, 56, 2115-2125. [CrossRef]

91. Remiszewski, P.; Jarocka-Karpowicz, I.; Biernacki, M.; Jastrząb, A.; Schlicker, E.; Toczek, M.; Harasim-Symbor, E.; PędzińskaBetiuk, A.; Malinowska, B. Chronic Cannabidiol administration fails to diminish blood pressure in rats with primary and secondary hypertension despite its effects on cardiac and plasma endocannabinoid system, oxidative stress and lipid metabolism. Int. J. Mol. Sci. 2020, 21, 1295. [CrossRef]

92. Pędzińska-Betiuk, A.; Weresa, J.; Schlicker, E.; Harasim-Symbor, E.; Toczek, M.; Kasacka, I.; Gajo, B.; Malinowska, B. Chronic cannabidiol treatment reduces the carbachol-induced coronary constriction and left ventricular cardiomyocyte width of the isolated hypertensive rat heart. Toxicol. Appl. Pharmacol. 2020, 411, 115368. [CrossRef]

93. Wheal, A.J.; Jadoon, K.; Randall, M.D.; O'Sullivan, S.E. In Vivo cannabidiol treatment improves endothelium-dependent vasorelaxation in mesenteric arteries of zucker diabetic fatty rats. Front. Pharmacol. 2017, 8, 248. [CrossRef] [PubMed]

94. Grambow, E.; Strüder, D.; Klar, E.; Hinz, B.; Vollmar, B. Differential effects of endogenous, phyto and synthetic cannabinoids on thrombogenesis and platelet activity. BioFactors 2016, 42, 581-590. [CrossRef]

95. Fouad, A.A.; Al-Mulhim, A.S.; Jresat, I. Cannabidiol treatment ameliorates ischemia/reperfusion renal injury in rats. Life Sci. 2012, 91, 284-292. [CrossRef]

96. Soares, R.Z.; Vuolo, F.; Dall'Igna, D.M.; Michels, M.; Crippa, J.A.; Hallak, J.E.; Zuardi, A.W.; Dal-Pizzol, F. Evaluation of the role of the cannabidiol system in an animal model of ischemia/reperfusion kidney injury. Rev. Bras. Ter. Intensiva 2015, 27, 383-389. [CrossRef] [PubMed]

97. Baban, B.; Khodadadi, H.; Vaibhav, K.; Marchetti, C.; Riccardi, C.; Mozaffari, M.S. Regulation of innate lymphoid cells in acute kidney injury: Crosstalk between cannabidiol and GILZ. J. Immunol. Res. 2020, 2020, 6056373. [CrossRef] [PubMed]

98. Rock, E.M.; Sullivan, M.T.; Collins, S.A.; Goodman, H.; Limebeer, C.L.; Mechoulam, R.; Parker, L.A. Evaluation of repeated or acute treatment with cannabidiol (CBD), cannabidiolic acid (CBDA) or CBDA methyl ester (HU-580) on nausea and/or vomiting in rats and shrews. Psychopharmacology 2020, 37, 2621-2631. [CrossRef]

99. Kossakowski, R.; Schlicker, E.; Toczek, M.; Weresa, J.; Malinowska, B. Cannabidiol affects the Bezold-Jarisch reflex via TRPV1 and $5-\mathrm{HT}_{3}$ receptors and has peripheral sympathomimetic effects in spontaneously hypertensive and normotensive rats. Front. Pharmacol. 2019, 10, 500. [CrossRef]

100. Mukhopadhyay, P.; Rajesh, M.; Horváth, B.; Bátkai, S.; Park, O.; Tanchian, G.; Gao, R.Y.; Patel, V.; Wink, D.A.; Liaudet, L.; et al. Cannabidiol protects against hepatic ischemia/reperfusion injury by attenuating inflammatory signaling and response, oxidative/nitrative stress, and cell death. Free Radic. Biol. Med. 2011, 50, 1368-1381. [CrossRef] [PubMed]

101. Wang, Y.; Mukhopadhyay, P.; Cao, Z.; Wang, H.; Feng, D.; Haskó, G.; Mechoulam, R.; Gao, B.; Pacher, P. Cannabidiol attenuates alcohol-induced liver steatosis, metabolic dysregulation, inflammation and neutrophil-mediated injury. Sci. Rep. 2017, 7, 12064. [CrossRef] [PubMed]

102. Avraham, Y.; Grigoriadis, N.; Poutahidis, T.; Vorobiev, L.; Magen, I.; Ilan, Y.; Mechoulam, R.; Berry, E. Cannabidiol improves brain and liver function in a fulminant hepatic failure-induced model of hepatic encephalopathy in mice. Br. J. Pharmacol. 2010, 162, 1650-1658. [CrossRef] 
103. Vilela, L.R.; Gomides, L.F.; David, B.A.; Antunes, M.M.; Diniz, A.B.; Moreira, F.; Menezes, G.B. Cannabidiol rescues acute hepatic toxicity and seizure induced by cocaine. Mediators Inflamm. 2015, 2015, 523418. [CrossRef]

104. Li, K.; Feng, J.Y.; Li, Y.Y.; Yuece, B.; Lin, X.H.; Yu, L.Y.; Li, Y.N.; Feng, Y.J.; Storr, M. Anti-inflammatory role of cannabidiol and O-1602 in cerulein-induced acute pancreatitis in mice. Pancreas 2013, 42, 123-129. [CrossRef] [PubMed]

105. Capasso, R.; Borrelli, F.; Aviello, G.; Romano, B.; Scalisi, C.; Capasso, F.; Izzo, A.A. Cannabidiol, extracted from Cannabis sativa, selectively inhibits inflammatory hypermotility in mice. Br. J. Pharmacol. 2008, 154, 1001-1008. [CrossRef] [PubMed]

106. Pagano, E.; Capasso, R.; Piscitelli, F.; Romano, B.; Parisi, O.A.; Finizio, S.; Lauritano, A.; Marzo, V.D.; Izzo, A.A.; Borrelli, F. An orally active cannabis extract with high content in cannabidiol attenuates chemically-induced intestinal inflammation and hypermotility in the mouse. Front. Pharmacol. 2016, 7, 341. [CrossRef] [PubMed]

107. Gáll, Z.; Farkas, S.; Albert, Á.; Ferencz, E.; Vancea, S.; Urkon, M.; Kolcsár, M. Effects of chronic cannabidiol treatment in the rat chronic unpredictable mild stress model of depression. Biomolecules 2020, 10, 801. [CrossRef] [PubMed]

108. Fiani, B.; Sarhadi, K.J.; Soula, M.; Zafar, A.; Quadri, S.A. Current application of cannabidiol (CBD) in the management and treatment of neurological disorders. Neurol. Sci. 2020, 41, 3085-3098. [CrossRef]

109. Patra, P.H.; Barker-Haliski, M.; White, H.S.; Whalley, B.J.; Glyn, S.; Sandhu, H.; Jones, N.; Bazelot, M.; Williams, C.M.; McNeish, A.J. Cannabidiol reduces seizures and associated behavioral comorbidities in a range of animal seizure and epilepsy models. Epilepsia 2019, 60, 303-314. [CrossRef]

110. Vilela, L.R.; Lima, I.V.; Kunsch, É.B.; Pinto, H.; De Miranda, A.S.; Vieira, É.; De Oliveira, A.; Moraes, M.; Teixeira, A.L.; Moreira, F.A. Anticonvulsant effect of cannabidiol in the pentylenetetrazole model: Pharmacological mechanisms, electroencephalographic profile, and brain cytokine levels. Epilepsy Behav. 2017, 75, 29-35. [CrossRef]

111. Pazos, M.R.; Mohammed, N.; Lafuente, H.; Santos, M.; Martínez-Pinilla, E.; Moreno, E.; Valdizan, E.; Romero, J.; Pazos, A.; Franco, R.; et al. Mechanisms of cannabidiol neuroprotection in hypoxic-ischemic newborn pigs: Role of 5HT $1 \mathrm{~A}$ and CB2 receptors. Neuropharmacology 2013, 71, 282-291. [CrossRef]

112. Lafuente, H.; Pazos, M.R.; Alvarez, A.; Mohammed, N.; Santos, M.; Arizti, M.; Alvarez, F.J.; Martinez-Orgado, J.A. Effects of cannabidiol and hypothermia on short-term brain damage in new-born piglets after acute hypoxia-ischemia. Front. Neurosci. 2016, 10, 323. [CrossRef]

113. Ruiz-Valdepeñas, L.; Martínez-Orgado, J.A.; Benito, C.; Millán, A.; Tolón, R.M.; Romero, J. Cannabidiol reduces lipopolysaccharideinduced vascular changes and inflammation in the mouse brain: An intravital microscopy study. J. Neuroinflamm. 2011, 8, 5. [CrossRef] [PubMed]

114. Hayakawa, K.; Mishima, K.; Irie, K.; Hazekawa, M.; Mishima, S.; Fujioka, M.; Orito, K.; Egashira, N.; Katsurabayashi, S.; Takasaki, K.; et al. Cannabidiol prevents a post-ischemic injury progressively induced by cerebral ischemia via a high-mobility group box1-inhibiting mechanism. Neuropharmacology 2008, 55, 1280-1286. [CrossRef] [PubMed]

115. Mishima, K.; Hayakawa, K.; Abe, K.; Ikeda, T.; Egashira, N.; Iwasaki, K.; Fujiwara, M. Cannabidiol prevents cerebral infarction via a serotonergic 5-hydroxytryptamine 1A receptor-dependent mechanism. Stroke 2005, 36, 1077-1082. [CrossRef] [PubMed]

116. Liou, G.; El-Remessy, A.; Ibrahim, A.; Caldwell, R.; Khalifa, Y.; Gunes, A.; Nussbaum, J. Cannabidiol as a putative novel therapy for diabetic retinopathy: A postulated mechanism of action as an entry point for biomarker-guided clinical development. Curr. Pharmacogen. Person Med. 2009, 7, 215-222. [CrossRef] [PubMed]

117. Liou, G.I.; Auchampach, J.A.; Hillard, C.J.; Zhu, G.; Yousufzai, B.; Mian, S.; Khan, S.; Khalifa, Y. Mediation of cannabidiol anti-inflammation in the retina by equilibrative nucleoside transporter and A2A adenosine receptor. Invest. Ophthalmol. Vis. Sci. 2008, 9, 5526-5531. [CrossRef]

118. Bielawiec, P.; Harasim-Symbor, E.; Konstantynowicz-Nowicka, K.; Sztolsztener, K.; Chabowski, A. Chronic cannabidiol administration attenuates skeletal muscle de novo ceramide synthesis pathway and related metabolic effects in a rat model of high-fat diet-induced obesity. Biomolecules 2020, 10, 1241. [CrossRef]

119. Zorzenon, M.; Santiago, A.N.; Mori, M.A.; Piovan, S.; Jansen, C.A.; Perina Padilha, M.E.; Ciotta, S.R.; Cezar De Freitas Mathias, P.; Guimarães, F.S.; Weffort De Oliveira, R.M.; et al. Cannabidiol improves metabolic dysfunction in middle-aged diabetic rats submitted to a chronic cerebral hypoperfusion. Chem. Biol. Interact. 2019, 312, 108819. [CrossRef]

120. Paoli, A.; Gorini, S.; Caprio, M. The dark side of the spoon-glucose, ketones and COVID-19: A possible role for ketogenic diet? J. Transl. Med. 2020, 18, 441. [CrossRef]

121. Iannotti, F.A.; Pagano, E.; Moriello, A.S.; Alvino, F.G.; Sorrentino, N.C.; D’Orsi, L.; Gazzerro, E.; Capasso, R.; De Leonibus, E.; De Petrocellis, L.; et al. Effects of non-euphoric plant cannabinoids on muscle quality and performance of dystrophic mdx mice. Br. J. Pharmacol. 2019, 176, 1568-1584. [CrossRef]

122. Atalay, S.; Gegotek, A.; Wroński, A.; Domigues, P.; Skrzydlewska, E. Therapeutic application of cannabidiol on UVA and UVB irradiated rat skin. A proteomic study. J. Pharm. Biomed. Anal. 2021, 192, 113656. [CrossRef]

123. Oláh, A.; Tóth, B.I.; Borbíró, I.; Sugawara, K.; Szöllõsi, A.G.; Czifra, G.; Pál, B.; Ambrus, L.; Kloepper, J.; Camera, E.; et al Cannabidiol exerts sebostatic and antiinflammatory effects on human sebocytes. J. Clin. Invest. 2014, 124, 3713-3724. [CrossRef]

124. Petrosino, S.; Verde, R.; Vaia, M.; Allarà, M.; Iuvone, T.; Di Marzo, V. Anti-inflammatory properties of cannabidiol, a nonpsychotropic cannabinoid, in experimental allergic contact dermatitis. J. Pharmacol. Exp. Ther. 2018, 365, 652-663. [CrossRef]

125. Cassol, O.J.; Comim, C.M.; Silva, B.R.; Hermani, F.V.; Constantino, L.S.; Felisberto, F.; Petronilho, F.; Hallak, J.E.; De Martinis, B.S.; Zuardi, A.W.; et al. Treatment with cannabidiol reverses oxidative stress parameters, cognitive impairment and mortality in rats submitted to sepsis by cecal ligation and puncture. Brain Res. 2010, 1348, 128-138. [CrossRef] 
126. Abdallah, S.J.; Smith, B.M.; Ware, M.A.; Moore, M.; Li, P.Z.; Bourbeau, J.; Jensen, D. Effect of vaporized cannabis on exertional breathlessness and exercise endurance in advanced chronic obstructive pulmonary disease. A Randomized Controlled Trial. Ann. Am. Thorac. Soc. 2018, 15, 1146-1158. [CrossRef]

127. Pickering, E.E.; Semple, S.J.; Nazir, M.S.; Murphy, K.; Snow, T.M.; Cummin, A.R.; Moosavi, S.H.; Guz, A.; Holdcroft, A. Cannabinoid effects on ventilation and breathlessness: A pilot study of efficacy and safety. Chron. Respir. Dis. 2011, 8, 109-118. [CrossRef] [PubMed]

128. Duran, M.; Pérez, E.; Abanades, S.; Vidal, X.; Saura, C.; Majem, M.; Arriola, E.; Rabanal, M.; Pastor, A.; Farré, M.; et al. Preliminary efficacy and safety of an oromucosal standardized cannabis extract in chemotherapy-induced nausea and vomiting. Br. J. Clin. Pharmacol. 2010, 70, 656-663. [CrossRef] [PubMed]

129. Luftner, D.; Possinger, K.; Ernst, G.; Ruhstaller, T.; Meissner, W.; Ko, Y.D.; Schnelle, M.; Reif, M.; Cerny, T. Comparison of orally administered cannabis extract and delta-9-tetrahydrocannabinol in treating patients with cancer-related anorexia-cachexia syndrome: A multicenter, phase III, randomized, double-blind, placebo-controlled clinical trial from the Cannabis-In-CachexiaStudy-Group. J. Clin. Oncol. 2006, 24, 3394-3400. [CrossRef]

130. Couch, D.G.; Cook, H.; Ortori, C.; Barrett, D.; Lund, J.N.; O'Sullivan, S.E. Palmitoylethanolamide and cannabidiol prevent inflammation-induced hyperpermeability of the human gut in vitro and in vivo-A randomized, placebo-controlled, doubleblind controlled trial. Inflamm. Bowel Dis. 2019, 25, 1006-1018. [CrossRef]

131. Naftali, T.; Mechulam, R.; Marii, A.; Gabay, G.; Stein, A.; Bronshtain, M.; Laish, I.; Benjaminov, F.; Konikoff, F.M. Lowdose cannabidiol is safe but not effective in the treatment for Crohn's disease, a randomized controlled trial. Dig. Dis. Sci. 2017, 62, 1615-1620. [CrossRef] [PubMed]

132. Irving, P.M.; Iqbal, T.; Nwokolo, C.; Subramanian, S.; Bloom, S.; Prasad, N.; Hart, A.; Murray, C.; Lindsay, J.O.; Taylor, A.; et al. A randomized, double-blind, placebo-controlled, parallel-group, pilot study of cannabidiol-rich botanical extract in the symptomatic treatment of ulcerative colitis. Inflamm. Bowel Dis. 2018, 24, 714-724. [CrossRef]

133. Zuardi, A.W.; Cosme, R.A.; Graeff, F.G.; Guimarães, F.S. Effects of ipsapirone and cannabidiol on human experimental anxiety. J. Psychopharmacol. 1993, 7, 82-88. [CrossRef]

134. Crippa, J.A.; Zuardi, A.W.; Garrido, G.E.; Wichert-Ana, L.; Guarnieri, R.; Ferrari, L.; Azevedo-Marques, P.M.; Hallak, J.E.; McGuire, P.K.; Filho Busatto, G. Effects of cannabidiol (CBD) on regional cerebral blood flow. Neuropsychopharmacology 2004, 29, 417-426. [CrossRef] [PubMed]

135. Zuardi, A.W.; Rodrigues, N.P.; Silva, A.L.; Bernardo, S.A.; Hallak, J.; Guimarães, F.S.; Crippa, J. Inverted U-shaped dose-response curve of the anxiolytic effect of cannabidiol during public speaking in real life. Front. Pharmacol. 2017, 8, 259. [CrossRef]

136. Bergamaschi, M.M.; Queiroz, R.H.; Chagas, M.H.; De Oliveira, D.C.; De Martinis, B.S.; Kapczinski, F.; Quevedo, J.; Roesler, R.; Schröder, N.; Nardi, A.E.; et al. Cannabidiol reduces the anxiety induced by simulated public speaking in treatment-naïve social phobia patients. Neuropsychopharmacology 2011, 36, 1219-1226. [CrossRef]

137. Crippa, J.A.; Derenusson, G.N.; Ferrari, T.B.; Wichert-Ana, L.; Duran, F.L.; Martin-Santos, R.; Simões, M.V.; Bhattacharyya, S.; Fusar-Poli, P.; Atakan, Z.; et al. Neural basis of anxiolytic effects of cannabidiol (CBD) in generalized social anxiety disorder: A preliminary report. J. Psychopharmacol. 2011, 25, 121-130. [CrossRef]

138. Elms, L.; Shannon, S.; Hughes, S.; Lewis, N. Cannabidiol in the treatment of post-traumatic stress disorder: A case series. J. Altern. Complement. Med. 2019, 25, 392-397. [CrossRef]

139. Shannon, S.; Lewis, N.; Lee, H.; Hughes, S. Cannabidiol in anxiety and sleep: A large case series. Perm. J. 2019, $23,18-41$. [CrossRef] [PubMed]

140. Appiah-Kusi, E.; Petros, N.; Wilson, R.; Colizzi, M.; Bossong, M.G.; Valmaggia, L.; Mondelli, V.; McGuire, P.; Bhattacharyya, S. Effects of short-term cannabidiol treatment on response to social stress in subjects at clinical high risk of developing psychosis. Psychopharmacology 2020, 237, 1121-1130. [CrossRef]

141. Wilson, R.; Bossong, M.G.; Appiah-Kusi, E.; Petros, N.; Brammer, M.; Perez, J.; Allen, P.; McGuire, P.; Bhattacharyya, S. Cannabidiol attenuates insular dysfunction during motivational salience processing in subjects at clinical high risk for psychosis. Transl. Psychiatry 2019, 9, 203. [CrossRef] [PubMed]

142. Allsop, D.J.; Copeland, J.; Lintzeris, N.; Dunlop, A.J.; Montebello, M.; Sadler, C.; Rivas, G.R.; Holland, R.M.; Muhleisen, P.; Norberg, M.M.; et al. Nabiximols as an agonist replacement therapy during cannabis withdrawal: A randomized clinical trial. JAMA Psychiatry 2014, 71, 281-291. [CrossRef]

143. Solowij, N.; Broyd, S.J.; Beale, C.; Prick, J.A.; Greenwood, L.M.; Van Hell, H.; Suo, C.; Galettis, P.; Pai, N.; Fu, S.; et al. Therapeutic effects of prolonged cannabidiol treatment on psychological symptoms and cognitive function in regular cannabis users: A pragmatic open-label clinical trial. Cannabis Cannabinoid Res. 2018, 3, 21-34. [CrossRef] [PubMed]

144. Hurd, Y.L.; Spriggs, S.; Alishayev, J.; Winkel, G.; Gurgov, K.; Kudrich, C.; Oprescu, A.M.; Salsitz, E. Cannabidiol for the reduction of cue-induced craving and anxiety in drug-abstinent individuals with heroin use disorder: A double-blind randomized placebo-controlled trial. Am. J. Psychiatry 2019, 176, 911-922. [CrossRef]

145. Hundal, H.; Lister, R.; Evans, N.; Antley, A.; Englund, A.; Murray, R.M.; Freeman, D.; Morrison, P.D. The effects of cannabidiol on persecutory ideation and anxiety in a high trait paranoid group. J. Psychopharmacol. 2018, 32, 276-282. [CrossRef]

146. Leweke, F.M.; Piomelli, D.; Pahlisch, F.; Muhl, D.; Gerth, C.W.; Hoyer, C.; Klosterkötter, J.; Hellmich, M.; Koethe, D. Cannabidiol enhances anandamide signaling and alleviates psychotic symptoms of schizophrenia. Transl. Psychiatry 2012, 2, e94. [CrossRef] [PubMed] 
147. McGuire, P.; Robson, P.; Cubala, W.J.; Vasile, D.; Morrison, P.D.; Barron, R.; Taylor, A.; Wright, S. Cannabidiol (CBD) as an adjunctive therapy in schizophrenia: A multicenter randomized controlled trial. Am. J. Psychiatry 2018, 175, 225-231. [CrossRef] [PubMed]

148. Boggs, D.L.; Surti, T.; Gupta, A.; Gupta, S.; Niciu, M.; Pittman, B.; Schnakenberg Martin, A.M.; Thurnauer, H.; Davies, A.; D'Souza, D.C.; et al. The effects of cannabidiol (CBD) on cognition and symptoms in outpatients with chronic schizophrenia a randomized placebo controlled trial. Psychopharmacology 2018, 235, 1923-1932. [CrossRef]

149. Capano, A.; Weaver, R.; Burkman, E. Evaluation of the effects of CBD hemp extract on opioid use and quality of life indicators in chronic pain patients: A prospective cohort study. Postgrad. Med. 2020, 132, 56-61. [CrossRef]

150. Cuñetti, L.; Manzo, L.; Peyraube, R.; Arnaiz, J.; Curi, L.; Orihuela, S. Chronic pain treatment with cannabidiol in kidney transplant patients in Uruguay. Transplant. Proc. 2018, 50, 461-464. [CrossRef]

151. Van De Donk, T.; Niesters, M.; Kowal, M.A.; Olofsen, E.; Dahan, A.; Van Velzen, M. An experimental randomized study on the analgesic effects of pharmaceutical-grade cannabis in chronic pain patients with fibromyalgia. Pain 2019, 160, 860-869. [CrossRef]

152. Russo, M.; Naro, A.; Leo, A.; Sessa, E.; D’Aleo, G.; Bramanti, P.; Calabrò, R.S. Evaluating Sativex®in neuropathic pain management: A clinical and neurophysiological assessment in multiple sclerosis. Pain Med. 2016, 17, 1145-1154. [CrossRef]

153. Hoggart, B.; Ratcliffe, S.; Ehler, E.; Simpson, K.H.; Hovorka, J.; Lejčko, J.; Taylor, L.; Lauder, H.; Serpell, M. A multicentre, open-label, follow-on study to assess the long-term maintenance of effect, tolerance and safety of THC/CBD oromucosal spray in the management of neuropathic pain. J. Neurol. 2015, 262, 27-40. [CrossRef] [PubMed]

154. Selvarajah, D.; Gandhi, R.; Emery, C.J.; Tesfaye, S. Randomized placebo-controlled double-blind clinical trial of cannabisbased medicinal product (Sativex) in painful diabetic neuropathy: Depression is a major confounding factor. Diabetes Care 2010, 33, 128-130. [CrossRef] [PubMed]

155. Lichtman, A.H.; Lux, E.A.; McQuade, R.; Rossetti, S.; Sanchez, R.; Sun, W.; Wright, S.; Kornyeyeva, E.; Fallon, M.T. Results of a double-blind, randomized, placebo-controlled study of nabiximols oromucosal spray as an adjunctive therapy in advanced cancer patients with chronic uncontrolled pain. J. Pain Symptom Manag. 2018, 55, 179-188. [CrossRef] [PubMed]

156. Miller, I.; Scheffer, I.E.; Gunning, B.; Sanchez-Carpintero, R.; Gil-Nagel, A.; Perry, M.S.; Saneto, R.P.; Checketts, D.; Dunayevich, E.; Knappertz, V. GWPCARE2 Study Group. Dose-Ranging effect of adjunctive oral cannabidiol vs placebo on convulsive seizure frequency in Dravet syndrome: A randomized clinical trial. JAMA Neurol. 2020, 77, 613-621. [CrossRef] [PubMed]

157. Devinsky, O.; Cross, J.H.; Laux, L.; Marsh, E.; Miller, I.; Nabbout, R.; Scheffer, I.E.; Thiele, E.A.; Wright, S. Cannabidiol in Dravet Syndrome Study Group. Trial of cannabidiol for drug-resistant seizures in the Dravet syndrome. N. Engl. J. Med. 2017, 376, 2011-2020. [CrossRef]

158. Devinsky, O.; Patel, A.D.; Cross, J.H.; Villanueva, V.; Wirrell, E.C.; Privitera, M.; Greenwood, S.M.; Roberts, C.; Checketts, D.; Van Landingham, K.E.; et al. GWPCARE3 Study Group. Effect of Cannabidiol on drop seizures in the Lennox-Gastaut syndrome. N. Engl. J. Med. 2018, 378, 1888-1897. [CrossRef]

159. Thiele, E.A.; Marsh, E.D.; French, J.A.; Mazurkiewicz-Beldzinska, M.; Benbadis, S.R.; Joshi, C.; Lyons, P.D.; Taylor, A.; Roberts, C.; GWPCARE4 Study Group; et al. Cannabidiol in patients with seizures associated with Lennox-Gastaut syndrome (GWPCARE4): A randomised, double-blind, placebo-controlled phase 3 trial. Lancet 2018, 391, 1085-1096. [CrossRef]

160. Wade, D.T.; Makela, P.; Robson, P.; House, H.; Bateman, C. Do cannabis-based medicinal extracts have general or specific effects on symptoms in multiple sclerosis? A double-blind, randomized, placebo-controlled study on 160 patients. Mult. Scler. 2004, 10, 434-441. [CrossRef]

161. Wade, D.T.; Makela, P.M.; House, H.; Bateman, C.; Robson, P. Long-term use of a cannabis-based medicine in the treatment of spasticity and other symptoms in multiple sclerosis. Mult. Scler. 2006, 12, 639-645. [CrossRef]

162. Contin, M.; Mancinelli, L.; Perrone, A.; Sabattini, L.; Mohamed, S.; Scandellari, C.; Foschi, M.; Vacchiano, V.; Lugaresi, A.; Riva, R. Tetrahydrocannabinol/cannabidiol oromucosal spray in patients with multiple sclerosis: A pilot study on the plasma concentration-effect relationship. Clin. Neuropharmacol. 2018, 41, 171-176. [CrossRef]

163. Haupts, M.; Vila, C.; Jonas, A.; Witte, K.; Álvarez-Ossorio, L. Influence of previous failed antispasticity therapy on the efficacy and tolerability of THC:CBD oromucosal spray for multiple sclerosis spasticity. Eur. Neurol. 2016, 75, 236-243. [CrossRef] [PubMed]

164. Palmieri, B.; Laurino, C.; Vadalà, M. A therapeutic effect of CBD-enriched ointment in inflammatory skin diseases and cutaneous scars. Clin. Ter. 2019, 170, e93-e99. [CrossRef]

165. Singh, J.; Antimisiaris, M.F. Epidiolex-induced skin rash. Epileptic Disord. 2020, 22, 511-514. [CrossRef]

166. Černe, K. Toxicological properties of $\Delta$ 9-tetrahydrocannabinol and cannabidiol. Arh. Ind. Hyg. Toksikol. 2020, 71, 1-11. [CrossRef]

167. Chesney, E.; McGuire, P.; Freeman, T.P.; Strang, J.; Englund, A. Lack of evidence for the effectiveness or safety of over-the-counter cannabidiol products. Ther. Adv. Psychopharmacol. 2020, 10, 2045125320954992. [CrossRef] [PubMed]

168. Dos Santos, R.G.; Guimarães, F.S.; Crippa, J.; Hallak, J.; Rossi, G.N.; Rocha, J.M.; Zuardi, A.W. Serious adverse effects of cannabidiol (CBD): A review of randomized controlled trials. Expert Opin. Drug Metab. Toxicol. 2020, 16, 517-526. [CrossRef]

169. Huestis, M.A.; Solimini, R.; Pichini, S.; Pacifici, R.; Carlier, J.; Busardò, F.P. Cannabidiol adverse effects and toxicity. Curr. Neuropharmacol. 2019, 17, 974-989. [CrossRef] [PubMed]

170. Bass, J.; Linz, D.R. A Case of toxicity from cannabidiol gummy ingestion. Cureus 2020, 12, e7688. [CrossRef]

171. Herbst, J.; Musgrave, G. Respiratory depression following an accidental overdose of a CBD-labeled product: A pediatric case report. J. Am. Pharm. Assoc. 2020, 60, 248-252. [CrossRef] 
172. Devinsky, O.; Cilio, M.R.; Cross, H.; Fernandez-Ruiz, J.; French, J.; Hill, C.; Katz, R.; Di Marzo, V.; Jutras-Aswad, D.; Notcutt, W.G.; et al. Cannabidiol: Pharmacology and potential therapeutic role in epilepsy and other neuropsychiatric disorders. Epilepsia 2014, 55, 791-802. [CrossRef]

173. Adapa, S.; Gayam, V.; Konala, V.M.; Annangi, S.; Raju, M.P.; Bezwada, V.; McMillan, C.; Dalal, H.; Mandal, A.; Naramala, S. Cannabis vaping-induced acute pulmonary toxicity: Case series and review of literature. J. Investig. Med. High. Impact Case Rep. 2020, 8, 2324709620947267. [CrossRef]

174. Millar, S.A.; Stone, N.L.; Bellman, Z.D.; Yates, A.S.; England, T.J.; O'Sullivan, S.E. A systematic review of cannabidiol dosing in clinical populations. Br. J. Clin. Pharmacol. 2019, 85, 1888-1900. [CrossRef]

175. Arkell, T.R.; Lintzeris, N.; Kevin, R.C.; Ramaekers, J.G.; Vandrey, R.; Irwin, C.; Haber, P.S.; McGregor, I.S. Cannabidiol (CBD) content in vaporized cannabis does not prevent tetrahydrocannabinol (THC)-induced impairment of driving and cognition. Psychopharmacology 2019, 236, 2713-2724. [CrossRef]

176. Greene, N.Z.; Wiley, J.L.; Yu, Z.; Clowers, B.H.; Craft, R.M. Cannabidiol modulation of antinociceptive tolerance to $\Delta 9$ Ktetrahydrocannabinol. Psychopharmacology 2018, 235, 3289-3302. [CrossRef]

177. Haney, M.; Malcolm, R.J.; Babalonis, S.; Nuzzo, P.A.; Cooper, Z.D.; Bedi, G.; Gray, K.M.; McRae-Clark, A.; Lofwall, M.R.; Sparenborg, S.; et al. Oral cannabidiol does not alter the subjective, reinforcing or cardiovascular effects of smoked Cannabis. Neuropsychopharmacology 2016, 41, 1974-1982. [CrossRef] [PubMed]

178. Karschner, E.L.; Darwin, W.D.; Goodwin, R.S.; Wright, S.; Huestis, M.A. Plasma cannabinoid pharmacokinetics following controlled oral delta9-tetrahydrocannabinol and oromucosal cannabis extract administration. Clin. Chem. 2011, 57, 66-75. [CrossRef] [PubMed]

179. Solowij, N.; Broyd, S.; Greenwood, L.M.; Van Hell, H.; Martelozzo, D.; Rueb, K.; Todd, J.; Liu, Z.; Galettis, P.; Martin, J.; et al. A randomised controlled trial of vaporised $\Delta 9$-tetrahydrocannabinol and cannabidiol alone and in combination in frequent and infrequent cannabis users: Acute intoxication effects. Eur. Arch. Psychiatry Clin. Neurosci. 2019, 269, 17-35. [CrossRef]

180. World Health Organization. Cannabidiol (CBD). Critical Review Report. Available online: https://www.who.int/medicines/ access / controlled-substances/CannabidiolCriticalReview.pdf (accessed on 1 February 2021).

181. Iffland, K.; Grotenhermen, F. An update on safety and side effects of cannabidiol: A review of clinical data and relevant animal studies. Cannabis Cannabinoid Res. 2017, 2, 139-154. [CrossRef]

182. Patsalos, P.N.; Szaflarski, J.P.; Gidal, B.; Van Landingham, K.; Critchley, D.; Morrison, G. Clinical implications of trials investigating drug-drug interactions between cannabidiol and enzyme inducers or inhibitors or common antiseizure drugs. Epilepsia 2020, 61, 1854-1868. [CrossRef] [PubMed]

183. Cortopassi, J. Warfarin dose adjustment required after cannabidiol initiation and titration. Am. J. Health Syst. Pharm. 2020, 77, 1846-1851. [CrossRef] [PubMed]

184. McNamara, N.A.; Dang, L.T.; Sturza, J.; Ziobro, J.M.; Fedak Romanowski, E.M.; Smith, G.C.; Joshi, S.M.; Leber, S.M.; Carlson, M.; Robertson, P.; et al. Thrombocytopenia in pediatric patients on concurrent cannabidiol and valproic acid. Epilepsia 2020, 61, e85-e89. [CrossRef]

185. Wilson-Morkeh, H.; Al-Abdulla, A.; Sien, L.; Mohamed, H.; Youngstein, T. Important drug interactions exist between cannabidiol oil and commonly prescribed drugs in rheumatology practice. Rheumatology 2020, 59, 249-251. [CrossRef]

186. Hsu, A.; Painter, N.A. Probable interaction between warfarin and inhaled and oral administration of cannabis. J. Pharm. Pract. 2020, 33, 915-918. [CrossRef]

187. Dey, T.; Chatterjee, S.; Manna, S.; Nandy, A.; Basak, S.C. Identification and computational analysis of mutations in SARS-CoV-2. Comput. Biol. Med. 2020, 129, 104166. [CrossRef] [PubMed]

188. Santos, R.; Sampaio, W.O.; Alzamora, A.C.; Motta-Santos, D.; Alenina, N.; Bader, M.; Campagnole-Santos, M.J. The ACE2/Angiotensin-(1-7)/MAS axis of the renin-angiotensin system: Focus on Angiotensin-(1-7). Physiol. Rev. 2018, 98, 505-553. [CrossRef] [PubMed]

189. Jia, H. Pulmonary angiotensin-converting enzyme 2 (ACE2) and inflammatory lung disease. Shock 2016, 46, 239-248. [CrossRef]

190. Feng, Y.; Wan, H.; Liu, J.; Zhang, R.; Ma, Q.; Han, B.; Xiang, Y.; Che, J.; Cao, H.; Fei, X.; et al. The angiotensin-converting enzyme 2 in tumor growth and tumor-associated angiogenesis in non-small cell lung cancer. Oncol. Rep. 2010, 23, 941-948. [CrossRef]

191. Imai, Y.; Kuba, K.; Rao, S.; Huan, Y.; Guo, F.; Guan, B.; Yang, P.; Sarao, R.; Wada, T.; Leong-Poi, H.; et al. Angiotensin-converting enzyme 2 protects from severe acute lung failure. Nature. 2005, 436, 112-116. [CrossRef] [PubMed]

192. He, H.; Liu, L.; Chen, Q.; Liu, A.; Cai, S.; Yang, Y.; Lu, X.; Qiu, H. Mesenchymal stem cells overexpressing angiotensin-converting enzyme 2 rescue lipopolysaccharide-induced lung injury. Cell. Transplant. 2015, 24, 1699-1715. [CrossRef] [PubMed]

193. Shenoy, V.; Kwon, K.C.; Rathinasabapathy, A.; Lin, S.; Jin, G.; Song, C.; Shil, P.; Nair, A.; Qi, Y.; Li, Q.; et al. Oral delivery of Angiotensin-converting enzyme 2 and Angiotensin-(1-7) bioencapsulated in plant cells attenuates pulmonary hypertension. Hypertension 2014, 64, 1248-1259. [CrossRef]

194. Rey-Parra, G.J.; Vadivel, A.; Coltan, L.; Hall, A.; Eaton, F.; Schuster, M.; Loibner, H.; Penninger, J.M.; Kassiri, Z.; Oudit, G.Y.; et al. Angiotensin converting enzyme 2 abrogates bleomycin-induced lung injury. J. Mol. Med. 2012, 90, 637-647. [CrossRef]

195. Marquez, A.; Wysocki, J.; Pandit, J.; Batlle, D. An update on ACE2 amplification and its therapeutic potential. Acta. Physiol. 2021, 231, e13513. [CrossRef] [PubMed]

196. Marshall, R.P.; Gohlke, P.; Chambers, R.C.; Howell, D.C.; Bottoms, S.E.; Unger, T.; McAnulty, R.J.; Laurent, G.J. Angiotensin II and the fibroproliferative response to acute lung injury. Am. J. Physiol. Lung. Cell. Mol. Physiol. 2004, 286, L156-L164. [CrossRef] 
197. Tan, W.; Liao, W.; Zhou, S.; Mei, D.; Wong, W.F. Targeting the renin-angiotensin system as novel therapeutic strategy for pulmonary diseases. Curr. Opin. Pharmacol. 2018, 40, 9-17. [CrossRef]

198. Kuba, K.; Imai, Y.; Ohto-Nakanishi, T.; Penninger, J.M. Trilogy of ACE2: A peptidase in the renin-angiotensin system, a SARS receptor, and a partner for amino acid transporters. Pharmacol. Ther. 2010, 128, 119-128. [CrossRef] [PubMed]

199. Ingraham, N.E.; Barakat, A.G.; Reilkoff, R.; Bezdicek, T.; Schacker, T.; Chipman, J.G.; Tignanelli, C.J.; Puskarich, M.A. Understanding the renin-angiotensin-aldosterone-SARS-CoV axis: A comprehensive review. Eur. Respir. J. 2020, 56, 2000912. [CrossRef]

200. Marshall, R.P.; Webb, S.; Bellingan, G.J.; Montgomery, H.E.; Chaudhari, B.; McAnulty, R.J.; Humphries, S.E.; Hill, M.R.; Laurent, G.J. Angiotensin converting enzyme insertion/deletion polymorphism is associated with susceptibility and outcome in acute respiratory distress syndrome. Am. J. Respir. Crit. Care. Med. 2002, 166, 646-650. [CrossRef]

201. Cruces, P.; Díaz, F.; Puga, A.; Erranz, B.; Donoso, A.; Carvajal, C.; Wilhelm, J.; Repetto, G.M. Angiotensin-converting enzyme insertion/deletion polymorphism is associated with severe hypoxemia in pediatric ARDS. Intensive Care. Med. 2012, 38, 113-119. [CrossRef] [PubMed]

202. Bourgonje, A.R.; Abdulle, A.E.; Timens, W.; Hillebrands, J.L.; Navis, G.J.; Gordijn, S.J.; Bolling, M.C.; Dijkstra, G.; Voors, A.A.; Osterhaus, A.D.; et al. Angiotensin-converting enzyme 2 (ACE2), SARS-CoV-2 and the pathophysiology of coronavirus disease 2019 (COVID-19). J. Pathol. 2020, 251, 228-248. [CrossRef]

203. Guan, W.J.; Ni, Z.Y.; Hu, Y.; Liang, W.H.; Ou, C.Q.; He, J.X.; Liu, L.; Shan, H.; Lei, C.L.; Hui, D.; et al. Clinical characteristics of coronavirus disease 2019 in China. N. Engl. J. Med. 2020, 382, 1708-1720. [CrossRef]

204. Sharma, R.K.; Stevens, B.R.; Obukhov, A.G.; Grant, M.B.; Oudit, G.Y.; Li, Q.; Richards, E.M.; Pepine, C.J.; Raizada, M.K. ACE2 (angiotensin-converting enzyme 2) in cardiopulmonary diseases: Ramifications for the control of SARS-CoV-2. Hypertension 2020, 76, 651-661. [CrossRef]

205. Leung, J.M.; Niikura, M.; Yang, C.; Sin, D.D. COVID-19 and COPD. Eur. Respir. J. 2020, 56, 2002108. [CrossRef]

206. Bilinska, K.; Butowt., R. Anosmia in COVID-19: A bumpy road to establishing a cellular mechanism. ACS Chem. Neurosci. 2020, 11, 2152-2155. [CrossRef]

207. Kimura, H.; Francisco, D.; Conway, M.; Martinez, F.D.; Vercelli, D.; Polverino, F.; Billheimer, D.; Kraft, M. Type 2 inflammation modulates ACE2 and TMPRSS2 in airway epithelial cells. J. Allergy. Clin. Immunol. 2020, 146, 80-88. [CrossRef]

208. Jiang, F.; Yang, J.; Zhang, Y.; Dong, M.; Wang, S.; Zhang, Q.; Liu, F.F.; Zhang, K.; Zhang, C. Angiotensin-converting enzyme 2 and angiotensin 1-7: Novel therapeutic targets. Nat. Rev. Cardiol. 2014, 11, 413-426. [CrossRef]

209. Zhong, J.; Basu, R.; Guo, D.; Chow, F.L.; Byrns, S.; Schuster, M.; Loibner, H.; Wang, X.H.; Penninger, J.M.; Kassiri, Z.; et al Angiotensin-converting enzyme 2 suppresses pathological hypertrophy, myocardial fibrosis, and cardiac dysfunction. Circulation 2010, 122, 717-728. [CrossRef]

210. Patel, V.B.; Bodiga, S.; Fan, D.; Das, S.K.; Wang, Z.; Wang, W.; Basu, R.; Zhong, J.; Kassiri, Z.; Oudit, G.Y. Cardioprotective effects mediated by angiotensin II type 1 receptor blockade and enhancing angiotensin 1-7 in experimental heart failure in angiotensin-converting enzyme 2-null mice. Hypertension 2012, 59, 1195-1203. [CrossRef] [PubMed]

211. Patel, V.B.; Zhong, J.C.; Grant, M.B.; Oudit, G.Y. Role of the ACE2/ Angiotensin 1-7 axis of the renin-angiotensin system in heart failure. Circ. Res. 2016, 118, 1313-1326. [CrossRef]

212. Donoghue, M.; Wakimoto, H.; Maguire, C.T.; Acton, S.; Hales, P.; Stagliano, N.; Fairchild-Huntress, V.; Xu, J.; Lorenz, J.N.; Kadambi, V.; et al. Heart block, ventricular tachycardia, and sudden death in ACE2 transgenic mice with downregulated connexins. J. Mol. Cell. Cardiol. 2003, 35, 1043-1053. [CrossRef]

213. Saponaro, F.; Rutigliano, G.; Sestito, S.; Bandini, L.; Storti, B.; Bizzarri, R.; Zucchi, R. ACE2 in the era of SARS-CoV-2: Controversies and novel perspectives. Front. Mol. Biosci. 2020, 7, 588618. [CrossRef]

214. Oudit, G.Y.; Kassiri, Z.; Patel, M.P.; Chappell, M.; Butany, J.; Backx, P.H.; Tsushima, R.G.; Scholey, J.W.; Khokha, R.; Penninger, J.M. Angiotensin II-mediated oxidative stress and inflammation mediate the age-dependent cardiomyopathy in ACE2 null mice. Cardiovasc. Res. 2007, 75, 29-39. [CrossRef] [PubMed]

215. Yamamoto, K.; Ohishi, M.; Katsuya, T.; Ito, N.; Ikushima, M.; Kaibe, M.; Tatara, Y.; Shiota, A.; Sugano, S.; Takeda, S.; et al. Deletion of angiotensin-converting enzyme 2 accelerates pressure overload-induced cardiac dysfunction by increasing local angiotensin II. Hypertension 2006, 47, 718-726. [CrossRef] [PubMed]

216. Burrell, L.M.; Risvanis, J.; Kubota, E.; Dean, R.G.; MacDonald, P.S.; Lu, S.; Tikellis, C.; Grant, S.L.; Lew, R.A.; Smith, A.I.; et al. Myocardial infarction increases ACE2 expression in rat and humans. Eur. Heart. J. 2005, 26, 369-375. [CrossRef] [PubMed]

217. Kassiri, Z.; Zhong, J.; Guo, D.; Basu, R.; Wang, X.; Liu, P.P.; Scholey, J.W.; Penninger, J.M.; Oudit, G.Y. Loss of angiotensinconverting enzyme 2 accelerates maladaptive left ventricular remodeling in response to myocardial infarction. Circ. Heart. Fail. 2009, 2, 446-455. [CrossRef] [PubMed]

218. Epelman, S.; Shrestha, K.; Troughton, R.W.; Francis, G.S.; Sen, S.; Klein, A.L.; Tang, W.H. Soluble angiotensin-converting enzyme 2 in human heart failure: Relation with myocardial function and clinical outcomes. J. Card. Fail. 2009, 15, 565-571. [CrossRef]

219. Li, Y.; Zhou, W.; Yang, L.; You, R. Physiological and pathological regulation of ACE2, the SARS-CoV-2 receptor. Pharmacol. Res. 2020, 157, 104833. [CrossRef]

220. Hamming, I.; Timens, W.; Bulthuis, M.L.; Lely, A.T.; Navis, G.; van Goor, H. Tissue distribution of ACE2 protein, the functional receptor for SARS coronavirus. A first step in understanding SARS pathogenesis. J. Pathol. 2004, 203, 631-637. [CrossRef] 
221. Lovren, F.; Pan, Y.; Quan, A.; Teoh, H.; Wang, G.; Shukla, P.C.; Levitt, K.S.; Oudit, G.Y.; Al-Omran, M.; Stewart, D.J.; et al. Angiotensin converting enzyme-2 confers endothelial protection and attenuates atherosclerosis. Am. J. Physiol. Heart. Circ. Physiol. 2008, 295, H1377-H1384. [CrossRef]

222. Sahara, M.; Ikutomi, M.; Morita, T.; Minami, Y.; Nakajima, T.; Hirata, Y.; Nagai, R.; Sata, M. Deletion of angiotensin-converting enzyme 2 promotes the development of atherosclerosis and arterial neointima formation. Cardiovasc. Res. 2014, 101, 236-246. [CrossRef]

223. Tang, N.; Li, D.; Wang, X.; Sun, Z. Abnormal coagulation parameters are associated with poor prognosis in patients with novel coronavirus pneumonia. J. Thromb. Haemost. 2020, 18, 844-847. [CrossRef]

224. Bonow, R.O.; Fonarow, G.C.; O'Gara, P.T.; Yancy, C.W. Association of coronavirus disease 2019 (COVID-19) with myocardial injury and mortality. JAMA Cardiol. 2020, 5, 751-753. [CrossRef]

225. Sawalha, A.H.; Zhao, M.; Coit, P.; Lu, Q. Epigenetic dysregulation of ACE2 and interferon-regulated genes might suggest increased COVID-19 susceptibility and severity in lupus patients. medRxiv 2020. [CrossRef]

226. Fraga-Silva, R.A.; Sorg, B.S.; Wankhede, M.; Dedeugd, C.; Jun, J.Y.; Baker, M.B.; Li, Y.; Castellano, R.K.; Katovich, M.J.; Raizada, M.K.; et al. ACE2 activation promotes antithrombotic activity. Mol. Med. 2010, 16, 210-215. [CrossRef] [PubMed]

227. Samavati, L.; Uhal, B.D. ACE2, much more than just a receptor for SARS-COV-2. Front. Cell. Infect. Microbiol. 2020, $10,317$. [CrossRef]

228. Konturek, P.C.; Harsch, I.A.; Neurath, M.F.; Zopf, Y. COVID-19 - more than respiratory disease: A gastroenterologist's perspective. J. Physiol. Pharmacol. 2020, 71. [CrossRef]

229. Hashimoto, T.; Perlot, T.; Rehman, A.; Trichereau, J.; Ishiguro, H.; Paolino, M.; Sigl, V.; Hanada, T.; Hanada, R.; Lipinski, S.; et al. ACE2 links amino acid malnutrition to microbial ecology and intestinal inflammation. Nature 2012, 487, 477-481. [CrossRef]

230. Garg, M.; Christensen, B.; Lubel, J.S. Gastrointestinal ACE2, COVID-19 and IBD: Opportunity in the face of tragedy? Gastroenterology 2020, 159, 1623-1624. [CrossRef] [PubMed]

231. Garg, M.; Royce, S.G.; Tikellis, C.; Shallue, C.; Batu, D.; Velkoska, E.; Burrell, L.M.; Patel, S.K.; Beswick, L.; Jackson, A.; et al. Imbalance of the renin-angiotensin system may contribute to inflammation and fibrosis in IBD: A novel therapeutic target? Gut 2020, 69, 841-851. [CrossRef]

232. Cao, X.; Lu, X.M.; Tuo, X.; Liu, J.Y.; Zhang, Y.C.; Song, L.N.; Cheng, Z.Q.; Yang, J.K.; Xin, Z. Angiotensin-converting enzyme 2 regulates endoplasmic reticulum stress and mitochondrial function to preserve skeletal muscle lipid metabolism. Lipids. Health. Dis. 2019, 18, 207. [CrossRef] [PubMed]

233. Osterreicher, C.H.; Taura, K.; De Minicis, S.; Seki, E.; Penz-Osterreicher, M.; Kodama, Y.; Kluwe, J.; Schuster, M.; Oudit, G.Y.; Penninger, J.M.; et al. Angiotensin-converting-enzyme 2 inhibits liver fibrosis in mice. Hepatology 2009, 50, 929-938. [CrossRef] [PubMed]

234. Chai, X.; Hu, L.; Zhang, Y.; Han, W.; Lu, Z.; Ke, A.; Zhou, J.; Shi, G.; Fang, N.; Fan, J.; et al. Specific ACE2 expression in cholangiocytes may cause liver damage after 2019-nCoV infection. medRxiv 2020.

235. Nadarajah, R.; Milagres, R.; Dilauro, M.; Gutsol, A.; Xiao, F.; Zimpelmann, J.; Kennedy, C.; Wysocki, J.; Batlle, D.; Burns, K.D. Podocyte-specific overexpression of human angiotensin-converting enzyme 2 attenuates diabetic nephropathy in mice. Kidney Int. 2012, 82, 292-303. [CrossRef] [PubMed]

236. Ortiz-Melo, D.I.; Gurley, S.B. Angiotensin converting enzyme 2 and the kidney. Curr. Opin. Nephrol. Hypertens. 2016, 25, 59-66. [CrossRef] [PubMed]

237. Cheng, Y.; Luo, R.; Wang, K.; Zhang, M.; Wang, Z.; Dong, L.; Li, J.; Yao, Y.; Ge, S.; Xu, G. Kidney disease is associated with in-hospital death of patients with COVID-19. Kidney Int. 2020, 97, 829-838. [CrossRef] [PubMed]

238. Li, Z.; Wu, M.; Yao, J.; Guo, J.; Liao, X.; Song, S.; Li, J.; Duan, G.; Zhou, Y.; Wu, X.; et al. Caution on kidney dysfunctions of COVID-19 patients. medRxiv 2020.

239. Xia, H.; Lazartigues, E. Angiotensin-converting enzyme 2 in the brain: Properties and future directions. J. Neurochem. 2008, 107, 1482-1494. [CrossRef]

240. Xiao, L.; Gao, L.; Lazartigues, E.; Zucker, I.H. Brain-selective overexpression of angiotensin-converting enzyme 2 attenuates sympathetic nerve activity and enhances baroreflex function in chronic heart failure. Hypertension 2011, 58, 1057-1065. [CrossRef] [PubMed]

241. Katsi, V.; Maragkoudakis, S.; Marketou, M.; Tsioufis, C.; Parthenakis, F.; Tousoulis, D. The role of angiotensin-(1-7)/Mas axis and angiotensin type 2 receptors in the central nervous system in cardiovascular disease and therapeutics: A riddle to be solved. Curr. Vasc. Pharmacol. 2019, 17, 319-325. [CrossRef]

242. Alenina, N.; Bader, M. ACE2 in brain physiology and pathophysiology: Evidence from transgenic animal models. Neurochem. Res. 2019, 44, 1323-1329. [CrossRef]

243. Kangussu, L.M.; Marzano, L.; Souza, C.F.; Dantas, C.C.; Miranda, A.S.; Simões E Silva, A.C. The renin-angiotensin system and the cerebrovascular diseases: Experimental and clinical evidence. Protein Pept. Lett. 2020, 27, 463-475. [CrossRef]

244. Gupta, A.; Madhavan, M.V.; Sehgal, K.; Nair, N.; Mahajan, S.; Sehrawat, T.S.; Bikdeli, B.; Ahluwalia, N.; Ausiello, J.C.; Wan, E.Y.; et al. Extrapulmonary manifestations of COVID-19. Nat. Med. 2020, 26, 1017-1032. [CrossRef]

245. Machhi, J.; Herskovitz, J.; Senan, A.M.; Dutta, D.; Nath, B.; Oleynikov, M.D.; Blomberg, W.R.; Meigs, D.D.; Hasan, M.; Patel, M.; et al. The natural history, pathobiology, and clinical manifestations of SARS-CoV-2 infections. J. Neuroimmune Pharmacol. 2020, 15, 359-386. [CrossRef] 
246. Zhou, Z.; Kang, H.; Li, S.; Zhao, X. Understanding the neurotropic characteristics of SARS-CoV-2: From neurological manifestations of COVID-19 to potential neurotropic mechanisms. J. Neurol. 2020, 267, 2179-2184. [CrossRef] [PubMed]

247. Najjar, S.; Najjar, A.; Chong, D.J.; Pramanik, B.K.; Kirsch, C.; Kuzniecky, R.I.; Pacia, S.V.; Azhar, S. Central nervous system complications associated with SARS-CoV-2 infection: Integrative concepts of pathophysiology and case reports. J. Neuroinflamm. 2020, 17, 231. [CrossRef]

248. Holappa, M.; Vapaatalo, H.; Vaajanen, A. Local ocular renin-angiotensin-aldosterone system: Any connection with intraocular pressure? A comprehensive review. Ann. Med. 2020, 52, 191-206. [CrossRef]

249. Holappa, M.; Vapaatalo, H.; Vaajanen, A. Many faces of renin-angiotensin system - Focus on eye. Open. Ophthalmol. J. 2017, 11, 122-142. [CrossRef]

250. Verma, A.; Shan, Z.; Lei, B.; Yuan, L.; Liu, X.; Nakagawa, T.; Grant, M.B.; Lewin, A.S.; Hauswirth, W.W.; Raizada, M.K.; et al. ACE2 and Ang-(1-7) confer protection against development of diabetic retinopathy. Mol. Ther. 2012, 20, 28-36. [CrossRef] [PubMed]

251. Zhu, P.; Verma, A.; Prasad, T.; Li, Q. Expression and function of Mas-related G Protein-Coupled Receptor D and its ligand alamandine in retina. Mol. Neurobiol. 2020, 57, 513-527. [CrossRef]

252. Duan, Y.; Beli, E.; Li Calzi, S.; Quigley, J.L.; Miller, R.C.; Moldovan, L.; Feng, D.; Salazar, T.E.; Hazra, S.; Al-Sabah, J.; et al. Loss of angiotensin-converting enzyme 2 exacerbates diabetic retinopathy by promoting bone marrow dysfunction. Stem. Cells. 2018, 36, 1430-1440. [CrossRef] [PubMed]

253. Verma, A.; Xu, K.; Du, T.; Zhu, P.; Liang, Z.; Liao, S.; Zhang, J.; Raizada, M.K.; Grant, M.B.; Li, Q. Expression of human ACE2 in Lactobacillus and beneficial effects in diabetic retinopathy in mice. Mol. Ther. Methods. Clin. Dev. 2019, 14, 161-170. [CrossRef]

254. Lazartigues, E.; Qadir, M.; Mauvais-Jarvis, F. Endocrine significance of SARS-CoV-2's reliance on ACE2. Endocrinology 2020, 161, bqaa108. [CrossRef] [PubMed]

255. Niu, M.J.; Yang, J.K.; Lin, S.S.; Ji, X.J.; Guo, L.M. Loss of angiotensin-converting enzyme 2 leads to impaired glucose homeostasis in mice. Endocrine 2008, 34, 56-61. [CrossRef]

256. Liu, F.; Long, X.; Zhang, B.; Zhang, W.; Chen, X.; Zhang, Z. ACE2 expression in pancreas may cause pancreatic damage after SARS-CoV-2 infection. Clin. Gastroenterol. Hepatol. 2020, 18, 2128-2130.e2. [CrossRef] [PubMed]

257. Gupte, M.; Thatcher, S.E.; Boustany-Kari, C.M.; Shoemaker, R.; Yiannikouris, F.; Zhang, X.; Karounos, M.; Cassis, L.A. Angiotensin converting enzyme 2 contributes to sex differences in the development of obesity hypertension in C57BL/6 mice. Arterioscler. Thromb. Vasc. Biol. 2012, 32, 1392-1399. [CrossRef]

258. Shoemaker, R.; Tannock, L.R.; Su, W.; Gong, M.; Gurley, S.B.; Thatcher, S.E.; Yiannikouris, F.; Ensor, C.M.; Cassis, L.A. Adipocyte deficiency of ACE2 increases systolic blood pressures of obese female C57BL/6 mice. Biol. Sex. Differ. 2019, 10, 45. [CrossRef] [PubMed]

259. Pan, P.P.; Zhan, Q.T.; Le, F.; Zheng, Y.M.; Jin, F. Angiotensin-converting enzymes play a dominant role in fertility. Int. J. Mol. Sci. 2013, 14, 21071-21086. [CrossRef]

260. Shan, T.; Shang, W.; Zhang, L.; Zhao, C.; Chen, W.; Zhang, Y.; Li, G. Effect of angiotensin-(1-7) and angiotensin II on the proliferation and activation of human endometrial stromal cells in vitro. Int. J. Clin. Exp. Pathol. 2015, 8, 8948-8957.

261. Domińska, K. Involvement of ACE2/Ang-(1-7)/MAS1 axis in the regulation of ovarian function in mammals. Int. J. Mol. Sci. 2020, 21, 4572. [CrossRef]

262. Reis, F.M.; Reis, A.M. Angiotensin-converting enzyme 2 (ACE2), angiotensin-(1-7) and Mas receptor in gonadal and reproductive functions. Clin. Sci (Lond). 2020, 134, 2929-2941. [CrossRef] [PubMed]

263. Honorato-Sampaio, K.; Andrade, R.F.; Bader, M.; Martins, A.S.; Santos, R.; Reis, A.M. Genetic deletion of the Angiotensin-(1-7) receptor Mas leads to a reduced ovulatory rate. Peptides 2018, 107, 83-88. [CrossRef]

264. Jing, Y.; Run-Qian, L.; Hao-Ran, W.; Hao-Ran, C.; Ya-Bin, L.; Yang, G.; Fei, C. Potential influence of COVID-19/ACE2 on the female reproductive system. Mol. Hum. Reprod. 2020, 26, 367-373. [CrossRef]

265. Palumbo, A.; Ávila, J.; Naftolin, F. The Ovarian Renin-Angiotensin System (OVRAS): A Major Factor in Ovarian Function and Disease. Reprod. Sci. 2016, 23, 1644-1655. [CrossRef]

266. Dhaundiyal, A.; Kumari, P.; Jawalekar, S.S.; Chauhan, G.; Kalra, S.; Navik, U. Is highly expressed ACE 2 in pregnant women "a curse" in times of COVID-19 pandemic? Life Sci. 2021, 264, 118676. [CrossRef]

267. Gilbert, J.S.; LaMarca, B.B.; Granger, J.P. ACE2 and ANG-(1-7) in the gravid uterus: The new players on the block. Am. J. Physiol. Regul. Integr. Comp. Physiol. 2008, 294, R915-R916. [CrossRef]

268. Bharadwaj, M.S.; Strawn, W.B.; Groban, L.; Yamaleyeva, L.M.; Chappell, M.C.; Horta, C.; Atkins, K.; Firmes, L.; Gurley, S.B.; Brosnihan, K.B.; et al. Angiotensin-converting enzyme 2 deficiency is associated with impaired gestational weight gain and fetal growth restriction. Hypertension 2011, 58, 852-858. [CrossRef]

269. Yamaleyeva, L.M.; Pulgar, V.M.; Lindsey, S.H.; Yamane, L.; Varagic, J.; McGee, C.; daSilva, M.; Lopes Bonfa, P.; Gurley, S.B.; Brosnihan, K.B. Uterine artery dysfunction in pregnant ACE2 knockout mice is associated with placental hypoxia and reduced umbilical blood flow velocity. Am. J. Physiol. Endocrinol. Metab. 2015, 309, E84-E94. [CrossRef]

270. Lumbers, E.R.; Delforce, S.J.; Pringle, K.G.; Smith, G.R. The lung, the heart, the novel coronavirus, and the renin-angiotensin system; The need for clinical trials. Front. Med. 2020, 7, 248. [CrossRef]

271. Pascolo, L.; Zito, G.; Zupin, L.; Luppi, S.; Giolo, E.; Martinelli, M.; De Rocco, D.; Crovella, S.; Ricci, G. Renin angiotensin system, COVID-19 and male fertility: Any risk for conceiving? Microorganisms 2020, 8, 1492. [CrossRef] 
272. Nozato, S.; Yamamoto, K.; Takeshita, H.; Nozato, Y.; Imaizumi, Y.; Fujimoto, T.; Yokoyama, S.; Nagasawa, M.; Takeda, M.; Hongyo, K.; et al. Angiotensin 1-7 alleviates aging-associated muscle weakness and bone loss, but is not associated with accelerated aging in ACE2-knockout mice. Clin. Sci. 2019, 133, 2005-2018. [CrossRef] [PubMed]

273. Ferrandi, P.J.; Alway, S.E.; Mohamed, J.S. The interaction between SARS-CoV-2 and ACE2 may have consequences for skeletal muscle viral susceptibility and myopathies. J. Appl. Physiol. 2020, 129, 864-867. [CrossRef] [PubMed]

274. Jin, M.; Tong, Q. Rhabdomyolysis as potential late complication associated with COVID-19. Emerg. Infect. Dis. 2020, 26, 1618-1620. [CrossRef] [PubMed]

275. Sampaio, W.O.; Nascimento, A.A.; Santos, R.A. Systemic and regional hemodynamic effects of angiotensin-(1-7) in rats. Am. J. Physiol. Heart. Circ. Physiol. 2003, 284, H1985-H1994. [CrossRef] [PubMed]

276. Krueger, J.G.; Murrell, D.F.; Garcet, S.; Navrazhina, K.; Lee, P.C.; Muscianisi, E.; Blauvelt, A. Secukinumab lowers expression of ACE2 in affected skin of patients with psoriasis. J. Allergy Clin. Immunol. 2020. [CrossRef] [PubMed]

277. Xue, X.; Mi, Z.; Wang, Z.; Pang, Z.; Liu, H.; Zhang, F. High expression of ACE2 on keratinocytes reveals skin as a potential target for SARS-CoV-2. J. Invest. Dermatol. 2021, 41, 206-209.e1. [CrossRef] [PubMed]

278. Garduño-Soto, M.; Choreño-Parra, J.A.; Cazarin-Barrientos, J. Dermatological aspects of SARS-CoV-2 infection: Mechanisms and manifestations. Arch. Dermatol. Res. 2020, 1-12. [CrossRef]

279. Tikellis, C.; Thomas, M.C. Angiotensin-converting enzyme 2 (ACE2) is a key modulator of the renin angiotensin system in health and disease. Int. J. Pept. 2012, 2012, 256294. [CrossRef] [PubMed] 